\title{
Medicinal Plants in the Treatment of Depression: Evidence from Preclinical Studies
}

Authors

Inés Moragrega ${ }^{1}$, José Luis Ríos ${ }^{2}$ (D)

Affiliations

1 Departament de Psicobiologia, Facultat de Psicologia, Universitat de València

2 Departament de Farmacologia, Facultat de Farmàcia, Universitat de València

\section{Key words}

medicinal plants, mood disorders, depression, antidepressant-like effect, herbal medicine, pro-inflammatory mediators, preclinical trials

$\begin{array}{ll}\text { received } & \text { July } 28,2020 \\ \text { accepted after revision } & \text { December 15, } 2020 \\ \text { published online } & \text { January } 12,2021\end{array}$

Bibliography

Planta Med 2021; 87: 656-685

DOI $10.1055 / \mathrm{a}-1338-1011$

ISSN 0032-0943

(C) 2021. Thieme. All rights reserved.

Georg Thieme Verlag KG, Rüdigerstraße 14,

70469 Stuttgart, Germany

\section{Correspondence}

Dr. Inés Moragrega

Departament de Psicobiologia, Facultat de Psicologia, Universitat de València

Av. Blasco Ibáñez 21, 46010 Valencia, Spain

Phone: + 34963543304 , Fax: + 34963544943

ines.moragrega@uv.es

\section{Correspondence}

Prof. José Luis Ríos

Departament de Farmacologia, Facultat de Farmàcia, Universitat de València

Av. Vicent Andrés Estellés s/n. 46100 Burjassot,

46100 Valencia, Spain

Phone: + 34963544973 , Fax: + 34963544943

jose.I.rios@uv.es $\bigoplus \begin{aligned} & \text { Supplementary material is available under } \\ & \text { https://doi.org/10.1055/a-1338-1011 }\end{aligned}$

\section{ABSTRACT}

Medicinal plants and their extracts are natural remedies with enormous potential for treating various diseases, including depression and anxiety. In the case of depression, hundreds of plants have traditionally been used in folk medicine for generations. Different plant extracts and natural products have been analyzed as potential antidepressant agents with validated models to test for antidepressant-like effects in animals, although other complementary studies have also been employed. Most of these studies focus on the possible mediators implicated in these potential effects, with dopamine, serotonin, and noradrenaline being the principal neurotransmitters implicated, both through interference with receptors and with their metabolism by monoamino oxidases, as well as through neuro-endocrine and neuroprotective effects. There are approximately 650 reports of antidepressant-like medicinal plants in PubMed; 155 of them have been compiled in this review, with a relevant group yielding positive results. Saffron and turmeric are the most relevant species studied in both preclinical and clinical studies; St. John's wort or kava have also been tested extensively. To the best of our knowledge, no review to date has provided a comprehensive understanding of the biomolecular mechanisms of action of these herbs or of whether their potential effects could have real benefits. The purpose of this narrative review is to provide an update regarding medicinal plants from the year 2000 to the present to examine the therapeutic potential of these antidepressantlike plants in order to contribute to the development of new therapeutic methods to alleviate the tremendous burden that depression causes worldwide.

\section{Introduction}

Depression is a syndrome characterized by profound sadness and a global inhibition of psychic functions. It is also the most common mental alteration among the general population, affecting about 322 million people worldwide [1]. It is estimated that the number of people living with depression increased by roughly $18 \%$ between 2005 and 2015, making it one of the great epidemics of the 21st century [2]. Depression manifests itself as sadness, hopelessness, apathy, and anhedonia, with feelings of worthless- 


\begin{tabular}{|c|c|}
\hline \multicolumn{2}{|c|}{ ABBREVIATIONS } \\
\hline 5-HIAA & 5-hydroxyindoleacetic acid \\
\hline 5-HT & 5-hydroxytriptamine (serotonin) \\
\hline AC-CAMP & $\begin{array}{l}\text { adenylate cyclase-cyclic adenosine } \\
\text { monophosphate }\end{array}$ \\
\hline ACh & acetylcholine \\
\hline AChE & acetylcholinesterase \\
\hline ACTH & adrenocorticotropic hormone \\
\hline Akt & protein kinase B \\
\hline Bax & Bcl-2 Associated X Protein \\
\hline $\mathrm{BCl}-2$ & B-cell lymphoma 2 \\
\hline BDNF & brain-derived neurotrophic factor \\
\hline CNS & central nervous system \\
\hline CREB & CAMP response element-binding \\
\hline CRF & corticotrophin releasing factor \\
\hline CSDS & chronic social defeat stress \\
\hline CUMS & chronic unpredictable mild stress \\
\hline DA & dopamine \\
\hline DAT & dopamine transporter \\
\hline DRL & 72-s differential reinforcement of low rate 72-s \\
\hline EPM & elevated plus maze \\
\hline ERK & extracellular signal-regulated kinase \\
\hline FST & forced swimming test \\
\hline GABA & gamma-aminobutyric acid \\
\hline GSK-3 $\beta$ & glycogen synthase kinase- $3 \beta$ \\
\hline HIF-1 & hypoxia inducible factor-1 \\
\hline HPA & hypothalamic-pituitary-adrenal \\
\hline HPT & hypothalamus-pituitary-thyroid \\
\hline IL & interleukin \\
\hline iNOS & inducibleNOS \\
\hline IT-TOF-MS & ion trap time-of-flight mass spectrometry \\
\hline JNK & c-Jun N-terminal kinase \\
\hline LDA & light dark activity test \\
\hline LHT & learned helplessness test \\
\hline MAO & monoamine oxidase \\
\hline MAPK & mitogen-activated protein kinases \\
\hline MDA & malondialdehyde \\
\hline MWM & Morris water maze \\
\hline NA & noradrenaline \\
\hline NAT & noradrenaline transporter \\
\hline NMDA & $N$-methyl-D-aspartate \\
\hline nNOS & neuronalNOS \\
\hline NO & nitric oxide \\
\hline NOS & nitric oxide synthase \\
\hline Nrf2 & nuclear factor erythroid 2-like 2 \\
\hline OFT & open-field test \\
\hline PFC & prefrontal cortex \\
\hline PI3K & phosphoinositide 3-kinase \\
\hline PKA & protein kinase $A$ \\
\hline ROS & reactive oxygen species \\
\hline SERT & serotonin transporter \\
\hline SOD & superoxide dismutase \\
\hline SPT & sucrose preference test \\
\hline SSRI & selective serotonin reuptake inhibitors \\
\hline
\end{tabular}

STAR * D Sequenced Treatment Alternatives to Relieve Depression

TNF tumor necrosis factor

TrkB tropomyosin-related kinase B

TST tail suspension test

UFLC ultra-fast liquid chromatography

ness or excessive guilt, insomnia or hypersomnia, significant weight loss or-contrarily-hyperphagia, cognitive alterations such as a diminished ability to concentrate, and often recurrent suicidal ideation [3]. The standard recommended treatment for depression often combines both psychological and pharmacological therapies (sometimes including brain stimulation) to manage the disease, but lack of adherence to treatment is frequent, mainly due to adverse reactions. According to the STAR*D trial document, undesirable effects have become a serious problem in psychiatry, afflicting about $30 \%$ of patients [4]. In addition, both the numerous difficulties in accessing proper treatment and the high number of patients who do not respond to pharmacological treatments (approximately 40\%) constitute significant barriers to a good treatment outcome [5]. Taken together, these factors have driven many people to focus on complementary and alternative medicines to try to avoid the common side effects of standard pharmacological treatment for depression $[1,6]$. This search for alternative approaches has led to an increased interest in herbal remedies; indeed, a broad range of medicinal plants are currently being tested for their potentially therapeutic effects in response to patients' demands. That being said, there are many more studies conducted as preclinical rather than clinical trials.

Our literature search revealed approximately 650 papers evaluating the effects of medicinal plants with promising potential in the treatment of general mood disorders, particularly major depressive disorder. Surprisingly, to the best of our knowledge, no literature review providing a comprehensive understanding of whether these drugs produce real benefits and which biomolecular mechanisms of action are involved has been published to date.

The purpose of this narrative systematic review is to provide an update regarding those medicinal plants that have been studied from 2000 to the present and which have been found to have some type of therapeutic potential in the treatment of depression or affective disorders, especially curcumin and saffron, which are the most frequently evaluated plant species in both preclinical and clinical studies. For this review, we compiled all articles published in English in peer review journals and cited in the Cochrane Library, PubMed, Scopus, and Web of Science databases; the timespan comprises the period from the year 2000 to March 2020. We have focused on preclinical evidence for medicinal plants with antidepressant-like activity. The key words employed for this review were "depression", "antidepressant", "medicinal plants", "in vivo antidepressant test", and "in vitro antidepressant test". For this preclinical review, the criteria of inclusion were that first, the studies included a standardized test, such as the FST and/ or the TST, and second, that they included the concept of CUMS in animal models or a specific in vitro test, for example, studies on 
neurotransmitters implicated in depression as well as their metabolic and signal pathways. Thus, the aim of this review is not only to find out which medicinal plants have potential antidepressantlike effects but also to ascertain the potential mechanisms of their active principles.

\section{Possible Mechanisms of Action for Antidepressant Agents}

The monoaminergic hypothesis is the classic explanation and most widely accepted molecular mechanism for the etiology of depression; as such, most pharmacological agents used to treat the disease target this pathway. The existing relationship between the physiological disturbances observed in depression and neurotransmitter activity-principally NA, 5-HT, DA, and HPA axis activity-along with oxidative and nitrosative stress and mitochondrial activity seems clear [7-11], although the relationship with other biochemical phenomena remains less so. This uncertainty has given rise to a certain urgency to test alternative hypotheses. In response, various studies have observed a relationship between depression and inflammation, thereby increasing interest in the roles of IL-6, TNF- $\alpha$, and C-reactive protein in depression, as well as in their potential as targets in the treatment of the disease [79]. A decrease in NO levels (elevated in patients with major depression) [11], possibly through the inhibition of iNOS, as well as the activity of nNOS in humans, could help to modulate the production of neurotransmitters such as NA [12]. In the case of oxidative stress, one of the mechanisms for evaluating active compounds examines their effects on either the oxidative enzymes or $\mathrm{Nrf2}$ involved in the expression of different genes, including those for antioxidant enzymes [12]. Other studies have found that depressive patients also usually present with altered mitochondrial membrane depolarization, which shows up as oxidized mitochondrial DNA, promoting high levels of central and peripheral ROS. In the brain, the effects of ROS, which are mainly due to peroxidation, are well established and involve neuronal damage, apoptosis, protein and DNA injury, reduced antioxidant defenses, and, of course, neuroinflammation. These facts have recently been discussed in an extensive review regarding the association between inflammation, mitochondrial dysfunction, and oxidative stress [5]. Taking all these data into account, medicinal plants may have a relevant role in the search for and development of new therapeutic approaches for the treatment of depression, especially for drug-resistant patients or those who suffer adverse side effects.

\section{Medicinal Plants as Antidepressant-like Agents}

Many medicinal plants have long been used in both folk medicine and phytotherapies for pathologies of the CNS, although most of them have not been evaluated in clinical trials. The ethnomedicinal use of these plants has led to a selection of several of them for clinical use after prior evaluation at the experimental level. Indeed, of the approximately 660 reports of "antidepressant medicinal plants" in PubMed, 183 have been included in this review, with a relevant number yielding positive results. Table 15 (Supplementary Information) provides a list of 155 species described or studied as either potential antidepressant agents or sources of active principles.

The main animal-specific protocols to test the efficacy of medicinal plants as antidepressant drugs are methods such as the FST, TST, and CUMS, which are then complemented with other instruments such the OFT or the EPM [13]. The FST or behavioral despair test, in which the mouse strain is of high interest, is one of the most used tools for screening antidepressants $[14,15]$ as it has both good reliability and predictive validity. The TST protocol is similar to that of the FST, except that mobility is impaired by suspending the test animal's tail. This test is especially useful as a tool in drug discovery for high-throughput screening of prospective antidepressant compounds [16-18]. In the case of CUMS, it is commonly used as a reliable and effective rodent model of depression, but is often difficult to reproduce in different laboratory settings, making it unsuitable as a standard method of testing [19]. These tests are frequently complemented with the OFT and EPM, which are used for measuring anxiety-like behavior; however, they are of ancillary interest in diseases such as major depression [20-22]. Still, various problems for evaluating the effects of medicinal plants exist, primarily the use of different solvents to obtain the extract (ethanol, methanol, water, or other solvents), choosing which vegetal organ to study (roots, leaves, stems), or the use of enriched extract (e.g., enriched in terpenoids, saponins, flavonoids, or other phenolics, among others).

The selected papers are compiled in Table 1S (Supplementary Information); some have already been cited in previous reviews [23-31]. The table includes the botanical and family name, common denomination, tests performed, part of plant tested, extractive solvent, doses, via of administration, possible mediators implicated, and references for each plant. These data are thus not included in the text. The names of the botanical species have been updated according to the latest revision of "The Plant List: A working list of all known plant species" [32].

\section{Experimental Studies in Animals or Cells}

Aconitum carmichaelii contains alkaloids and polysaccharides as active principles. While the polysaccharide fraction had no effect on brain monoamine levels in the frontal cortex, it did increase the expression of BDNF in the brains of mice, as well as the number of dentate gyrus neurons [33]. In the case of the alkaloid fraction, it was shown to enhance the ratio of phosphorylated-CREB and BDNF protein levels in the frontal cortex and hippocampus in ovariectomized mice. Unfortunately, the 8-acetyl,14-benzoyl diester diterpene alkaloids are highly toxic; however, during the preparation process (decoction), the toxic diester alkaloids can be hydrolyzed into less toxic monoester aconitine alkaloids, which can then be converted to even less toxic aconine alkaloids with no observable reduction in pharmacological activity [34].

Both the essential oil and the water extract of Acorus calamus var. angustatus shows antidepressant-like effects in the FST and TST, but not in the OFT [35-37]. Using these same tests, Han et al. [35] demonstrated that the essential oil from the rhizomes of the plant, along with its major compounds, principally $\beta$-asarone (47, Fig.6S, Supplementary Information), exert antidepressantlike effects. Similar conclusions were obtained by Dong et al. 
[36], who assayed $\beta$-asarone in a CUMS model and found that this compound significantly increased the expression of BDNF at both the transcription and translation levels. With regard to the mechanism of action, this compound acts in a stress-dependent manner to block ERK1/2-CREB signaling but exhibited no effects in nonstressed rats. In a subsequent study, Zang et al. [37] observed similar effects for the petroleum ether and water fractions, demonstrating that even water fractions with only trace amounts of $\beta$-asarone exert antidepressant-like effects. The active extract contains different phenolics with the activity due to the regulation of SERT activity [37].

Actaea cimicifuga reduced immobility duration in both the FST and TST without affecting locomotor activity, enhanced the 5-hydroxytryptophan-induced head-twitch response, decreased the levels of plasma ACTH, and lowered serum corticosterone and adrenal gland weight in CUMS-treated female rats. Both serotonergic and noradrenergic activation are implicated in the effects as well as the normalization of the HPA axis [38]. A related plant, Actaea racemosa is traditionally used for ameliorating premenstrual and dysmenorrheic disorders as well as neurovegetative climacteric complaints. Winterhoff et al. [39] tested the standardized BNO 1055 extract using a TST and observed a significant decrease in the period of immobility along with a reduction in the frequency of hot flashes, a result that is in agreement with the therapeutic responses in climacteric women [39]. Aegle marmelos was analyzed for its potential antidepressant-like effect with a TST as well as with the EPM as an anxiolytic test. While the extract showed demonstrable effects in the TST, its activity was significantly decreased by the $\alpha_{1}$ and $D_{2}$ antagonists, as well as by the $\mathrm{CABA}_{\mathrm{B}}$ agonist, thus implying the involvement of the adrenergic and dopaminergic systems [40]. The antidepressant-like mechanism of Agapanthus campanulatus was tested in vitro with a functional uptake inhibition assay against SERT, NAT, and DAT. The ethanolic extract demonstrated dose-dependent antidepressantlike effects in the FST and TST while inhibiting SERT, NAT, and DAT $[41,42]$. Likewise, Akebia quinata was shown to decrease immobility in both the FST and TST in mice and reversed CUMS-induced inhibition of sucrose consumption in rats. The effects were associated with decreased levels of plasma ACTH and serum corticosterone in CUMS-rats [43]. Jing et al. [44] established that hederagenin (1, Fig. 1S, Supplementary Information) was the principal active compound, finding that it inhibited SERT, NAT, and DAT in rat brain membrane preparations and HEK293 cells transfected with the corresponding human SERTs. Hederagenin increased both NA and 5-HT levels as well as the expression of 5- $\mathrm{HT}_{1 \mathrm{~A}}$ receptor mRNA, while decreasing the expression of the mRNA for SERT and affecting the expression of BDNF [45]. Alafia multiflora showed positive effects in both the anxiolytic (EPM, OFT) and antidepressant tests (FST) in rats and mice but had no effect on locomotor activity. The researchers suggested the implication of monoamine systems but could not establish their involvement [46]. The antidepressant and anxiolytic effects of Albizia julibrissin (water extract) were investigated with the EPM [47] while the methylene chloride fraction was assayed with the TST [48]. In the first case, an increase was noted in both time spent and arm entries, whereas in the latter test, the fraction reduced the immobility time compared to the control group [47]. This antidepressant- like effect was reversed by treatment with a $5-\mathrm{HT}_{1 \mathrm{~A}}$ receptor antagonist but was not affected by treatment with $5-\mathrm{HT}_{1 \mathrm{~B}}$ or $5-\mathrm{HT}_{2 \mathrm{~A}}$ receptor antagonists; therefore, the plant extract seems to exert its antidepressant effects through $5-\mathrm{HT}_{1 \mathrm{~A}}$ receptors [48]. Several years later, Liu et al. [49] determined that one of the active principles of this plant extract was the compound (-)-syringaresinol-4-O- $\beta$-D-apiofuranosyl-( $1 \rightarrow 2)$ - $\beta$-D-glucopyranoside (52, Fig. 6S, Supplementary Information), which increased the percentage of entries into and time spent on the open arms of the EPM while lowering the concentration of ACTH and corticosterone in plasma and decreasing the amount of neurotransmitters (DA, $\mathrm{NA}, 5-\mathrm{HT}$ ) and their metabolites in the cerebral cortex and hippocampus of treated rat brains. These results point to disease inhibition via the HPA axis [49]. Albizia lebbeck decreased the duration of immobility time in a dose-dependent manner in both the FST and TST in mice but exerted no effect on the locomotor activity of the mice [50].

Daily administration of Allium cepa powder reduced the immobility time in the FST without changing the motor dysfunction. The authors concluded that onion's antidepressant-like activity is independent of the HPA axis because plasma corticosterone levels were not affected [51]. Ten years later, Samad et al. [52] tested onion powder in mice with various protocols, including the EPM, LDA, FST, and MWM. They also examined the powder's effects on brain lipid peroxidation, antioxidant enzymes, and AChE. They concluded that antioxidant enzymes have a relevant role in the attenuation of stress-induced anxiety and depression and that they also enhance cognitive function [52]. Allium macrostemon was likewise studied with the FST and TST protocols; in vitro tests with the born cells in the subgranular zone and the granule cell layer were also carried out and the expression levels of BDNF were examined by means of western blotting and immunohistochemistry. The results demonstrated that the immobility duration in both tests was reduced, whereas there were increases both in the number of cells and in the BDNF expression levels, which are associated with neurogenesis [53]. Chen et al. [54] also studied the antidepressant-like effect of this species but with a rat model of depression induced by exposure to chronic immobilization stress; the results were obtained through chromatographic methods. Differences were noted between the plasma lipid and acylcarnitine profiles of depressed rats and those in the control group, with most of the dysregulated metabolites returning to their normal values in the treated rats. These changes indicate that depression in rats is associated with several inflammatory conditions along with an incomplete $\beta$-oxidation of fatty acids [54]. The third species of Amaryllidaceae to be studied was Allium sativum. In this case, researchers tested the effects of the essential oil after 28 consecutive days, with a reduction of the immobility time (FST) and a reversal of the decrease in the sucrose preference index induced by 5 wk of CUMS. The essential oil also decreased the frontal cortex turnover ratio of 5-HT and DA by increasing their levels but had no hippocampal effects. However, its chronic administration was shown to increase hippocampal BDNF, CREB, and Akt expression, most likely due to the modulation of monoamine neurotransmitters and the BDNF-related signaling pathway. The authors were unable to unequivocally establish the main active principle; when they tested garlic's major organosulfur 
component, diallyl disulfide, it showed less activity than the essential oil, which points to the presence of other active principles in garlic [55].

Aloysia gratissima was tested by Zeni et al. [56] in mice. The anti-immobility effect caused by the TST was prevented by specific antagonists of the monoaminergic receptors, leading to the conclusion that the activity of the compound depends on the serotonergic (5- $\mathrm{HT}_{1 \mathrm{~A}}$ and $\left.5-\mathrm{HT}_{2 \mathrm{~A} / 2 \mathrm{C}}\right)$, noradrenergic $\left(\alpha_{1}\right.$ and $\left.\alpha_{2}\right)$, and dopaminergic $\left(D_{1}\right.$ and $\left.D_{2}\right)$ systems [56]. Aloysia polystachya was tested in both the EPM and FST on female rats. The authors established that the monoterpenes thujone and carvone, among others, may be potential active compounds, with a possible mechanism in which GABA could be implicated [57]. However, in a second study they cited flavonoids as the most likely active compounds [58]. Recently, the main chemical compound of the extracts was established as being acteoside (53, Fig. 6S, Supplementary Information), which might also be the active principle. This experiment involved examining the effect of caffeine on zebrafish, which produces an anxiogenic effect that can be reversed by the hydroalcoholic extract in the same way that fluoxetine does. The researchers thus concluded that $A$. polystachya has anxiolytic and antidepressant-like activity, probably due to the presence of acteoside [59]. In the case of Aloysia citriodora, the authors proposed the implication of the GABAergic and serotoninergic systems, which could mean that this plant may also function as an antidepressant-like drug in addition to its anxiolytic properties [60]. There are other studies on the plant's CNS activity; however, the use of different extracts (polar and non-polar) hinders an accurate evaluation of the results in order to elucidate the activity of lemon verbena as an antidepressant-like plant [61].

When Anacyclus pyrethrum was tested for antidepressant-like activity, it reduced the immobility caused by both the FST and TST, prompting the authors to hypothesize that the antidepressant-like effect could be due to its interaction with adrenergic and dopaminergic receptors, and through an increase in DA and NA levels in the brains of mice [62]. The main bioactive principle of Andrographis paniculata, andrographolide (23, Fig. 35, Supplementary Information), which had previously been tested for multiple pharmacological properties, was recently evaluated as a potential antidepressant agent in mice. Andrographolide showed activity in both the FST and TST without influencing the locomotor activity of the test mice; it also exhibited significant antidepressant-like effects in the CUMS model and prevented decreases in hippocampal BDNF signaling and neurogenesis in mice, an effect that could be considered the antidepressant-like mechanism [63]. Using the FST, Ren et al. tested the effects of sarsasapogenin (6, Fig. 1S, Supplementary Information) isolated from Anemarrhena asphodeloides in mice. The compound affected the immobile response but did not modify the locomotor activity. It also increased NA and 5-HT levels in both the hypothalamus and the hippocampus. Moreover, sarsasapogenin inhibited MAO in the mouse brain. The authors therefore hypothesized that the antidepressant-like activity of sarsasapogenin involves the central monoaminergic neurotransmitter systems $[64,65]$.

Riparin III (80, Fig. 8S, Supplementary Information) from Aniba riparia was studied as an antidepressant-like compound in different protocols. The compound decreased the immobility time in both the TST and FST, with no effects on the spontaneous motor activity in mice [66]. In a complementary study, these same authors established that the antidepressant-like effect is dependent on the compound's interaction with the serotonergic, noradrenergic $\left(\alpha_{1}\right.$ and $\left.\alpha_{2}\right)$, and dopaminergic $\left(D_{2}\right)$ receptors [67]. In addition, mice exposed to the corticosterone-induced chronic depression model and treated with riparin III showed increased BDNF protein levels in the hippocampus [68]. The compound likewise exhibited anxiolytic-like properties [69]. Riparin II (79) [70] and riparin I (78, Fig. 8S, Supplementary Information) [71] were also tested as potential antidepressant-like agents. The former was tested in rodents, with the results showing a significant decrease of immobility time in both the FST and TST. Pretreatment of test mice with receptor antagonists $\left(\alpha_{1}, \mathrm{D}_{1}, \mathrm{D}_{2}\right.$, and $\left.5-\mathrm{HT}_{1 \mathrm{~A}}\right)$, an inhibitor of 5-HT synthesis, and a serotonin receptor antagonist completely blocked the anti-immobility effects elicited by riparin II in the FST. These results indicate that the antidepressant-like activity of riparin II is dependent on its interaction with the noradrenergic, dopaminergic, and serotonergic systems [70]. When riparin I was tested using the FST and TST, it also decreased the immobility time. Pretreatment with monoamine antagonists likewise demonstrated the implication of these systems in the compound's effects [71].

Martínez-Vázquez et al. [72] studied an alkaloid-enriched extract from Annona cherimolia in mice, using the FST for evaluating the compound's activity as well as different agonist and antagonist effects of monoamines. The results gave a positive result, with the mechanism being attributed to an increase in monoamine turnover. The alkaloids in the extracts were identified as anonaine (63), liriodenine (64), nornuciferine (65), and 1,2-dimethoxy-5,6,6a,7-tetrahydro-4H-dibenzoquinoline-3,8,9,10-tetraol (66) (see Fig. 7S, Supplementary Information) [72]. Annona coriacea was also evaluated, as well as caffeic acid (48, Fig. 6S, Supplementary Information), the major phenolic present in the extract. The results indicated that both samples have antidepressant-like effects as well as anxiolytic properties, both involving the GABAergic and monoaminergic systems [73]. Annona vepretorum's essential oil was tested in a protocol similar to that used for $A$. coriacea with similar results, but in this case, the antidepressant-like effect was related to its action on serotonergic receptors whereas it anxiolytic properties were associated with the GABAergic system. [74].

Apocynum venetum, used in traditional Chinese medicine [75], was studied by Butterweck et al. [76] as a potential antidepressant-like agent in rats. The researchers speculated that the effect might be related to the major flavonoids present in the extract, hyperoside (37) and isoquercitrin (38, Fig. 1S, Supplementary Information) [76]. They also compared the short-term (2wk) and long-term ( $8 \mathrm{wk}$ ) effects of this extract with those of imipramine, detecting marked changes in DA and NA levels in the rat hypothalamus, striatum, and hippocampus after $8 \mathrm{wk}$; 5-HT levels were not affected. They also established the relationship between decreased NA levels and presynaptic $\alpha_{2}$-receptors, whereas there was no effect on the $\beta$-adrenergic receptors [77]. These results were corroborated by Zheng et al. [78], who studied the antidepressant-like effect and monoaminergic mechanism of a flavonoid-enriched extract of this plant. The results were attributed to 
increased levels of NA and DA, together with their respective metabolites, in the mouse hippocampus, which were dependent on the interaction of the extract with $D_{1}$ and $D_{2}$ receptors [78]. Previously, these same authors had suggested that the flavonoid hyperoside could be the principal antidepressant agent and proposed a possible mechanism of action involving a heightened expression of BDNF and CREB through the signal pathway AC-CAMPCREB [79]. Additional studies with the same extract in rats using the CUMS model showed reduced serum corticosterone and ACTH levels. The extract also increased the activities and gene expression of antioxidant enzymes such as SOD, catalase, and glutathione peroxidase, while decreasing ROS generation levels and lipid peroxidation in the rat hippocampus. Moreover, the extract suppressed the apoptosis of hippocampus cells by modulating the $\mathrm{BCl}-2 / \mathrm{Bax}$ pathways and improved hippocampal BDNF expression. The researchers concluded that the extract exerted antidepressant-like effects through prevention of oxidative stress, the inhibition of hippocampal neuronal apoptosis, and the upregulation of hippocampal BDNF levels [80]. In a similar study, Wu et al. [81] demonstrated that the extract improved depressive behavior in CUMS rats because it reversed the increased apoptosis of hippocampus and cortical neurons and increased Bcl-2, BDNF, and CREB protein expression while simultaneously decreasing Bax, cytochrome $\mathrm{c}$, and caspase family protein expression. These findings indicate that $A$. venetum exerts its antidepressant-like activity mainly through the suppression of neuronal apoptosis.

Areca catechu is the fourth most widely used psychoactive substance in the world after caffeine, nicotine, and alcohol [82]. Previous reports have shown that this nut exerts antidepressant-like effects in mice and rats in both the FST and TST while also decreasing the levels of MAO in rat brain homogenates. Areca nut has also been shown to have antidepressant-like effects in mice and rats; in this case, the activity was associated with the regulation of DA and 5-HT levels through MAO inhibition [83]. It has also been tested using behavioral and biochemical tests in rats and showed activity in both the acute and sub-chronic FST, with the saponins being the most likely active compounds due to the significant elevation of 5-HT and NA levels compared to the controls [82]. Artemisia absinthium reduced the immobility period in both the FST and TST in a dose-dependent manner. In this case, the activity was associated with the compound's antioxidant properties, which come from its high content in flavonoids and other phenolics [82]. Asparagus racemosus decreased immobility in the FST and increased the avoidance response in the LHT, which is indicative of antidepressant-like activity. The authors concluded that this activity could be mediated through the serotonergic and the noradrenergic systems, as well as an increase in antioxidant defenses $[84,85]$. Moreover, $A$. racemosus is a nonselective competitive inhibitor for both AChE and MAO enzymes and thus may produce some interactions with other drugs and food [86].

Bacopa monnieri is used as a dietary antioxidant and has been described as a protector of the brain against oxidative damage and age-related cognitive decline [87-89]. Sairam et al. [90] described the effect of a standardized extract (38\% of bacoside $A$, 7, Fig. 2S, Supplementary Information) as antidepressant-like in FST and LHT models of depression in rats, but no mechanisms were proposed [90]. Bhattacharya et al. [91] demonstrated its antioxidant properties while also finding evidence of reduced oxidative stress in the aging brain, which could be hypothesized as a mechanism for improving cognition [89]. Basella alba showed similar activity in both the FST and TST, most likely due to the main compounds present in the extract, which include alkaloids, tannins, and flavonoids, but no mechanism was proposed [92]. In the case of Benincasa hispida, the activity (assayed with the FST) is due to the inhibition of MAO-A; an interaction with the dopaminergic, $\alpha_{1}$-adrenergic, serotoninergic, and GABAergic systems was implicated in the mechanism [93]. Boophone disticha was also tested with the FST and TST and showed functional inhibition of SERT, NAT, and DAT. Various studies with Amaryllidaceae alkaloids, including those present in this plant, showed activity with regard to SERT, while the alkaloids buphanidrine (76) and buphanamine (77, Fig. 7S, Supplementary Information) were shown to exhibit selective $5-\mathrm{HT}$ reuptake inhibition, leading the authors to establish alkaloids as the active compounds in this plant [41, 94]. Bupleurum falcatum reduced the total duration of immobility in mice in the TST with no modification observed in the OFT. The activity was dose-dependent and involved the serotonergic and noradrenergic systems [95]. In addition, it significantly reduced depression-like symptoms following repeated restraint stress through hypothalamic CRF modulation and noradrenergic system regulation in the locus coeruleus of treated rats [96].

Camellia sinensis leaves are commercially available in different forms, differing mostly in the degree of fermentation, which has an effect on their antioxidant properties [97]. Several studies have established the relationship between a higher consumption of green tea and a lower prevalence of depression [98]. To confirm these properties, Zhu et al. [99] used different mouse models of depression (FST and TST) for testing green tea polyphenols and their mechanisms of action as potential antidepressant agents. Green tea polyphenols were found to reduce immobility in both tests. They also reduced serum corticosterone and ACTH levels, but did not modify the locomotor activity in the OFT. This led the researchers to conclude that the polyphenols in green tea exert their antidepressant-like effects in mice through the inhibition of the HPA axis [99]. In a complementary study, Liu et al. [100] investigated the antidepressant-like effects of tea polyphenols using the mouse model of CUMS-induced depression and found that the activity was exerted through both monoaminergic pathways (5-HT and NA) and antioxidant defenses [100]. Similar results were obtained by Di Lorenzo et al. [101], who used both green tea and GABA green tea (special green tea with a high GABA content) in a mouse model of post-stroke depression. Both teas showed a significant effect on the modulation of depressive symptoms, restoring normal behavior and improving the antioxidant endogenous defenses through the reduction of oxidative stress [101]. GABA green tea was also studied by Teng et al. [102], who observed that the GABA present in green tea has a healthy effect on the prevention and alleviation of depression by modulating GABAergic neurotransmission in the mouse cerebral cortex by up-regulating the expression of the GABA $\mathrm{A}$ receptor $\alpha_{1}$ subunit [102].

Concanavalin $\mathrm{Br}$ is a lectin with mannose/glucose affinity isolated from Canavalia brasiliensis seeds. When this compound was tested in a mouse FST model, it elicited an anti-immobility effect 
that could be prevented by pretreating the test mice with differ-

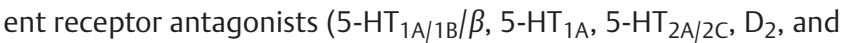
$\alpha_{2}$ ) but not with the $\mathrm{D}_{1}$ or $\alpha_{1}$ receptor antagonists. This indicates that the antidepressant-like effect of this lectin elicited in this protocol is due to its interaction with the serotoninergic, noradrenergic, and dopaminergic systems. Considering the presence of lectins in the brain and based on these results, the elucidation of a possible role of endogenous lectins in the modulation of CNS system function is of great interest [103]. The same research group $[104,105]$ thus went on to study the role of concanavalin $\mathrm{Br}$ in the brain along with the role of endogenous lectins in the modulation of CNS function. Because many receptors, ion channels, and transporters making up the CNS are glycoproteins, where the glycan chains are modulator elements and lectins are proteins, these recognize and bind carbohydrate complexes. The antidepressant and neuroprotective effects of concanavalin $\mathrm{Br}$ may thus be dependent on carbohydrate interaction. Rieger et al. [104] demonstrated that this lectin improves BDNF expression, probably through a mechanism dependent on CREB activation mediated by PKA, ERK1, and Akt. In addition, this lectin inhibited the NMDA receptor and reduced NO and cGMP synthesis [105], which could justify in part the antidepressant-like effect of concanavalin $\mathrm{Br}$ in the FST. Zhao et al. [106] found that the ethanolic extract of the flowers of Carthamus tinctorius inhibited 5-HT uptake in Chinese hamster ovary cells. Following an activity-guided isolation, these researchers identified $N^{1}, N^{5}-(Z)-N^{10}-(E)$-tri-p-coumaroylspermidine (81, Fig. $8 \mathrm{~S}$, Supplementary Information) as the active principle. After more testing, this compound was found to be a novel 5 -HT transporter inhibitor, with $\mathrm{IC}_{50}$ values of $0.74 \mu \mathrm{M}$ (S6 cells) and $1.07 \mu \mathrm{M}$ (synaptosomes), and with a reversible competitive property for the inhibition of 5-HT-uptake [106]. Qazi et al. [107] studied the petal extract with similar results in an FST [107] while Abbasi-Maleki et al. [108] studied the flower extract in a TST model and described the involvement of both dopaminergic $\left(D_{1}\right.$ and $\left.\mathrm{D}_{2}\right)$ and serotonergic $\left(5-\mathrm{HT}_{1 \mathrm{~A}}\right.$ and $\left.5-\mathrm{HT}_{2 \mathrm{~A}}\right)$ receptors. They postulated a relevant role for $\mathrm{N}$-hexadecanoic acid as the major compound found in the extract (about 20\%) [108]. Casimiroa edulis reduced the immobility time with respect to the controls, increasing the climbing behavior in a similar way as the selective 5-HT reuptake inhibitor fluoxetine; however, the authors did not cite any active principles [109]. Han et al. [110] isolated 7 flavonoids from a methanol extract of Cayratia japonica through an activityguided isolation using a MAO inhibition assay model. Of these, apigenin, luteolin, and quercetin were the most potent MAO inhibitors, with specificity against MAO-A vs. MAO-B.

Centella asiatica contains pentacyclic triterpenes, mainly asiatic acid (11), asiaticoside (12), madecassic acid (13), and madecasosside (14, Fig. 2S, Supplementary Information) [111]. Many clinical studies of these compounds have been carried out, especially against dermatological disorders [112], but different experiments with animals have demonstrated the potential of the total triterpenes fraction as an antidepressant, reducing the immobility time in the FST in mice [113], ameliorating the function of the HPA axis, increasing the neuronal monoamine neurotransmitters (DA, 5-HT, NA) and their metabolites, and reducing the corticosterone levels in serum [114]. In subsequent research, Ceremuga et al. [115] investigated the anxiolytic and antidepressant effects of asi- atic acid and its potential modulation of the $\mathrm{GABA}_{\mathrm{A}}$ receptor using the EPM and the FST in rats. The results were significant with regard to the ratio of open arm time, maximum speed, and time spent mobile in the asiatic acid group as well as in the group treated with asiatic acid combined with midazolam. Flumazenil counteracted the anxiolytic effects. From these results, the authors concluded that asiatic acid acts on the $\mathrm{GABA}_{\mathrm{A}}$ receptor [115]. Polyphenols from Ceratonia siliqua have been shown to exert antidepressant-like effects in both the FST and TST in mice. Their activity is due to their $\alpha$-adrenoceptor and $D_{2}$ antagonist properties, as clearly indicated by the fact that the effects are mediated by DA and NA [116]. Different species of Rutaceae have edible fruits, such as bitter orange (Citrus $\times$ aurantium), pomelo (Citrus maxi$m a$ ), and grapefruit (Citrus paradisi). Bitter orange and pomelo were studied in both the FST and OFT whereas pomelo was also studied with a TST. The anti-immobility effect of orange fruits observed in the FST was prevented by pretreating test rats with various specific antagonists (but not prazosin), which led to the hypothesis that the active extracts act through the participation of $5-\mathrm{HT}_{1 \mathrm{~A}}, 5-\mathrm{HT}_{2 \mathrm{~A}}, \mathrm{D}_{1}, \mathrm{D}_{2}$, and $\alpha_{2}$ receptors but not their $\alpha_{1}$-adrenergic counterparts [117]. In the case of $C$. maxima, the extract reduced the immobility time in both tests, indicating that the mechanism may involve a possible increase in NA levels in the synapses [118]. In the third species, the flavonoids were proposed as the potential active agents [119].

Clitoria ternatea has been used in Ayurvedic medicine for centuries to treat various nervous system diseases, including as an antidepressant [120], but an early study concluded that the alcoholic extract only acts at high doses [121]. Some year later, Jain et al. [122] observed that the extract decreased the duration of immobility in the TST. It also showed a tendency to reduce the intensity of behavior mediated by 5 -HT and ACh whereas its effect on behavior mediated by DA and NA was not significant [122]. Malik et al. [123] further corroborated these findings and evaluated the activity in the TST in mice. In another study, the immobility time of rats was also reduced in a dose-dependent manner in both the FST and TST, leading the authors to hypothesize that the effects may be due to the presence of flavonoids and that the mechanism could involve an interaction with the $\mathrm{GABA}_{\mathrm{A}}$ receptors [124]. Dhingra and Valecha [125] assayed different extracts of Convolvulus prostratus, but only the chloroform fraction was found to significantly reduce the immobility time in both the FST and TST by interacting with the adrenergic, dopaminergic, and serotonergic systems. However, the methanolic extract showed antidepressant-like effects in the SPT, FST, and CUMS. Moreover, the extract reduced the increased levels of pro-inflammatory cytokines IL-1 $\beta$, IL-6, TNF- $\alpha$, and the liver biomarkers ALT and AST in CUMS-exposed rats. Furthermore, the extract restored the NA and 5-HT levels in the hippocampus as well as in the PFC of CUMS-exposed rats. The authors thus concluded that $C$. prostratus exerted its antidepressant-like effect through its anti-inflammatory properties, restoring liver biomarkers and monoaminergic responses in the stressed rats [126].

The main components of Crocus sativus are its essential oil (with safranal, 15, Fig. 3S (Supplementary Information), as the most abundant component), bitter principles, dye material, and other minor compounds, such as the phenolic fraction, made up 
of flavonoids, cyanidins, and anthraquinones [127-131]. Saffron has been used and assessed as a medicinal agent, and different properties have been described for both saffron and its principles [127, 132-138]. However, the principal interest in saffron could be due to its anticonvulsant, anti-anxiety, and hypnotic properties $[139,140]$. In addition, antioxidant properties have been attributed to saffron and its various compounds [141,142], which may partly justify its neuroprotective effects. Several recent studies have demonstrated that saffron not only inhibits reuptake of monoamines (DA, NA, 5-HT), but that it also exhibits both NMDA receptor antagonism and $G_{A B A_{A}}$ agonism, which seem to be responsible for its antidepressant-like and anxiolytic effects demonstrated in animal models (EPM and OFT) [143-145]. Two extracts of Cucurbita pepo were studied in an FST model in rats and found to decrease immobility time, with the antioxidant properties of the aqueous extract being responsible for this effect [146]. The total furocoumarin extract of Cullen corylifolium was likewise tested with the FST and was found to reduce the immobility time and inhibit both MAO-A and MAO-B, with a more potent effect on the latter. The extract also blocked plasma-elevated cortisol levels and decreased liver SOD activity and MDA levels. The authors concluded that the antidepressant-like effects of furocoumarin extract are mediated by MAO activity, HPA axis action, and oxidative stress [147]. A similar study was performed by Xu et al. [148] and Yi et al. [149], but in these experiments, the authors concentrated on psoralen (49, Fig.6S, Supplementary Information), the major compound found in the furanocoumarins [148] and psoralidin (51, Fig. 6S, Supplementary Information) [149]. Psoralen reversed FST-induced alterations in 5-HT levels in the frontal cortex and hippocampus in mice while attenuating FST-induced elevations in serum CRF and corticosterone [148]. Not only did psoralidin affect 5-HT, CRF, and corticosterone levels, but it also changed DA levels in the striatum of mice exposed to FST while elevating ACTH in serum [149]. These results point to an implication of both the monoamine neurotransmitter and the HPA axis systems [148, 149].

Turmeric (Curcuma longa) is used as a condiment and flavor corrector, although its use in phytotherapy is also well-established. The European Pharmacopoeia recognizes the entire rhizome as a phytotherapeutic agent [150-154]. The species C. aromatica and C. zanthorrhiza are also used for the same purposes [150,151,155-158]. Of its various pharmacological properties, the anti-inflammatory [155] and neuroprotective [156,157] properties are the most remarkable. Different researchers have focused their efforts on demonstrating the properties of curcumin (57, Fig.6S, Supplementary Information), the main active component, and its potential as a therapeutic agent, especially in CNS pathologies. Consequently, interest in this compound as a possible antidepressant has grown in recent years, with studies focusing on its antidepressant activity in relation to its anti-inflammatory properties. Indeed, both the anti-inflammatory and antioxidant properties of curcumin have been demonstrated in various studies $[12,158,159]$ using different experimental protocols; this has favored the jump to its clinical use. Among the antidepressant effects of curcumin observed in animal models, the most notable are its action on the neurotransmitters involved in depression, its modification of the response of the HPA axis, and its reduction of oxidative stress and mitochondrial damage [160] due to its anti-inflammatory and antioxidant properties. More than 40 studies have been conducted in animals using the aforementioned protocols, including the FST or TST, although other more specific techniques have also been used, such as sleep deprivation, immobilization stress, and cold stress, all as models of chronic stress. Surgical procedures including bilateral olfactory bulbectomy and ligation of sciatic nerves have also been employed [6]. In all cases, the findings have indicated a possible antidepressant effect. For example, it was demonstrated that the administration of curcumin to rats and mice improves the study parameters, both in acute and chronic depression models, with similar effects to those obtained with fluoxetine and imipramine [6, $160,161]$. The results also demonstrated that the antidepressant mechanism of curcumin involves both the serotonergic system [162] and the AC-cAMP pathway [163]. Curcumin has also been shown to improve the anti-immobility effect of subliminal doses of various antidepressant drugs such as fluoxetine, venlafaxine, or bupropion [164], while the combination of curcumin with piperine (a bioavailability enhancer) significantly increased the anti-mobility effects, the potentiation of the neurotransmitters 5-HT and DA, and the inhibitory effects of MAO-A with respect to curcumin administered alone [165]. Other studies established the effect of curcumin in rats with bilateral olfactory bulbectomy, which causes behavioral changes that lead to characteristics similar to those observed in patients with depression. Bulbectomy causes important dysfunction in the cortico-hippocampal-amygdaloidal circuit similar to that observed in depressed people [166]; however, researchers found that the administration of curcumin modifies the changes provoked by bulbectomy as effectively as antidepressants, reducing the immobility time and reversing the behavioral abnormalities induced by the procedure [167]. Curcumin also attenuated the depletion of monoamines and the reserpine-induced increase of oxidative stress [168] along with the behavioral changes induced by corticosterone [169]. In addition, curcumin was shown to revert or protect rat hippocampal neurons from damage in response to chronic stress via positive regulation of $5-\mathrm{HT}_{1 \mathrm{~A}}$ and $\mathrm{BDNF}$ receptors, 2 molecules involved in the neurogenesis of the hippocampus [170]. Ceremuga et al. [171] studied the anxiolytic and antidepressant-like effects of curcumin in various selective tests and concluded that curcumin's effects were not due to its interaction with the benzodiazepine site of the $G A B A_{A}$ receptor. This means that the observed effects are likely due to the modulation of other subunits on the $G A B A_{A}$ receptor or even interactions with other CNS neurotransmitter systems, thereby confirming the mechanisms previously cited for curcumin [171]. - Table 1 contains a concise summary of the main results obtained in vivo, with reference to the possible mode of action and the mediators involved in the mechanism of action of curcumin as an antidepressant. The total glycoside-fraction of Cynanchum auriculatum was also tested with the FST, TST, and LAT. In addition, the authors tested for the inhibition of 5-HT reuptake in rat brain synaptosomes to conclude that the antidepressant-like effects are due to the inhibitory effect on serotonin reuptake [172].

Eleutherococcus senticosus is used with similar indications to those of Panax ginseng, although in the latter, other organs such 
- Table 1 Some relevant in vivo studies on the antidepressant-like activity of curcumin.

\begin{tabular}{|c|c|c|}
\hline Dose & Effect & Ref. \\
\hline 10-80 mg/kg, i. p., mice & $\begin{array}{l}\text { Reduced the period of immobility and increased levels of 5-HT and DA (at higher doses) } \\
\text { and inhibited both MAO-A and MAO-B }\end{array}$ & [164] \\
\hline $\begin{array}{l}20 \text { and } 40 \mathrm{mg} / \mathrm{kg} \text {, i. p., } 21 \text { days with } \\
\text { piperine }(2.5 \mathrm{mg} / \mathrm{kg} \text {, i. p., } 21 \text { days), rats }\end{array}$ & $\begin{array}{l}\text { Increased the anti-mobility effect, potentiation of the neurotransmitters 5-HT and DA, } \\
\text { and the inhibitory effects of MAO-A with respect to curcumin administered alone }\end{array}$ & [165] \\
\hline $1.25-10.0 \mathrm{mg} / \mathrm{kg}$ for 14 days, rats & $\begin{array}{l}\text { Reduced the immobility time and reversed the behavioral abnormalities induced by said } \\
\text { procedure }\end{array}$ & [167] \\
\hline $100-300 \mathrm{mg} / \mathrm{kg}$, i. p., rats & $\begin{array}{l}\text { Attenuates depletion of monoamines and the increase of oxidative stress with reserpine } \\
(1 \mathrm{mg} / \mathrm{kg}, \text { s. c., } 3 \text { days })\end{array}$ & [168] \\
\hline $\begin{array}{l}20 \mathrm{mg} / \mathrm{kg}, \text { p. o. and corticosterone } \\
(40 \mathrm{mg} / \mathrm{kg}, \text { s. c.) for } 3 \text { weeks, rats }\end{array}$ & $\begin{array}{l}\text { Reduce the alteration of the behavior of the rats after an injection of corticosterone. } \\
\text { There was a } 46 \% \text { increase in sucrose consumption and } 57 \% \text { reduction in immobility time } \\
\text { versus negative control (only corticosterone). }\end{array}$ & [169] \\
\hline 10 and $20 \mathrm{mg} / \mathrm{kg}$, p. o., rats & $\begin{array}{l}\text { Revert or protect hippocampal neurons from increased damage via positive regulation } \\
\text { of } 5-\mathrm{HT}_{1 \mathrm{~A}} \text { and BDNF receptors }\end{array}$ & {$[170]$} \\
\hline
\end{tabular}

as leaves are also employed [173], including for the treatment of mental and emotional problems, as well as an antistress agent [174]. This has prompted several research groups to investigate its efficacy as an antidepressant in animals, but no studies in humans have been reported. In this context, jin et al. studied the antidepressant-like activity at very high doses using FST and TST protocols. The higher dose elevated the levels of $5-\mathrm{HT}$, NA, and DA in the whole mouse brain. Moreover, the extract upregulated the level of CREB protein at both doses, leading the authors to hypothesize that the antidepressant effects of E. senticosus are mediated by the central monoaminergic neurotransmitter system and CREB protein expression [174]. In a complementary study, Wu et al. [175] demonstrated the protective effects of $E$. senticosus on corticosterone-induced neurotoxicity (PC12 cells) as an in vitro model of depression. They observed that the extract increased cell viability, decreased lactate dehydrogenase release, suppressed the apoptosis of PC12 cells, attenuated intracellular $\mathrm{Ca}^{2+}$ overloading, and upregulated BDNF mRNA levels and CREB protein expression in comparison with the control group. One year later, Gaire and Lim [176] studied the antidepressant effects of $E$. senticosus in rats (TST and FST) and evaluated the serum corticosterone levels. They noted that at the higher dose, the extract ameliorated depressive behaviors and restored HPA activity [176].

Icariin (44, Fig. 5S, Supplementary Information), a prenyl-flavonoid glycoside isolated from Epimedium brevicornu, was tested in a CUMS model of depression in rats. Administration of icariin reversed the CUMS-induced sucrose intake reduction and CRF elevation, which affected the HPA axis functions but not the hypothalamus-pituitary-thyroid (HPT) axis [177]. Two species of Eugenia, E. brasiliensis and E. uniflora, were tested both for their antidepressant-like effects and to assess the implication of the monoaminergic systems in the mechanism of action. In the case of $E$. brasiliensis, the effect in the TST was mediated by the serotoninergic (5- $\mathrm{HT}_{1 \mathrm{~A}}$ and $\left.5-\mathrm{HT}_{2}\right)$, noradrenergic $\left(\alpha_{1}\right)$, and dopaminergic $\left(D_{1}\right.$ and $\left.D_{2}\right)$ systems [178], whereas in the case of $E$. uniflora, the activity was attributed to the serotoninergic $\left(5-\mathrm{HT}_{2 \mathrm{~A} / 2 \mathrm{C}}\right)$ and nor- adrenergic $\left(\alpha_{1 / 2}\right)$ receptors; the dopaminergic system was not involved [179].

Gastrodia elata has previously been studied as an antidepressant in different tests in which the serotonergic and dopaminergic systems were implicated $[180,181]$. In addition, when it was tested in the CSDS model, it ameliorated depression-like behaviors and stress-induced elevations of corticosterone. It also increased the expression of BDNF and promoted the hippocampal protein phosphorylation ratio of CREB and Akt as a possible mechanism of action [182], whereas in the CUMS protocol this extract restored the cerebral turnover rates of DA and 5-HT and decreased serum corticosterone levels [183]. Gentiana acaulis and its major compound, gentiacaulein, inhibited MAO-A activity in a crude brain mitochondrial fraction of mice treated with the extract [184]. The standardized extract (Ginkgolon-24) of Ginkgo biloba reduced the immobility time in both the FST and TST, prompting researchers to assign its antidepressant-like activity to flavonoid-glycosides; however, other compounds were also implicated, including ginkgolides and bilobalide. The most likely mechanism involves the extract's effects on monoamines and MAPKs in the brain [185]. In the case of the EGb761 standardized extract, Rojas et al. [186] suggested that the antidepressant-like effect may be partly due to its observed neuroprotective effects through its antioxidant properties [186]. Recently, Zhang et al. [187] described the compound's antidepressant-like activities and the improved cardiac function in mice with heart failure (SPT and OFT), with the compound reducing levels of TNF- $\alpha, \mathrm{IL}-1 \beta$, and $5-\mathrm{HT}$ in the hippocampus, blocking the release of $5-\mathrm{HT}$ in peripheral blood and triggering HIF-1-induced anti-apoptotic pathways [187]. Glycyrrhiza glabra (liquorice) reduced the immobility times of mice in both the FST and TST, with various monoamine receptor antagonists $\left(D_{2}\right.$ and $\left.\alpha_{1}\right)$ reducing the effect, indicating that the extract's antidepressant-like effects are due to an increase of DA and NA (but not of 5-HT) activity in the brain, [188]. In the case of G. uralensis, similar effects were observed in the same tests when the isolated compounds liquiritin (40) and isoliquiritin (41, Fig. 5S, Supplementary Information) were used, but in these experi- 
ments, the mechanism of action for both compounds was attributed to the increase of 5-HT and NA in the mouse hippocampus, hypothalamus, and cortex, with no effect on DA [189].

Handroanthus impetiginosus was studied for its antidepressantlike effect (FST, TST, OFT), with the anti-immobility effect being related to the serotonergic $\left(5-\mathrm{HT}_{2 \mathrm{~A}}\right)$, adrenergic $\left(\alpha_{1}, \alpha_{2}\right.$, and $\left.\beta\right)$, and dopaminergic $\left(D_{1}\right.$ and $\left.D_{2}\right)$ systems [190] as it increased not only both CREB and ERK1 phosphorylation but also BDNF signaling pathways in olfactory bulbectomized rats [191]. Moreover, it reduced NO levels in the cerebral cortex, an effect that is dependent on a blockade of NMDA receptor activation and inhibition of NO-cGMP synthesis [192]. Hedyosmum brasiliense also exerted an antidepressant-like effect (FST and TST), as did its isolated sesquiterpenoid, podoandin (20, Fig. 3S, Supplementary Information). The activity was reported to be dependent on the serotonergic, noradrenergic, and dopaminergic systems but not on the GABAergic, opioid and oxidonitrergic systems [193]. Hemerocallis citrina reduced the immobility time in both the FST and TST models for depression in mice with no concomitant changes in locomotor activity observed in the OFT. These results were found to be dependent on the serotonergic $\left(5-\mathrm{HT}_{1 \mathrm{~A}}\right.$ and $\left.5-\mathrm{HT}_{2}\right)$, noradrenergic $\left(\alpha_{1}, \alpha_{2}\right.$, and $\left.\beta\right)$, and dopaminergic $\left(D_{2}\right)$ systems, as well as on the elevation of 5-HT, NA, and DA levels in the mouse brain [194]. Moreover, the extract reversed the aforementioned changes and upregulated the BDNF and TrkB receptor protein expression in both the frontal cortex and hippocampus [195] while reversing the decreased sucrose preference in the SPT and inhibiting IL- $1 \beta$, IL-6, and TNF- $\alpha$ expression [196]. When the potential neuropharmacological components of a standardized mixture of its principal flavonoids rutin (45) and hesperidin (46) (Fig. 5S, Supplementary Information) were tested, the activity was attributed to the serotonergic and dopaminergic systems [197]. Xu et al. [198] tested the total phenol fraction of $H$. citrina using a CUMS model and described a potential mechanism mediated by regulation of neurotransmitters and BDNF levels in the brain and alleviation of both the corticosterone levels and oxidative stress [198]. The flavonoid hesperidin has also been shown to exert an antidepressant-like effect mediated in an ERK-dependent manner [199]. Hibiscus rosasinensis decreased the immobility time (TST and FST) and attenuated the duration of immobility induced by $\mathrm{D}_{2}$ and $\alpha_{1}$ antagonists, and acted as an 5-HT inhibitor synthesis in both tests. These results indicate the implication of the dopaminergic, noradrenergic, and serotonergic systems [200]. In the case of Hippeastrum vittatum, the alkaloid montanine (73, Fig. 7S, Supplementary Information), isolated from fresh bulbs, was found to increase the time spent struggling in the FST model, but no mechanism was proposed [201]. Hordeum vulgare showed an antidepressant-like effect in the FST, reducing both the duration of immobility and the expression of mRNA for nerve growth factor in the hippocampus in a dose-dependent manner, which could also be the mechanism for its antidepressant activities [202]. Both the $\mathrm{CO}_{2}$ extract and the $\alpha$-acid-enriched fraction of Humulus lupulus reduced immobility time during the behavioral despair test, but neither of them affected the locomotor activity in the OFT or exerted an anxiolytic effect [203].

The genus Hypericum includes over 500 species, which often leads to confusion for some authors, since different species are used around the world. The species Hypericum perforatum is known as St. John's wort, and its flowering tops have traditionally been used in Europe as a first-line treatment of major depressive disorder $[12,204]$. There are 2 main groups of principles, naphthodianthrones (hypericin 55 and similar) and phloroglucinols (hyperforin 56 and others) (Fig. 6S, Supplementary Information), but other constituents are also relevant. The presence of pyrrolizidines is not natural in the plant, although they may appear during the harvesting process [205]. Several in vitro studies have established that St. John's wort could be an inhibitor of MAO-A and MAO-B activity while also inhibiting the neuronal reuptake of serotonin, dopamine, and noradrenaline; however, it also has a significant affinity for adenosine, $G A B A_{A}, G A B A_{B}$, and glutamate receptors. Other studies have demonstrated a relationship between the activity of St. John's wort extract and the downregulation of $\beta$ adrenergic receptors with a concomitant upregulation of $5-\mathrm{HT}_{2}$ receptors. Recent research has also established the implication of several compounds (most likely hypericin, hyperforin, and several flavonoids) in the regulation of genes that control HPA axis function. With regard to the antidepressant effects of St. John's wort extract, many of the pharmacological activities appear to be attributable to hypericin, hyperforin, and several flavonoids [206]. In this last case, one study has shown that the absence of rutin reduced the antidepressant activity of St. John's wort, and that hyperforin was the only plant compound present in the brains of rodents after oral administration of the alcoholic extracts, unlike hypericins and flavonoids, which were not present [207]. Bukhari and Dar [208] tested a standardized extract of $H$. perforatum using the FST as an animal model of depression and found that the antidepressant-like properties were related to selective 5-HT reuptake inhibitors. Recently, Zirak et al. [209] reviewed this species and established that $H$. perforatum and its principal compounds, hypericin and hyperforin, possess antidepressant properties similar to those of tricyclic antidepressants and SSRI and that their mechanism is due to inhibition of MAO-A, modulation of the concentrations of DA, 5-HT, and NA in the brain and peripheral tissues, inhibition of synaptosomal reuptake of amines, inhibition of monoamine transporters, and upregulation of $5-\mathrm{HT}_{1 \mathrm{~A}}$ and $5-\mathrm{HT}_{2 \mathrm{~A}}$ receptors. Apparently, hypericin is the main active principle from the extract [209]. Other species of Hypericum have also been studied as potential antidepressant-like agents, including H. canariense [210], H. caprifoliatum [211-217], H. glandulosum [210,211], H. grandifolium [211], H. perfoliatum [218,219], $H$. polyanthemum [220], and $H$. reflexum [211]. All were studied in similar protocols, but $H$. caprifoliatum was the most extensively researched, with both the extract and the phloroglucinol fraction evaluated in an FST model. The activity was associated with an increase in monoaminergic transmission due to the inhibition of monoamine uptake [212], along with the inhibition of $\mathrm{Na}^{+}$influx, which increases hippocampal and cortical $\mathrm{Na}^{+} \mathrm{K}^{+}$-ATPase activities [213] by the phloroglucinol compounds. The lipophilic extract was also found to prevent stress-induced corticosterone increases in the mouse frontal cortex but not in plasma, exerting an antinociceptive effect mediated indirectly by the opioid system [214]. It was also shown to reduce immobility time and the FST-induced increase of serum and cortical corticosterone levels while modifying the HPA axis reactivity to stress [215]. Other studies have focused 
on the flavonoid hyperoside, the antidepressant-like effect of which in rats was prevented by sulpiride, a $\mathrm{D}_{2}$ antagonist, thus implicating the dopaminergic system [216]. But recently, Stolz et al. [217] tested the effect of the dimeric phloroglucinol uliginosin B (54, Fig. 6S, Supplementary Information) using various protocols and observed that uliginosin B inhibited monoamine reuptake, activated DA receptors, and indirectly stimulated the opioid system [217].

Macranthol (60, Fig.6S, Supplementary Information) from Illicium dunnianum was tested in the FST, TST, and CUMS models, attenuating the reduction of serotonergic neurotransmission in the frontal cortex and hippocampus regions of the brain and ameliorating the chronic but not acute, treatment-enhanced BDNF expression [221]. This antidepressant-like action was associated with BDNF-TrkB and downstream activation of the PI3K/Akt$\mathrm{BCl}-2 /$ caspase-3 signaling pathway [222]. In addition, this lignan decreased the levels of elevated pro-inflammatory cytokines such as IL- $1 \beta$, IL-6, and TNF- $\alpha$ in serum and the PFC, indicating that the antidepressant-like properties may be mediated by the suppression of microglia-related neuro-inflammation in the PFC [223]. The compound 1,3,7-trihydroxy-2-(3-methylbut-2-enyl)-xanthone (62, Fig. 6S, Supplementary Information) from Kielmeyera coriacea acts as an antagonist of $5-\mathrm{HT}_{1 \mathrm{~A}}$ autoreceptors in the intra-median raphe nucleus while increasing $5-\mathrm{HT}$ availability in projection regions [224]. Lafoensia pacari reduced immobility time in antidepressant-like tests (FST, TST, and OFT) in mice without affecting motor activity; however, no mechanism or active compounds were cited [225]. In a second study, it exerted the effect by acting on the serotonergic and catecholaminergic systems and increased hippocampal BDNF levels without affecting MAO activity, with the phytochemical analysis indicating the presence of saponins, tannins, steroids, and triterpenes [226].

Different species of Lavandula and their essential oils have been reviewed by Cavanagh and Wilkinson [227], who noted that aromatherapy with these oils could be effective due to both the psychological and the physiological effects of the inhaled volatile compounds because of the participation of both the amygdala and hippocampus. Although the mechanism is unknown, some authors have suggested that the essential oil of lavender (Lavandula angustifolia) may have a similar action to that of benzodiazepines, enhancing the effects of GABA in the amygdala. Other authors have cited the effect of linalool (18, Fig. 3S, Supplementary Information), which serves as an ACh release inhibitor and alters ion channel function at the neuromuscular level [227]. Hritcu et al. [228] used the EPM and FST to evaluate the effects of the essential oils of lavender on neurological capacity in a scopolamineinduced dementia model in rats, demonstrating that these essential oils exert antidepressant activity. In a similar study, the hydroalcoholic extract ameliorated scopolamine-induced memory impairment and depression-like behavior in a dose-dependent manner [229]. Lavender oil and linalool also modulate the neuroendocrine system by interfering with activation-induced tryptophan breakdown and indoleamine 2,3-dioxygenase activity [230]. López et al. [231] established that lavender essential oil exerts its effects by modulating the NMDA receptor. Caputo et al. [232] analyzed both the essential oil and linalool, demonstrating that both compounds reversed social aversion behaviors, while linalool also inhibited the expression of phosphorylated-ERK and kinase A, which are involved in the transmission of nerve signals [232]. The oral administration of lavender essential oil attenuated nerve injury-induced neuropathic pain symptoms in mice while simultaneously exerting an antidepressant-like activity through the inhibition of spinal ERK and JNK phosphorylation, along with the reduction of iNOS expression [233]. Lepidium meyenii (Maca) has been used to treat various maladies, including depression. It was tested in the CUMS model of depression in mice and was found to decrease immobility time in the TST; it also reduced corticosterone levels in serum. In addition, DA and NA levels increased and ROS were inhibited in the mouse brain tissue [234]; however, MAO-A was not inhibited [235]. Lycium barbarum's (wolfberry) antidepressant-like effect is due to the enhancement of synaptic plasticity but not hippocampal neurogenesis [236].

Marsilea minuta reduced immobility in the FST and TST in rodents, with the activity due to the downregulation of $5-\mathrm{HT}_{2 \mathrm{~A}}$ receptors in the frontal cortex [237]. Melissa officinalis is also used as an antidepressant [238], with its extracts and essential oil showing antidepressant-like effects in mice and rats [239-241]. In 2015, Lin et al. [242] tested rosmarinic acid (58, Fig. 6S, Supplementary Information), and found that both extract and rosmarinic acid modulated serotonergic neurotransmission and down-regulated the turnover of 5-HT in the FST model. Mimosa pudica reduced immobility time in both the FST and TST, but exhibited no effects in the OFT (locomotor activity) and increased DA and NA levels in the brain. In addition, the extract showed anti-anxiety and memory enhancing activities [243]. In the case of Mitragyna speciosa, the major alkaloid (mitragynine 67, Fig. 1S, Supplementary Information) was tested and shown to reduce the immobility time of mice in both the FST and TST, with no concomitant effect on locomotor activities. The alkaloid also reduced the release of corticosterone in mice. The authors hypothesized that mitragynine's antidepressant-like effects are most likely due to its interaction with the neuroendocrine HPA axis systems [244]. Momordica charantia also reduced the duration of immobility in the FST and TST; in this case, the antidepressant-like effect was found to be dependent on the monoamine receptors (5- $\mathrm{HT}_{2}, \alpha_{1}$, $\alpha_{2}$, and $D_{2}$ ), but the muscarinic cholinergic systems and benzodiazepine-type receptor also seem to be implicated in the plant's anxiolytic activity [245].

Morinda officinalis has antidepressant and anti-inflammatory activities [246]. Zhang et al. [247] studied its effects in an FST animal model of depression, as well as in a behavioral screening known to be both selective and sensitive to antidepressant drugs, namely the DRL 72-s schedule. The plant extract exerted effects similar to those of the antidepressant drug desipramine in rats in the DRL 72-s test, reducing the response rate and efficiency ratio and increasing the reinforcement rate. In the FST, the extract also elicited a significant reduction in the duration of immobility, as did the reference drug [247]. Other research has focused on the inulin-type oligosaccharides MW-97 (1 glucose and 3 to 6 fructose) and $\mathrm{P}_{6}$ ( 6 units, 1 glucose and 5 fructose) obtained from this plant, finding that they both increased 5-HT levels in the brains of reserpinized mice while normalizing the hyperactive state of the HPA axis induced by chronic stress in mice or rats [248]. In a subsequent study, the same authors demonstrated that $\mathrm{P}_{6}$ and de- 
sipramine antagonize the apoptosis induced by corticosterone in PC12 cells, which may be one of the cellular mechanisms behind their antidepressant effects. In addition, MW-97 increased both the 5-HT levels and the activity of the Gs protein-AC-cAMP pathway, with both leading to an increase in the neurotrophic factors. This hypothesis explains why MW-97 increases the activity of AC in vivo, while having no effect in vitro. This inulin-type hexasaccharide $\left(P_{6}\right.$, but referred to as IHS in this paper) decreased intracellular $\mathrm{Ca}^{2+}$ overloading, thereby upregulating nerve growth factor mRNA expression in corticosterone-treated PC12 cells. This cytoprotective and neuroprotective action may be part of the mechanism behind its antidepressant effects [249, 250]. Xu et al. [251] described the positive effects of a mixture of oligosaccharides from $M$. officinalis on chronic, unpredictable stress-induced depression-like behavior in the SPT and FST. Indeed, the mixture attenuated chronic, unpredictable stress-induced abnormalities in the BDNF-GSK-3 $\beta$ - $\beta$-catenin pathway and ameliorated synaptic protein deficits in the medial-but not the orbitofrontal-PFC. However, the phosphoinositide-3 kinase inhibitor LY294002 reversed the antidepressant-like effects of these oligosaccharides in the FST, most likely because of the activation of GSK-3 $\beta$ by the inhibitor. In addition, naïve rats treated with oligosaccharides exhibited resistance to CUMS, accompanied by increases in the expression of BDNF, phosphorylated-Ser9-GSK-3 $\beta$, and $\beta$-catenin in the medial PFC [251].

Moringa oleifera also produced significant changes in FST, TST, and LAT models, with the activity involving the noradrenergic-serotonergic systems [252]. In the case of Morus alba, it decreased immobility in the FST in rats, decreasing the HPA axis response to stress in the hippocampal and hypothalamic paraventricular nucleus region [253]. In contrast, the antidepressant-like activity (FST, TST, and CUMS in mice) of Mucuna pruriens involved the dopaminergic system [254]. Myristica fragrans also decreased the immobility period of mice in FST and TST models, with no effect on locomotor activity. Different selective inhibitors of monoamine activity/receptor/synthesis reduced or abolished the effects, which led to the hypothesis that the antidepressant-like effect of nutmeg is mediated by its interaction with the adrenergic $\left(\alpha_{1}\right)$ and dopaminergic $\left(D_{2}\right)$ receptors, along with 5-HT synthesis [255]. Moinuddin et al. obtained similar results working with rats [256], but no mechanisms were proposed.

The activity of Nardostachys jatamansi was studied in silico. The docking results prompted the authors to propose that the compounds of this plant can modify depression through multiple molecular targeting of different compounds [257]. Other authors studied these compounds in vivo and observed that they produced a decrease in brain MAO-A and MAO-B activities, consequently increasing monoamine levels. In addition, the extract also interacted with $\mathrm{GABA}_{B}$ receptors, resulting in a decrease in GABA levels in the mouse brain [258]. Working with Nelumbo nucifera, researchers isolated the bisbenzylisoquinoline alkaloids neferine (68), liensinine (69), and isoliensinine (70, Fig. 7S, Supplementary Information), which were studied for their antidepressant-like activity (FST) in mice. The effect in this case was mediated by the $5-\mathrm{HT}_{1 \mathrm{~A}}$ receptor, whereas other subtypes of 5- $\mathrm{HT}$ and adrenergic receptors $\left(\alpha_{1}\right)$ were not implicated $[259,260]$. Extracts enriched in flavonoids, saponins, alkaloids, tannins, and terpenoids were also tested and likewise showed antidepressant-like activity in the FST as well as anxiolytic effects in the EPM, but no mechanisms were elucidated [261]. Ocimum tenuiflorum shortened the immobility time in both the TST and FST while also decreasing anxiety in different models but had no effects on the motor coordination of mice. No mechanisms or active compounds were proposed [262].

Paeonia lactiflora reduced the duration of immobility in mice, with the effect being related to the central monoaminergic neurotransmitter system [263], the modulation of the function of the HPA axis, the inhibition of oxidative stress, and the up-regulation of neurotrophins [264]. To identify the potential active principles, the total glycosides of peony were tested in the same protocols. The results suggested that the antidepressant-like effects are mediated by the inhibition of MAO [265]. Albiflorin (19, Fig. 3S, Supplementary Information) from this plant exhibited activity in both the FST and in a CUMS-induced model of depression in rats. This monoterpene-glycoside reversed both the immobility and the reduced SPT while increasing 5-HT levels in serum and those of its metabolite 5-HIAA in the hypothalamus. It also abolished the over-expression of $5-\mathrm{HT}_{1 \mathrm{~A}}$ and $5-\mathrm{HT}_{2 \mathrm{~A}}$ receptors in the hypothalamus caused by CUMS. In addition, albiflorin enhanced DA and NA concentration in the serum and hypothalamus, while increasing levels of tyrosine hydroxylase, enhancing the $D_{2}$ receptor and reducing DAT expression in the hypothalamus, thus demonstrating that not only the serotonergic system but also the dopaminergic system is involved in the antidepressant-like effect of albiforin [266].

Panax ginseng has been used for generations in Asian countries to combat various maladies, including neurodegenerative diseases and cognitive dysfunctions [267]. It was shown to reduce immobility time in both the FST and TST [268]. The molecular and cellular mechanisms of ginseng include the modulation of the monoamine neurotransmitter system, the upregulation of the expression of neurotrophic factors, the regulation of HPA axis function, anti-inflammatory effects [269], and antioxidant activity through the Nrf2/heme oxygenase-1 system [270]. Several studies have focused on the pharmacological effects of different samples, such as the ginseng extract G115 [271], the sesquiterpene fraction [272], or saponins [273], which are the most relevant chemicals in the roots. The ginsenosides are the principal active group of chemicals found in this plant; of these, the ginsenoside Rg1 (9) has been shown to exert antidepressant-like effects in mice via activation of the hippocampal BDNF signaling pathway [274]. Indeed, treatment with ginsenoside Rb1 (10, Fig. 2S, Supplementary Information) attenuated the CUMS-induced decrease in the activities of BDNF, TrkB, Akt, ERK, and CREB in the mouse hippocampal $C A 3$ region and $P F C$. These results suggest that BDNF-TrkB-CREB signaling may be involved in the antidepressant mechanism of the action of Rb1 [269]. This compound also exhibited a significant antidepressant-like effect in behavioral tests in mice (FST and TST), chronic animal models, and drug interactions. Its mechanism is mainly mediated by central neurotransmitters with a significant upregulation of 5-HT, NA, and DA levels in CUMS rat brains [275]. However, not only is the monoaminergic system implicated; the glutamatergic and GABAergic receptors may also be involved in the antidepressant-like effect of Rb1, mainly be- 
cause ginsenoside Rb1 has been shown to up-regulate the levels of the monoaminergic and GABAergic systems while decreasing the level of glutamate in the mouse hippocampus CA3 region and PFC [276]. Ginsenoside Rg1 (9) also modulated HPA and the hypothalamic-pituitary-gonadal axis in research carried out by Mou et al. [277], who proposed this new mechanism for the antidepressant-like effects of ginsenoside Rg1. The compound downregulated serum corticosterone levels while increasing androgen receptor protein levels in the PFC of gonadectomized-treated mice, a result that provides theoretical clues for potential clinical therapies [277]. Another mechanism proposed for ginsenoside $\mathrm{Rg} 1$ is its effect on the corticosterone-induced Gap junction intercellular communication dysfunction in astrocytes from the PFC and hippocampus, which may have clinical significance in the treatment of depression, as observed by Xia et al. [278]. With a chemical structure similar to that of ginsenoside Rg1, ginsenoside Rg5 (8, Fig. 2S, Supplementary Information) likewise has antineuroinflammatory effects and leads to cognitive improvements. Xu et al. [279] studied the antidepressant-like effects of ginsenoside Rg5 using different models of depression. Ginsenoside Rg5 exhibited antidepressant-like activity in both the FST and TST without affecting locomotor activity. It was also effective in the CSDS model of depression, restoring the CSDS-induced decrease in the hippocampal BDNF signaling cascade. The authors thus concluded that ginsenoside Rg5 exerts its antidepressant activities via the activation of the hippocampal BDNF system [279]. Panax notoginseng has been used to achieve the same objectives as true ginseng. It is similar in composition, pharmacological make-up, and mechanisms for its effects [280]. For example, saponins found in the plant exerted antidepressant-like activity in CUMS, FST, and TST models through regulation of 5-HT, DA, and NA; modulation of GABA neurotransmission, the glutamatergic system, the HPA axis, and BDNF and its intracellular signaling pathways in the CNS; and by producing neuronal protection by means of anti-inflammatory, antioxidant, and anti-apoptotic effects [280, 281].

Paullinia cupana was assayed and compared with caffeine. It reduced the duration of immobility in the FST but had no effect on ambulation in the OFT. These results seem to indicate that the mechanism of guaraná does not involve the adenosinergic system [282]. Peganum harmala inhibited MAO-A due to its high content in the $\beta$-carboline alkaloids harmaline (71) and harmine (72, Fig. 7S, Supplementary Information) [235]. Perilla frutescens oil reduced immobility time in an FST rat model, increasing both BDNF and 5-HT levels in the brain, thus partly explaining the antidepressant-like properties of this oil [283]. In contrast, the essential oil reversed the alterations in the concentrations of 5-HT and 5-HIAA and reduced the IL-6, IL-1 $\beta$, and TNF-levels in mice with CUMS-induced depression. The antidepressant-like activity in this case is related to the alteration of serotonergic responses and anti-inflammatory effects [284]. Phyllanthus emblica was tested with the FST and TST in mice; its observed activity may come about through its interaction with $\mathrm{GABA}_{\mathrm{B}}, \alpha_{1^{-}}$, and $\mathrm{D}_{2}$-receptors, along with 5-HT synthesis [285]. Different species of Piper have been studied for their antidepressant-like effects in specific protocols in vivo and in vitro [286-291]. Piper laetispicum was shown to decrease IL-6 and TNF- $\alpha$ (pro-inflammatory), upregulate the expres- sion of BDNF mRNA, and downregulate caspase-3 mRNA [286]. An amide alkaloid, laetispicine (82, Fig. 8S, Supplementary Information) decreased the immobility time (FST) [287], with a complementary study revealing another antidepressant-like compound identified as leatispiamide A (83, Fig. 8S, Supplementary Information) [288]. Piper nigrum decreased swimming time while increasing immobility time in the FST; the mechanism involved attenuation of the oxidative stress in the rat amygdala [289]. Piper sarmentosum activity seems to be mediated by the modulation of the HPA axis along with phosphorylation and expression of BDNF, CREB, and ERK in the hippocampus [290]. Piplartine, (84, Fig. 8S, Supplementary Information) an amide alkaloid, was isolated from Piper tuberculatum and shown to exhibit significant anxiolytic and antidepressant activities, but no mechanisms were proposed for the latter effect [291]. Other species of Piper, such as $P$. longum L. and P. methysticum have also been described as antidepressants [292].

The genus Polygala has 4 species with antidepressant-like properties, all of which have been tested by different authors using similar protocols (FST, OFT). In the case of Polygala paniculata, the activity was mediated by an interaction with the serotonergic $\left(5-\mathrm{HT}_{2 \mathrm{~A}}\right)$, adrenergic $\left(\alpha_{2}\right.$ and $\left.\beta\right)$, and dopaminergic $\left(\mathrm{D}_{1}\right.$ and $\left.\mathrm{D}_{2}\right)$ receptors [293], as occurs in the case of scopoletin (50, Fig. 6S, Supplementary Information) isolated from Polygala sabulosa; however, in the latter case the effect involved the $\alpha_{1}$ but not the $\beta$-adrenoceptor [294]. In the case of Polygala sibirica, the activity was related to the normalization of the deficit in hippocampal neurogenesis with inhibition of newborn neuron apoptosis [295]. A mechanism similar for Polygala tenuifolia has likewise been cited [296], with a relevant role for the HPA axis, but in this species, researchers studied a particular isolated compound, 3,6'-disinapoyl sucrose (61, Fig. 6S, Supplementary Information), and found that its antidepressant-like properties were mediated by the inhibition of MAO-A, MAO-B, the HPA axis, and the oxidative systems, all through increases in SOD activity, inhibition of lipid peroxidation, and decreases in the production of MDA [297]. The antidepressant effects of a mixture of $\alpha$-amyrin (2) and $\beta$-amyrin (3, Fig. 1S, Supplementary Information) isolated from Protium heptaphyllum were evaluated in the standard protocol of antidepressant-like effects, and their activity was attributed to a noradrenergic mechanism [298]. In contrast, the activity of Ptychopetalum olacoides seems to be mediated by $\beta$-adrenergic and $D_{1}$ receptors [299] along with the prevention of stress-induced HPA hyperactivity [300]. Pueraria montana var. lobata was tested against depressive-like behaviors of mice exposed to cerebral ischemia reperfusion and was found to modify the disturbance of DA and NA systems in both the hippocampus and striatum; this activity was more important in the development of depressive-like behavior in mice than that of the 5-HT system [301].

Rhazya stricta [302,303], along with Rosa $\times$ damascena [304, 305] were both studied and found to possess antidepressant properties. There are many papers on the potential of Rosmarinus officinalis as an antidepressant drug, but no relevant clinical studies have been performed. Machado et al. [306] observed a marked antidepressant-like effect in mice (FST and TST). Pretreatment with a 5-HT synthesis inhibitor and receptor antagonists (5- $\mathrm{HT}_{2 \mathrm{~A}}$, 5- $\mathrm{HT}_{3}, \alpha_{1}, \mathrm{D}_{1}$, and $\mathrm{D}_{2}$ )-but not with an $\alpha_{2}$-adrenoceptor antago- 
nist-reversed the anti-immobility effect. The authors concluded that the antidepressant effect of rosemary is mediated by an interaction with the monoaminergic system. These same authors [307] established the effect of this extract in olfactory bulbectomized mice, observing an increase in hippocampal AChE activity. They hypothesized that rosemary extract could thus be used in the treatment of depression [307]. In 2 complementary studies, these same researchers established that the potential active compounds of this extract, tested in the same protocols, were ursolic acid (4) [308], betulinic acid (5) (Fig. 1S, Supplementary Information), and carnosol (25, Fig.3S, Supplementary Information), [309]. However, other authors have cited luteolin (28, Fig. 4S, Supplementary Information), carnosic acid (26, Fig. 3S, Supplementary Information), and rosmarinic acid (58, Fig. 6S, Supplementary Information) as potential active compounds because they were shown to regulate DA, NA, $5-\mathrm{HT}$, and ACh, as well as the gene expression of tyrosine hydroxylase and pyruvate carboxylase, 2 major genes involved in dopaminergic, serotonergic, and GABAergic pathway regulation [310]. Rosmarinic acid, luteolin-7O-glucuronide (39, Fig. 5S, Supplementary Information), and caffeic acid (48, Fig. 6S, Supplementary Information), all of which are AChE inhibitors [311], as well as salvigenin (29), cirsimaritin (30, Fig. 4S, Supplementary Information), and rosmanol (27, Fig. 35, Supplementary Information), which produce biphasic modulation of $\mathrm{GABA}_{A}$ receptors [312], have also been proposed as active constituents. In one interesting study, Guo et al. [313] investigated the antidepressant effects of rosemary extracts on chronic restraint stress mice along with the inflammatory mechanisms related to the gut microbiome. The results showed that the extract significantly ameliorates depressive-like behaviors in chronic restraint stress mice. This effect was due to the inhibition of inflammatory reactions in the hippocampus and serum, as well as in microglia cells (BV-2), and the promotion of BDNF and p-Akt/Akt expression in the hippocampus, along with a rebalance of gut microbiota. This data is of interest because there is a clear relationship between depression and abundance of Lactobacillus, Bacteroidetes, Firmicutes, and Proteobacteria. The rosemary extracts were found to decrease the proportion of both Bacteroidetes and Proteobacteria while promoting an abundance of Lactobacillus and Firmicutes. With respect to the pro-inflammatory mediators, the extract reduced IL- $1 \beta$, TNF- $\alpha$, and $\mathrm{p}-\mathrm{NF}-\mathrm{KB}$, indicating a protective effect for rosemary extract in mice and its implication in the antidepressant-like properties of the plant [313]. A lipid extract (D004) of Roystonea regia increased mouse immobility in both the FST and TST but showed no effects in other behavioral tests [314].

Three species of Salvia have been tested as potential antidepressant-like agents in rodents. Salvinorin A (23, Fig. 3S, Supplementary Information), the major compound from Salvia divinorum, was isolated and tested in EPM, FST, and TST rodent models. The authors concluded that the anxiolytic- and antidepressantlike effects of salvinorin $A$ are mediated by both opioid and endocannabinoid systems but that the compound had a very weak affinity for cannabinoid $\mathrm{CB}_{1}$ receptors [315]. Salvia elegans was also tested, but no significant activities were described [316]. In the case of Salvia sclarea, the essential oil showed antidepressant-like effects in the FST in rats. This property seems to be closely associated with modulation of the dopaminergic pathway [317]. Sceleti- um tortuosum is also used as an antidepressant, with different studies in animals demonstrating its activity [318-320]. The active compounds have been identified as mesembrine alkaloids [321]. Of these, both mesembrine (74) and mesembrenone (75, Fig. 7S, Supplementary Information) are 5-HT reuptake inhibitors, but mesembrenone also has a reasonably potent inhibitory effect on phosphodiesterase-4 [321] while mesembrine was shown to be the most active alkaloid against SERT [322]. While this species has antidepressant properties, it also produces ataxia, which may limit its usefulness as an antidepressant [318]. The activity of Schinus molle was shown to be due to its interaction with the serotonergic (synthesis and $5-\mathrm{HT}_{1 \mathrm{~A}}, 5-\mathrm{HT}_{2 \mathrm{~A} / 2 \mathrm{C}}, 5-\mathrm{HT}_{3}$ receptors), noradrenergic ( $\alpha_{1}$ - and $\alpha_{2}$-adrenoceptors), and dopaminergic ( $D_{1}$ and $\mathrm{D}_{2}$ receptors) systems. Although the extract contains triterpenoids as major compounds, no principles specifically responsible for these effects have been identified. Further chemical analysis of the extract is planned in order to isolate and characterize the active compounds responsible for the observed effects [323]. In addition, rutin (45, Fig. 5S, Supplementary Information) was also tested, and authors justified that the antidepressant-like effect of Schinus molle was due to rutin, which acts by increasing the availability of 5-HT and NA in the synaptic cleft [324].

Schisandra chinensis produces an antidepressant-like effect in corticosterone-induced depression in mice; the effect seems to be mediated by the modification of the stress-based HPA axis dysfunction and upregulation of the BDNF/TrkB/CREB signaling pathway $[325,326]$ along with the PI3K/Akt/GSK-3 $\beta$ pathways [326]; however, the modification of noradrenergic, dopaminergic, GABAergic, and glutamatergic systems may also play a role [327]. Scrophularia ningpoensis has also been described as an antidepressant-like medicinal plant in an LHT model of depression [328]. Scrophularia striata exerts its anxiolytic and antidepressant effects through modulation of the GABAergic system, most probably $G_{A B A}$, as was demonstrated in EPM and FST models, as well as through modulation of the intracerebroventricular administration of an agonist or antagonist, which was shown to enhance or block the effect of the ethanol extract [329]. Scutellaria baicalensis reduced immobility time (FST and TST), increased sucrose consumption (SPT), alleviated the damage from CUMS-induced neurogenesis, and improved depressive-like behavior through the regulation of the CAMP/PKA neurogenesis pathway. The authors identified wogonin (31), baicalein (32, Fig. 4S, Supplementary Information), baicalin (42), and wogonoside (43, Fig. 5S, Supplementary Information) as the principal compounds responsible for these effects [330]. Of these, baicalin has been studied as an isolated compound and was shown to increase sucrose consumption in the SPT as well as the number of crossings in the OFT. It also attenuated immobility time in the TST, with its mechanism seemingly related to the promotion of neuron differentiation via the Akt/FOXG1 pathway [331]. In addition, baicalin increased DA levels in the rat striatum, hippocampus, and cortex and ameliorated the synaptogenesis associated with $\mathrm{GABA}_{A}$ receptor downregulation following abnormal stimulation of $D_{1}$ receptors [332]. Securidaca longepedunculata probably exerts its antidepressant-like effects through the opioidergic pathway [333].

Sedum roseum is used as an adaptogen, antidepressant, and anti-inflammatory agent [334-336]. A wide variety of preclinical 
in vivo and ex vivo studies with laboratory animals suggests the presence of several biochemical and pharmacological antidepressant-like actions [337]. Different studies in animals established that golden root extract and its principal constituent, salidroside (59, Fig. 6S, Supplementary Information), interact with different mediators implicated in several molecular networks of the neuroendocrine and neurotransmitter systems involved in the pathophysiology of depression. It was shown to improve depressive-like behaviors through its anti-inflammatory effects (reducing TNF- $\alpha$ and IL-1 $\beta$ levels in the hippocampus) and the regulation of HPA axis activity (increasing glucocorticoid receptor and BDNF expression in the hippocampus, attenuating $\mathrm{CRH}$ expression in the hypothalamus, and reducing corticosterone in serum) in olfactory bulbectomized rats [338]. In summary, the principal targets and pathways that have been established for these extracts are the CREB/microphthalmia-associated transcription factor/tyrosinase pathway, the 5- $\mathrm{HT} / 5-\mathrm{HT}_{1 \mathrm{~A}}$ receptors, and MAO-A, p-JNK, NO, cortisol and neuropeptide $Y[337,339,340]$. In the case of salidroside, the principal targets are BDNF, CREB, TrkB, the glucocorticoid receptor, $\mathrm{CRH}, \mathrm{NA}, \mathrm{P}-\mathrm{JNK}, \mathrm{NO}$, neuropeptide $\mathrm{Y}$, heat shock factor 1 , and heat shock protein-70 [337,338]. Two species of the genus Senna have been tested, S. septemtrionalis and S. spectabilis. In the former, the $\alpha_{2}$-adrenoceptors are probably responsible for the plant's antidepressant-like effects as observed in both the FST and TST [341]. As for the latter species, different analogs of the natural piperidine alkaloid (-)-3-O-acetylspectaline isolated from it were studied for their antidepressant-like activities. In the end, the derivative ethyl 2-[(3-nitropyridin-2-yl)sulfanyl]acetate was shown to decrease the immobility time of mice in the FST without affecting locomotor activity; unfortunately, no mechanism was proposed [342]. Sida tiagii showed activity in the FST and TST, acting through the inhibition of both MAO (more selectivity on MAO-A than on MAO-B) and lipid peroxidation [343]. Siphocampylus verticillatus was also studied for its potential antidepressant-like effect in 2 models in mice and against synaptosomal uptake of 5-HT, NA, and DA. The authors concluded that the extract elicited its antidepressant-like effect through interaction with the adrenergic, dopaminergic, glutamatergic, and serotonergic systems [344]. Solanum torvum inhibited the immobility period (FST and TST), increased DA, NA, and 5-HT levels, and inhibited $\mathrm{MAO}$ in mice [345]. In a second study, these same authors examined the effect of torvanol A (36, Fig. 4S, Supplementary Information), and found that it likewise decreased the immobility period in the specific tests through implication of the noradrenergic, dopaminergic, serotonergic, and GABAergic systems [346]. In another study, Sonchus oleraceus reduced the immobility time in the FST and TST [347].

Two species of Tagetes have been studied by various researchers. Tagetes erecta inhibited the immobility period in mice (FST), with the serotonergic and nitrergic pathways, as well as the $\sigma$-opioid receptors, all being implicated in the antidepressant-like activity [348]. Tagetes /ucida reduced immobility and increased swimming without affecting climbing behavior in the FST; in addition, it affected neither motor activity nor male sexual behavior in rats, which may explain its antidepressant-like properties [349]. The effect seems to be mediated by the serotonergic system [350] and is blocked by $\mathrm{HT}_{2 \mathrm{~A}}$ receptor antagonists and serotonin synthesis inhibitors but not by $\beta$ - and $\alpha_{2}$-noradrenergic receptor antagonists, indicating that the extract modulates the release/reuptake of serotonin [351]. Tanacetum parthenium has exhibited anxiolytic and antidepressant-like effects in various tests, prompting the authors to propose the involvement of the GABAergic system [352]. Terminalia bellirica exerted its antidepressant-like effects (FST and TST) in mice through interaction with the adrenergic $\left(\alpha_{1}\right)$, dopaminergic $\left(D_{2}\right)$, and serotonergic (release/reuptake of 5-HT) systems [353]. In the case of Theobroma cacao, the antidepressant-like effect of the polyphenol-enriched extract was studied and justified in part by the antioxidant effects of its polyphenols; however, the high amount of magnesium found in the extract could also be implicated, as this mineral has been reported to be effective against depression-like behavior in mice [354]. The methanol extracts and essential oils from the aerial parts of 3 species of Thymus-T. fallax, T. kotschyanus, and T. pubescens-were studied in mice, with all 3 species shortening the duration of immobility in the FST. In addition, the activities of the essential oils were lower than those of the extracts, with both the extracts and oils of $T$. fallax being more active than those of $T$. kotschyanus and $T$. pubescens [355]. The effect of $T$. kotschyanus extract was corroborated in FST and TST mouse models by Doosti et al. [356]. Tinospora sinensis produced a significant antidepressant-like effect in both the FST and TST, acting through the $\alpha_{1}$-adrenoceptor, $\mathrm{D}_{2}$-receptor, 5-HT release/reuptake, and $\mathrm{CABA}_{B}$ reduction while also reducing MAO-A and MAO-B levels overall in mice, leading to an increase in brain monoamine levels [357]. In a preliminary study, Campos et al. [358] described the antidepressant-like effects of Trichilia catigua in rodents (FST), inhibiting the uptake and increasing the release of both $5-\mathrm{HT}$ and DA from rat brain synaptosomes [358]. The content in simple phenolics and tannins could explain this effect as they exert a strong antioxidant activity [359]. In a complementary study, Bonassoli et al. [360] likewise observed antidepressant-like effects along with the induction of hippocampal cell proliferation in mice for this same extract, whereas Bernardo et al. [361] demonstrated that the aqueous extract of the bark of this plant inhibited MAO-A and AChE activities, inhibiting the xanthine/xanthine oxidase pathway and throwing the oxidative stress out of equilibrium by acting as a SOD anion radical scavenger, which may account for its antidepressant-like effects. In a screening for antidepressant and anti-anxiety plants, 17 plant species were tested for their affinity to the 5-HT transporter and for inhibition of MAO-A. Of these, Trigonella foenum-graecum was the most active in the MAO-A assay, with no effect on 5-HT reuptake [362]. This property was subsequently confirmed by Khursheed et al. [363] with a similar extract, which exhibited activity in the FST and TST but not in the OFT, reducing both MAO-A and MAO-B. In addition, the flavonoid-enriched extracts from the seeds of this plant were shown not only to reverse the CRS-induced behavioral abnormalities but also to restore the induced changes in serum levels of corticosterone, as well as those of the neurotransmitters DA, NA, and 5-HT in the PFC and hippocampus, and those of NA in striatum. The extract also inhibited MAO-A activity as well as downregulating the KLF11, SIRT1, and MAO-A protein expression levels in the PFC and hippocampus. These results justify the role of flavonoids in the antidepressant-like effects of this species [364]. Uncaria lanosa var. appendiculata was assayed 
in FST and TST mouse models, increasing the levels of 5-HT and 5-HIAA in the cortex, striatum, hippocampus, and hypothalamus, as well as increasing NA levels in the cortex, hippocampus, and striatum along with the 4-dihydroxyphenylacetic acid levels in striatum [365].

Grouped under the common name of valerian, there are about 200 known species of the genus Valeriana, but $V$. officinalis is the most commonly used for medicinal purposes and the only one accepted by the European Medicines Agency to treat insomnia as a sedative-hypnotic, as well as for its anxiolytic, antidepressant, and anticonvulsant properties [366]. Valerian roots contain volatile oils and the iridoids known as valepotriates (valtrates, 21, Fig. 35, Supplementary Information). Hattesohl et al. [367] carried out various experiments with 4 commercially available preparations on mice and rats, finding anxiolytic and antidepressant activities but not sedative or myorelaxant properties. The extracts increased BDNF levels in vitro, an effect that was completely reversed after removal of valerenic acid (22, Fig. 35, Supplementary Information) from the extract, indicating that this compound is crucial for the neuronal activity [368]. Three other species of Valeriana were also tested: V. fauriei $[369,370]$, V. glechomifolia [371-373], and $V$. jatamansi [374]. In the first species, bicyclo $[8,1,0] 5 \beta$-hydroxyl-7 $\beta$-1acetoxyl-5,11,11'-trimethyl-E-1(10)-ene4,15 -olide was identified as the principal active compound, increasing the immobility time in the FST in mice [369]. The extract enhanced the stimulation of Nrf-2 pathways, in accordance with upregulation in protein expression of BDNF [370]. In the second assay, a supercritical $\mathrm{CO}_{2}$ extract enriched in valepotriates was tested in TST and FST models and showed an anti-immobility effect that was reversed by both the $\alpha_{2}$-adrenoceptor antagonist and $D_{1}$ and $D_{2}$ receptor antagonists, whereas neither $\alpha_{1}$-adrenoceptor antagonists nor serotonin synthesis inhibitors had any effect on the anti-immobility effect of the extract. These results account for the antidepressant-like activity of valepotriates through their interaction with dopaminergic and noradrenergic neurotransmission [371]. The synergistic interactions between diene valepotriates (valtrate, acevaltrate, 1 - $\beta$-acevaltrate, 1 - $\beta$-aceacevaltrate, and isovaltrate) and various standard antidepressants highlight their potential as adjuvants because they target different neuronal transporters than those targeted by standard treatments [372]. Moreover, the activity of diene valepotriates in the FST was reduced by a protein synthesis inhibitor that works by inhibiting Trk receptors, which could explain the role of diene valepotriates in the extract's antidepressant-like activity, namely through its reduction of hippocampal DNA methylation together with increased protein synthesis. Furthermore, BDNF-mediated TrkB signaling also contributes to the antidepressant-like effect of this extract [373]. In the third case, the extract increased DA and NA levels in the forebrain [374].

Vanda spathulata inhibit both MAO-A and MAO-B in mouse brains in both the FST and TST [375]. Three flavonoids were isolated from Viola odorata and tested in mice (TST and FST) to compare their antidepressant-like effects with those of the standard drug, fluoxetine. The compounds were identified as 5,7-dihydroxy-3,6-dimethoxyflavone (33), 5,7,4' -trihydroxy-3',5'dimethoxyflavone (34), and 5,7,4'-trihydroxy-3'-methoxyflavone (35, Fig.4S, Supplementary Information); all exhibited activity on
$5-\mathrm{HT}_{1 \mathrm{~A}}, 5-\mathrm{HT}_{2 \mathrm{~A}}$, and $5-\mathrm{HT}_{3}$ receptors but not on $\mathrm{D}_{1}$ and $\mathrm{D}_{2}$ receptors. There was likewise no effect on 5-HT synthesis, indicating that the antidepressant-like effects involve the serotonergic system [376].

A glycowithanolide-enriched fraction from Withania somnifera exhibited antidepressant effects in the FST in rats [377]. Shah et al. [378] tested an extract of ashwagandha alone as well as in combination with standard drugs; in both cases, imipramine and fluoxetine produced a significant decrease in the mean immobility time in the FST, an effect that seems to be mediated partly through the $\alpha$-adrenoceptor and alterations in the levels of central biogenic amines [378]. Ashwagandha also exhibited anxiolytic effects in the EPM [379] as well as anti-inflammatory and antioxidant properties [380], which may strengthen its antidepressantlike effects. Xylopia aethiopica showed antidepressant-like properties through its effects on $5-\mathrm{HT}$ neurotransmission, but also by a synergistic effect with the glycineB receptor (possible glutamatergic effect) and NOS inhibition. The adrenergic system was not involved, as indicated by the fact that catecholamine depletion did not affect the antidepressant properties [381]. In the case of Xysmalobiyum undulatum, the extract showed activity in mice but not in rats (FST). Moreover, it showed affinity to SERT, but, when used at a different concentration, had no effect on SERT, NAT, or DAT transporters, indicating that the effects are most likely due to another mechanism [41]. In one early study on Zingiber officinale, Sharma et al. [382] described the effect of the ethanol extract in different CNS tests, including the FST and TST, in which it was shown to decrease time of immobility; this effect was related to its antioxidant properties. Martínez et al. [383] isolated and studied a phenolic from the rhizomes, dehydrozingerone (85, Fig. 8S, Supplementary Information), which showed antioxidant activity in the hippocampus, cortex, and cerebellum of mice, as analyzed in TST and FST models, reducing the immobility time in both tests with no concomitant effect on locomotor activity in the OFT. Its activity involved $5-\mathrm{HT}_{2 \mathrm{~A} / 2 \mathrm{C}}$ and $5-\mathrm{HT}_{3}$ receptors, as well as $\alpha_{1}$ - and $\alpha_{2}$-adrenoceptors. The antidepressant-like effect of ginger thus involves the serotonergic and noradrenergic systems as well as its antioxidant properties [383]. However, in a study by KukulaKoch et al. [384], the nonpolar fraction of the oleoresin was as also found to possess antidepressant activities. Of the different principles, (-)-geraniol (16) and (-)-terpinen-4-ol (17, Fig. 1S, Supplementary Information) were found to be the strongest MAO-A inhibitors [384].

Finally, although other species have been previously described, no studies on them have been conducted since the year 2000 , and, in many cases, the protocols and mediators have never been described. The principal species in this category are true cinnamon tree (Cinnamomum verum J.Presl, syn: Cinnamomum zeylanicum Blume, Lauraceae) [28], bindweed (Cissampelos sympodialis Eichler, Menispermaceae) [292], Indian coleus (Coleus forskohlii (Willd.) Briq., Lamiaceae) [292], dodder (Cuscuta sp., Convolvulaceae) [12], red feathers (Echium amoenum Fisch. \& C.A.Mey., Boraginaceae) [24, 27, 292], common water hyacinth (Eichhornia crassipes (Mart.) Solms, Pontederiaceae [28,29], “árnica roja” (Galphimia glauca Cav., Malpighiaceae) [24], Levant cotton (Gossypium herbaceum L., Malvaceae) [292], imperforate St John's wort (Hypericum maculatum Crantz, Hypericaceae) [29], “xuan fu 
hua” (Inula japonica Thunb., Compositae) [292], Thai black ginger (Kaempferia parviflora Wall. ex Baker, Zingiberaceae) [292], Indian tobacco (Lobelia inflata L., Campanulaceae) [25, 292], houpu magnolia (Magnolia officinalis Rehder \& E.H.Wilson, Magnoliaceae) [23, 25, 292], “gondolosi” (Mondia whitei (Hook.f.) Skeels, Apocynaceae) [41], evening-primrose (Oenothera biennis L., Onagraceae) [23], wild maracuja (Passiflora foetida L., Passifloraceae) [29], musk willow (Salix aegyptiaca L., Salicaceae) [28], “sanjeevani” (Selaginella bryopteris (L.) Baker, Selaginellaceae) [29], "dhiguthiyara” (Senna occidentalis (L.) Link, syn: Cassia occidentalis L., Leguminosae) [29], wild marigold (Tagetes minuta L., Compositae) [25], yellow trumpetbush (Tecoma stans (L.) Juss. ex Kunth, Bignoniaceae) [29], common nettle (Urtica dioica L., Urticaceae) [29], common grape vine (Vitis vinifera L., Vitaceae) [292], and “katber" (Ziziphus xylopyrus (Retz.) Willd., Rhamnaceae) [385]. Species such as Eysenhardtia polystachya (Ortega) Sarg. (Leguminosae) [386], Capparis brassii DC (syn: Capparis thonningii Schumach., Capparaceae) [387], and Cnestis ferruginea Vahl ex DC (Connaraceae) [388] could also be of interest for antidepressant studies.

\section{Concluding Remarks}

The purpose of this narrative review has been to provide an update on the medicinal plants studied from the year 2000 to the present. It includes approximately 660 preclinical studies cited in PubMed in which 155 species have been shown to have some kind of effect. An additional 27 species had also been previously described, but no new studies on them have been undertaken.

Animal models have provided significant information on the pathophysiology of depression, although they are insufficient for explaining depressive syndrome in all its complexity due to obvious differences in genetics and pharmacokinetics. Moreover, and perhaps more importantly, animals cannot provide information regarding core symptoms of depression such as depressed mood, suicide ideation, low self-esteem, feelings of worthlessness, and excessive or inappropriate guilt. However, depression and other related disorders involve several endophenotypes [31] that can be approached separately with different animal tests to also provide important evidence regarding the potential activity of medicinal plants as antidepressant agents. On the one hand, the FST and TST are the 2 principal animal models measuring behavioral distress in mice and/or rats. On the other hand, the SPT aims to cover the endophenotype of anhedonia, while the CUMS test, along with other complementary tests such as the OFT and EPM, are validated models for behavior related to anxiety. In the case of the FST and TST, the immobility time was selected as the dependent variable, and its decrease was used to establish the potential of a drug or pharmacological agent as an antidepressant. These results were then combined with the lack of locomotor activity as determined in the complementary tests. In general, many preclinical studies of species tested as antidepressant agents focused on the neurotransmission role of DA, NA, and 5-HT, especially in the involvement of the $\alpha_{1}$-adrenoceptor, $\mathrm{D}_{1}$ and $\mathrm{D}_{2}$ receptor antagonists, and the $5-\mathrm{HT}_{1 \mathrm{~A}}$ receptor. Moreover, the effects of selective 5-HT reuptake inhibition and the inhibition of SERT, NAT, and DAT as a target to ameliorate depressive symtoms have been explained by the monoaminergic theory of depression, based on the assumption of a lack of monoamine neurotransmitters in depressive patients. Today, antidepressants that have been developed according to this theory constitute the "first line of treatment", although they have documented issues, namely a mere $60 \%$ response rate, a therapeutic latency of 2 or $3 \mathrm{wk}$, important side effects, and a major relapse risk if treatment is not continuous [389].

The expression of BDNF in the brain has also been postulated as a core explanation for depression by the neurotrophic or neuroplasticity hypothesis. According to this theory, mood disorders are related to a decreased synthesis of BDNF in the brain due to a deficiency of neurotrophic factors, producing a subsequent impairment in synaptogenesis and neuronal activity. Medicinal plants can act to prevent the decreases in hippocampal BDNF signaling observed in depression, promoting neurogenesis in mice, an effect that could be considered an antidepressant-like mechanism [63]. Plasticity enhancements (e.g., neurogenesis, dendritic branching, and synaptogenesis) have antidepressant effects promoting BDNF secretion in the brain; even an increase in serum is associated with recovery [390]. Electroconvulsive therapy, repetitive transcranial magnetic stimulation, transcranial direct-current stimulation, and ketamine and its derivatives have demonstrated some efficacy as therapies for depression [391]. In contrast, stress and other risk factors for depression can reduce neuroplasticity in the hippocampus and PFC [392]. Therefore, it seems reasonable to hypothesize a common pathway underlying the pathogenesis and vulnerability to depression. However, there are still some gaps underlying molecular mechanisms of neuroplasticity, depression, and antidepressant efficacy, particularly the interaction between neurotransmitter receptors and their signaling pathways. Thus, the neuroplasticity hypothesis has unfortunately not yet been validated clinically although many of the benefits of antidepressant treatments that work lead to it.

Depression also involves dysfunctional glutamate signaling in the brain, which leads to impaired neuroplasticity. Microglia activated by excess inflammation, astroglial loss, and inappropriate glutamate receptor activation ultimately disrupt the delicate balance of neuroprotective versus neurotoxic effects in the brain, potentially leading to depression [392]. Moreover, we must take into account the spectacular clinical finding that i.v. infusion of the NMDA receptor antagonist ketamine can produce an immediate antidepressant effect in patients with treatment-resistant depression [393]. Therefore, it seems reasonable that one of the targets in the treatment of depression is to down-regulate the glutamatergic system. Glutamatergic inhibition in nerve terminals through the exposure of synaptosomes to the $\mathrm{K}^{+}$channel blocker 4-aminopyridine is one of the known antidepressant mechanisms of action of curcumin [394]. Other antiglutamatergic agents such as amantadine, ketamine, memantine, and riluzole have also demonstrated antidepressant properties [392, 395]. The neuroprotective effects of ketamine and memantine may be explained by their NMDA antagonism, which inhibits microglial release of pro-inflammatory mediators, avoiding neurotoxicity. How this occurs is not completely known yet.

The GABAergic system also plays a relevant role in depression [396], which could have a potential additive effect on motor activity, as well as on both neuro-endocrine (HPA axis, CRF) and, im- 
portantly, neuroprotective effects, in the same way that antiglutamatergic mechanisms do.

Other additional hypotheses on the pathogenesis of depression are based on the modulation of cholinergic transmission, the stress/HPA-axis, the reward system, and neuroinflammation. It is known that inflammation leads to increased permeability of the brain-blood barrier, allowing for easier entry of inflammatory molecules or immune cells into the CNS, leading to both structural and functional changes, with the hippocampus as the main structure affected [397]. On the other hand, physiological or psychological conditions that cause a strong activation of the immune system make patients more susceptible to depression [398]. These facts have increased both the interest in and the corpus of studies of those medicinal plants with anti-inflammatory and antioxidant properties, as well as the mediation of pro-inflammatory factors, mitochondrial damage, and oxidative stress in neuronal damage (e.g., Curcuma longa, Ginkgo biloba, Panax ginseng, Rosmarinus officinalis, and Sedum roseum). It thus seems clear that depression activates inflammatory processes and interacts with the immune system through biochemical and bio-behavioral mechanisms, although more research is needed.

According to the data compiled in this paper, use of medicinal plants in combatting depression would offer at least 3 benefits. First, an increasing amount of evidence indicates that these plants exert antidepressant effects on their own, as is the case with green tea (Camellia sinensis), saffron (Crocus sativus), St. John's wort (Hypericum perforatum), lavender (Lavandula angustifolia), Indian mulberry (Morinda officinalis), ginseng (Panax ginseng), rosemary (Rosmarinus officinalis), golden root (Sedum roseum), ashwagandha or Indian ginseng (Withania somnifera), and especially turmeric (Curcuma longa) and its active principle curcumin. Other potentially effective plants that should be tested, including in humans, are Jack-beans from Brazil (Canavalia brasiliensis), gotu kola (Centella asiatica), Asian pigeonwings (Clitoria ternatea), Siberian ginseng (Eleutherococcus senticosus), and Indian mulberry (Morinda officinalis). We strongly recommend carrying out larger experimental studies on the active compounds of these plants and their mechanisms of action, as well as clinical studies and randomized controlled trials of many of them. Regarding cannabis (Cannabis sativa L., Cannabaceae), various articles have been published demonstrating its antidepressant-like activity [399-401], with cannabidiol as the principal active compound and serotonergic $\left(5-\mathrm{HT}_{1 \mathrm{~A}}\right)[399,400]$ and BDNF-TrkB signaling pathways [401] as the principal mechanisms. However, due to its relevance, this species will be treated more fully in the second part of this review (clinical trials).

Recent research has shown that adjunctive treatment can increase the efficacy of standard treatments for depression, such as using ketamine with SSRIs or buprenorphine and sanidorphan [389]. This provides a second benefit for medicinal plants, namely that they can be co-prescribed in combination with standard pharmacological agents; for example, St. John's wort can enhance the serotonergic effects of SSRIs [12]. If the combination produces beneficial synergistic effects, then a lower dosage of antidepressants can be used to prevent or avoid undesirable side effects in patients who frequently exhibit them, thereby obtaining a third benefit. Of course, the opposite can also occur, namely, an increase in adverse side effects. Therefore, we strongly recommend caution as a rule since larger and more robust studies are needed to explore these synergies.

There are several limitations of the studies compiled in this revision, including the wide range of dosages, the different solvents used to obtain the extract, and the use of distinct vegetable products, including roots, leaves, stems, or the use of enriched extract. Another limitation is the great variety of the animal models used. Although these are designed to capture a specific endophenotype of depression, it is impossible for one of them to encompass the tremendous heterogeneity of depressive behavior. Regarding the limitations that the lack of an integrative explanation regarding the pathophysiology of depression represents for this review, the preclinical data explored herein aims to be a starting point for encouraging robust research to test the most promising medicinal herbs, such as turmeric and its active compound curcumin, along with saffron.

We must not forget the large number of patients who do not experience total or even partial remission of their depressive symptoms. They deserve alternative or complementary treatments that could relieve their suffering and lower the incidence of suicidal ideation and attempts, thereby helping their families cope with the depression of their loved ones and consequently decrease their distress.

There is an immense number of targets to help alleviate the tremendous burden that depression causes worldwide, and despite the limitations of the current research and the challenges of conducting large clinical trials in the future, medicinal plants have much to offer in the field of antidepressant treatments and adjuvants.

\section{Supporting Information}

This section consists of a table with all the medicinal plants cited in the text, with the updated botanical and family name, the common name, the plant part and kind of extract used in the studies, the range of doses used in $\mathrm{mg} / \mathrm{kg}$ and via of administration, potential active compounds, neurochemical pathways implicated in the process, and references. The figures compile the principal chemical products identified as being responsible for this activity if they were clearly identified or studied as potential active principles.

\section{Contributors' Statement}

Both authors have participated in the preparation of the document jointly.

\section{Conflict of Interest}

The authors declare that they have no conflict of interest.

\section{References}

[1] Fusar-Poli L, Vozza L, Gabbiadini A, Vanella A, Concas I, Tinacci S, Petralia A, Signorelli MS, Aguglia E. Curcumin for depression: a meta-analysis. Crit Rev Food Sci Nutr 2019; 19: 1-11

[2] World Health Organization. Depression and other common mental Disorders. Global Health Estimates. Geneve: WHO; 2017 
[3] American Psychiatric Association. Diagnostic and statistical Manual for mental Disorders, 5a ed (DSM-5). Arlington: American Psychiatric Publishing; 2013

[4] Rush AJ, Trivedi MH, Wisniewski SR, Nierenberg AA, Stewart JW, Warden D, Niederehe G, Thase ME, Lavori PW, Lebowitz BD, McGrath PJ, Rosenbaum JF, Sackeim HA, Kupfer DJ, Luther J, Fava M. Acute and Ionger-term outcomes in depressed outpatients requiring one or several treatment steps: a STAR*D report. Am J Psychiatry 2006; 163: 19051917

[5] Visentin APV, Colombo R, Scotton E, Fracasso DS, da Rosa AR, Branco CS, Salvador M. Targeting inflammatory-mitochondrial response in major depression: current evidence and further challenges. Oxid Med Cell Longev 2020; 2020: 2972968

[6] Lopresti AL. Curcumin for neuropsychiatric disorders: a review of in vitro, animal and human studies. J Psychopharmacol 2019; 31: 287-302

[7] Zunszain PA, Hepgul N, Pariante CM. Inflammation and depression. Curr Topics Behav Neurosci 2013; 14: 135-151

[8] Lotrich FE. Inflammatory cytokine-associated depression. Brain Res 2015; 1617: 113-125

[9] Lopresti AL. Cognitive behaviour therapy and inflammation: a systematic review of its relationship and the potential implications for the treatment of depression. Aust N Z J Psychiatry 2017; 51: 565-582

[10] Maes M, Galecki P, Chang YS, Berk M. A review on the oxidative and nitrosative stress (O\&NS) pathways in major depression and their possible contribution to the (neuro)degenerative processes in that illness. Prog Neuropsychopharmacol Biol Psychiatry 2011; 35: 676-692

[11] Moylan S, Maes M, Wray NR, Berk M. The neuroprogressive nature of major depressive disorder: pathways to disease evolution and resistance, and therapeutic implications. Mol Psychiatry 2013; 18: 595-606

[12] Sarris J. Herbal medicines in the treatment of psychiatric disorders: 10-year updated review. Phytother Res 2018; 32: 1147-1162

[13] Guest PC. Pre-clinical Models. Techniques and Protocols. New York: Humana Press; 2019

[14] Kraeuter AK, Guest PC, Sarnyai Z. The forced swim test for depressionlike behavior in rodents. Methods Mol Biol 2019; 1916: 75-80

[15] Petit-Demouliere B, Chenu F, Bourin M. Forced swimming test in mice: a review of antidepressant activity. Psychopharmacology (Berl) 2005; 177: 245-255

[16] Can A, Dao DT, Arad M, Terrillion CE, Piantadosi SC, Gould TD. The tail suspension test. J Vis Exp 2012; 59: e3638

[17] Can A, Dao DT, Terrillion CE, Piantadosi SC, Bhat S, Gould TD. The tail suspension test. J Vis Exp 2012; 59: e3769

[18] Cryan JF, Mombereau C, Vassout A. The tail suspension test as a model for assessing antidepressant activity: review of pharmacological and genetic studies in mice. Neurosci Biobehav Rev 2005; 29: 571-625

[19] Antoniuk S, Bijata M, Ponimaskin E, Wlodarczyk J. Chronic unpredictable mild stress for modeling depression in rodents: meta-analysis of model reliability. Neurosci Biobehav Rev 2019; 99: 101-116

[20] Kraeuter AK, Guest PC, Sarnyai Z. The elevated plus maze test for measuring anxiety-like behavior in rodents. Methods Mol Biol 2019; 1916: 69-74

[21] Kraeuter AK, Guest PC, Sarnyai Z. The open field test for measuring locomotor activity and anxiety-like behavior. Methods Mol Biol 2019; 1916 : 99-103

[22] Horii Y, McTaggart I, Kawaguchi M. Testing animal anxiety in rats: effects of open arm ledges and closed arm wall transparency in elevated plus maze test. J Vis Exp 2018; 136: 56428

[23] Dhingra D, Sharma A. A review on antidepressant plants. Nat Prod Rad 2006; 5: 144-152

[24] Sarris ], Panossian A, Schweitzer I, Stough C, Scholey A. Herbal medicine for depression, anxiety and insomnia: a review of psychopharmacology and clinical evidence. Eur Neuropsychopharmacol 2011; 21: 841-860
[25] Farahani MS, Bahramsoltani R, Farzaei MH, Abdollahi M, Rahimi R. Plantderived natural medicines for the management of depression: an overview of mechanisms of action. Rev Neurosci 2015; 26: 305-321

[26] Martins J, Brijesh S. Phytochemistry and pharmacology of anti-depressant medicinal plants: A review. Biomed Pharmacother 2018; 104: 343-365

[27] Lee G, Bae $\mathrm{H}$. Therapeutic effects of phytochemicals and medicinal herbs on depression. Biomed Res Int 2017; 2017: 6596241

[28] Bakhshaeil S. Effect of nine medicinal plants as a traditional treatment on depression. J Appl Pharm 2017; 9: 244

[29] Rahman MR, Ali M, Sharif M, Tajmin A. A review study on the traditional plants has potential antidepressant property. MOJ Cell Sci Rep 2017; 4: 00100

[30] Muszyńska B, Łojewski M, Rojowski ], Opoka W, Sułkowska-Ziaja K Natural products of relevance in the prevention and supportive treatment of depression. Psychiatr Pol 2015; 49: 435-453

[31] Ismail H, Amanat MA, Iqbal A, Mirza B. Medicinal plants: a complementary and alternative antidepressant therapy. Curr Pharm Des 2018; 24: 2609-2624

[32] The Plant List. A working list of all known plant species. Royal Botanic Gardens, Kew and Missouri Botanical Garden. Version 1.1. Accessed June 30, 2020 at: http://www.theplantlist.org/

[33] Yan HC, Qu HD, Sun LR, Li SJ, Cao X, Fang YY, Jie W, Bean JC, Wu WK, Zhu $\mathrm{XH}$, Gao TM. Fuzi polysaccharide-1 produces antidepressant-like effects in mice. Int J Neuropsychopharmacol 2010; 13: 623-633

[34] Zhao L, Sun Z, Yang L, Cui R, Yang W, Li B. Neuropharmacological effects of aconiti lateralis radix praeparata. Clin Exp Pharmacol Physiol 2020; 47: 531-542

[35] Zhang FH, Wang ZM, Liu YT, Huang JS, Liang S, Wu HH, Xu YT. Bioactiv ities of serotonin transporter mediate antidepressant effects of Acorus tatarinowii Schott. J Ethnopharmacol 2019; 241: 111967

[36] Dong $\mathrm{H}$, Gao Z, Rong $\mathrm{H}$, Jin $\mathrm{M}$, Zhang $\mathrm{X}$. $\beta$-Asarone reverses chronic unpredictable mild stress-induced depression-like behavior and promotes hippocampal neurogenesis in rats. Molecules 2014; 19: 5634-5649

[37] Han P, Han T, Peng W, Wang XR. Antidepressant-like effects of essential oil and asarone, a major essential oil component from the rhizome of Acorus tatarinowii. Pharm Biol 2013; 51: 589-594

[38] Ye L, Hu Z, Du G, Zhang J, Dong Q, Fu F, Tian J. Antidepressant-like effects of the extract from Cimicifuga foetida L. J Ethnopharmacol 2012; 144: 683-691

[39] Winterhoff H, Spengler B, Christoffel V, Butterweck V, Löhning A. Cimicifuga extract BNO 1055: reduction of hot flushes and hints on antidepressant activity. Maturitas 2003; 44: S51-S58

[40] Kothari S, Minda M, Tonpay SD. Anxiolytic and antidepressant activities of methanol extract of Aegle marmelos leaves in mice. Indian J Physiol Pharmacol 2010; 54: 318-328

[41] Pedersen ME, Szewczyk B, Stachowicz K, Wieronska J, Andersen J Stafford GI, van Staden J, Pilc A, Jäger AK. Effects of South African traditional medicine in animal models for depression. J Ethnopharmacol 2008; 119: 542-548

[42] Nielsen ND, Sandager M, Stafford GI, van Staden J, Jäger AK. Screening of indigenous plants from South Africa for affinity to the serotonin reuptake transport protein. J Ethnopharmacol 2004; 94: 159-163

[43] Zhou D, Jin H, Lin HB, Yang XM, Cheng YF, Deng FJ, Xu JP. Antidepressant effect of the extracts from fructus akebiae. Pharmacol Biochem Behav 2010; 94: 488-495

[44] Jin ZL, Gao N, Zhou D, Chi MG, Yang XM, Xu JP. The extracts of Fructus Akebiae, a preparation containing $90 \%$ of the active ingredient hederagenin: serotonin, norepinephrine and dopamine reuptake inhibitor. Pharmacol Biochem Behav 2012; 100: 431-439

[45] Liang BF, Huang F, Wang HT, Wang GH, Yuan X, Zhang MZ, Guo HB, Cheng YF, Xu JP. Involvement of norepinephrine and serotonin system 
in antidepressant-like effects of hederagenin in the rat model of unpredictable chronic mild stress-induced depression. Pharm Biol 2015; 53 : 368-377

[46] Foyet AS, Tsala DE, Bouba AA, Hritcu L. Anxiolytic and antidepressantlike effects of the aqueous extract of Alafia multiflora stem barks in rodents. Adv Pharmacol Sci 2012; 2012: 912041

[47] Kim WK, Jung JW, Ahn NY, Oh HR, Lee BK, Oh JK, Cheong JH, Chun HS, Ryu JH. Anxiolytic-like effects of extracts from Albizzia julibrissin bark in the elevated plus-maze in rats. Life Sci 2004; 75: 2787-2795

[48] Kim JH, Kim SY, Lee SY, Jang CG. Antidepressant like effects of Albizzia julibrissin in mice: involvement of the $5-\mathrm{HT}_{1 \mathrm{~A}}$ receptor system. Pharmacol Biochem Behav 2007; 87: 41-47

[49] Liu J, Lv YW, Shi JL, Ma X], Chen Y, Zheng ZQ, Wang SN, Guo JY. Anti-anxiety effect of $(-)$-syringaresnol-4-O- $\beta$-D-apiofuranosyl-( $1 \rightarrow 2)$ - $\beta$-D-glucopyranoside from Albizzia julibrissin Durazz (Leguminosae). Molecules 2017; 22: E1331

[50] Velraj M, Vijayalakshmi A, Jayakumari S, Ramamoorthy S, Ravichandiran V, Srikanth J. Antidepressant activity of the ethanolic extract of Albizzia lebbeck (Linn) bark in animal models of depression. Drug Invent Today 2009; 1: 112-115

[51] Sakakibara H, Yoshino S, Kawai Y, Terao ]. Antidepressant-like effect of onion (Allium cepa L.) powder in a rat behavioral model of depression. Biosci Biotechnol Biochem 2008; 72: 94-100

[52] Samad N, Saleem A. Administration of Allium cepa L. bulb attenuates stress-produced anxiety and depression and improves memory in male mice. Metab Brain Dis 2018; 33: 271-281

[53] Lee S, Kim DH, Lee CH, Jung JW, Seo YT, Jang YP, Ryu JH. Antidepressantlike activity of the aqueous extract of Allium macrostemon in mice. J Ethnopharmacol 2010; 131: 386-395

[54] Chen S, Wei C, Gao P, Kong H, Jia Z, Hu C, Dai W, Wu Y, Xu G. Effect of Allium macrostemon on a rat model of depression studied by using plasma lipid and acylcarnitine profiles from liquid chromatography/mass spectrometry. J Pharm Biomed Anal 2014; 89: 122-129

[55] Huang Y], Lu KH, Lin YE, Panyod S, Wu HY, Chang WT, Sheen LY. Garlic essential oil mediates acute and chronic mild stress-induced depression in rats via modulation of monoaminergic neurotransmission and brainderived neurotrophic factor levels. Food Funct 2019; 10: 8094-8105

[56] Zeni AL, Zomkowski AD, Maraschin M, Tasca Cl, Rodrigues AL. Evidence of the involvement of the monoaminergic systems in the antidepressant-like effect of Aloysia gratissima. J Ethnopharmacol 2013; 148: 914 920

[57] Mora S, Díaz-Véliz G, Millán R, Lungenstrass H, Quirós S, Coto-Morales T, Hellión-Ibarrola MC. Anxiolytic and antidepressant-like effects of the hydroalcoholic extract from Aloysia polystachya in rats. Pharmacol Biochem Behav 2005; 82: 373-378

[58] Hellión-Ibarrola MC, Ibarrola DA, Montalbetti Y, Kennedy ML, Heinichen O, Campuzano M, Ferro EA, Alvarenga N, Tortoriello J, De Lima TC, Mora S. The antidepressant-like effects of Aloysia polystachya (Griseb.) Moldenke (Verbenaceae) in mice. Phytomedicine 2008; 15: 478-483

[59] Costa de Melo N, Sánchez-Ortiz BL, Dos Santos Sampaio TI, Matias Pereira AC, Pinheiro da Silva Neto FL, Ribeiro da Silva H, Alves Soares Cruz $\mathrm{R}$, Keita H, Soares Pereira AM, Tavares Carvalho JC. Anxiolytic and antidepressant effects of the hydroethanolic extract from the leaves of Aloysia polystachya (Griseb.) Moldenke: a study on zebrafish (Danio rerio). Pharmaceuticals (Basel) 2019; 12: 106

[60] Jiménez-Ferrer E, Santillán-Urquiza MA, Alegría-Herrera E, Zamilpa A, Noguerón-Merino C, Tortoriello J, Navarro-García V, Avilés-Flores M, Fuentes-Mata M, Herrera-Ruiz M. Anxiolytic effect of fatty acids and terpenes fraction from Aloysia triphylla: serotoninergic, GABAergic and glutamatergic implications. Biomed Pharmacother 2017; 96: 320-327

[61] Bahramsoltani R, Rostamiasrabadi P, Shahpiri Z, Marques AM, Rahimi R, Farzaei MH. Aloysia citrodora Paláu (Lemon verbena): a review of phytochemistry and pharmacology. J Ethnopharmacol 2018; 222: 34-51
[62] Badhe SR, Badhe RV, Ghaisas MM, Chopade VV, Deshpande AD. Evaluations of antidepressant activity of Anacyclus pyrethrum root extract. Int | Green Pharm 2010; 4: 79-82

[63] Zhang J], Gao TT, Wang Y, Wang JL, Guan W, Wang Y], Wang CN, Liu JF, jiang B. Andrographolide exerts significant antidepressant-like effects involving the hippocampal BDNF system in mice. Int J Neuropsychopharmacol 2019; 22: 585-600

[64] Ren LX, Luo YF, Li X, Zuo DY, Wu YL. Antidepressant-like effects of sarsasapogenin from Anemarrhena asphodeloides Bunge (Liliaceae). Biol Pharm Bull 2006; 29: 2304-2306

[65] Ren LX, Luo YF, Li X, Wu YL. Antidepressant activity of sarsasapogenin from Anemarrhena asphodeloides Bunge (Liliaceae). Pharmazie 2007; 62: 78-79

[66] Sousa FC, Melo CT, Monteiro AP, Lima VT, Gutierrez S], Pereira BA Barbosa-Filho JM, Vasconcelos SM, Fonteles MF, Viana GS. Antianxiety and antidepressant effects of riparin III from Aniba riparia (Nees) Mez (Lauraceae) in mice. Pharmacol Biochem Behav 2004; 78: 27-33

[67] Melo CT, de Carvalho AM, Moura BA, Teixeira CP, Vasconcelos LF, Feitosa ML, de Oliveira GV, Barbosa-Filho JM, Chavez Gutiérrez SJ, de França Fonteles MM, Vasconcelos SM, de Sousa FC. Evidence for the involvement of the serotonergic, noradrenergic, and dopaminergic systems in the antidepressant-like action of riparin III obtained from Aniba riparia (Nees) Mez (Lauraceae) in mice. Fundam Clin Pharmacol 2013; 27: 104-112

[68] Vasconcelos AS, Oliveira IC, Vidal LT, Rodrigues GC, Gutierrez S], Barbosa-Filho JM, Vasconcelos SM, de França Fonteles MM, Gaspar DM, de Sousa FC. Subchronic administration of riparin III induces antidepressive-like effects and increases BDNF levels in the mouse hippocampus. Fundam Clin Pharmacol 2015; 29: 394-403; Erratum in: Fundam Clin Pharmacol 2017; 31: 481

[69] de Melo CT, Monteiro AP, Leite CP, de Araújo FL, Lima VT, Barbosa-Filho JM, de França Fonteles MM, de Vasconcelos SM, de Barros Viana GS, de Sousa FC. Anxiolytic-like effects of (O-methyl)- $\mathrm{N}-2$, 6-dihydroxybenzoyltyramine (riparin III) from Aniba riparia (Nees) Mez (Lauraceae) in mice. Biol Pharm Bull 2006; 29: 451-454

[70] Teixeira CP, de Melo CT, de Araújo FL, de Carvalho AM, Silva MI, BarbosaFilho JM, Macêdo DS, de Barros Viana GS, de Sousa FC. Antidepressantlike effect of riparin II from Aniba riparia in mice: evidence for the involvement of the monoaminergic system. Fundam Clin Pharmacol 2013; 27 : $129-137$

[71] de Sousa FC, Oliveira IC, Silva MI, de Melo CT, Santiago VR, de Castro Chaves R, Fernandes ML, Gutiérrez S], Vasconcelos SM, Macêdo DS, Barbosa Filho JM. Involvement of monoaminergic system in the antidepressant-like effect of riparin I from Aniba riparia (Nees) Mez (Lauraceae) in mice. Fundam Clin Pharmacol 2014; 28: 95-103

[72] Martínez-Vázquez M, Estrada-Reyes R, Araujo Escalona AG, Ledesma Velázquez I, Martínez-Mota L, Moreno J, Heinze G. Antidepressant-like effects of an alkaloid extract of the aerial parts of Annona cherimolia in mice. J Ethnopharmacol 2012; 139: 164-170

[73] Monteiro ÁB, Kelly de Souza Rodrigues C, Petícia do Nascimento E, Sales VDS, de Araújo Delmondes G, Nogueira da Costa MH, Pereira de Oliveira VA, Pereira de Morais L, Boligon AA, Barbosa R, Martins da Costa JG, Alencar de Menezes IR, Bezerra Felipe CF, Kerntopf MR. Anxiolytic and antidepressant-like effects of Annona coriacea (Mart.) and caffeic acid in mice. Food Chem Toxicol 2020; 136: 111049

[74] Diniz TC, de Oliveira Júnior RG, Miranda Bezerra Medeiros MA, Gama E Silva M, de Andrade Teles RB, Dos Passos Menezes P, de Sousa BMH, Abrahão Frank L, de Souza Araújo AA, Russo Serafini M, Stanisçuaski Guterres S, Pereira Nunes CE, Salvador MJ, da Silva Almeida JRG. Anticonvulsant, sedative, anxiolytic and antidepressant activities of the essential oil of Annona vepretorum in mice: involvement of GABAergic and serotonergic systems. Biomed Pharmacother 2019; 111: 1074-1087 
[75] Xie W, Zhang X, Wang T, Hu J. Botany, traditional uses, phytochemistry and pharmacology of Apocynum venetum L. (Luobuma): a review. J Ethnopharmacol 2012; 141: 1-8

[76] Butterweck V, Nishibe S, Sasaki T, Uchida M. Antidepressant effects of Apocynum venetum leaves in a forced swimming test. Biol Pharm Bull 2001; 24: 848-851

[77] Butterweck V, Simbrey K, Seo S, Sasaki T, Nishibe S. Long-term effects of an Apocynum venetum extract on brain monoamine levels and $\beta$-AR density in rats. Pharmacol Biochem Behav 2003; 75: 557-564

[78] Zheng M, Fan Y, Shi D, Liu C. Antidepressant-like effect of flavonoids extracted from Apocynum venetum leaves on brain monoamine levels and dopaminergic system. J Ethnopharmacol 2013; 147: 108-113

[79] Zheng M, Liu C, Pan F, Shi D, Zhang Y. Antidepressant-like effect of hyperoside isolated from Apocynum venetum leaves: possible cellular mechanisms. Phytomedicine 2012; 19: 145-149

[80] Li X, Wu T, Yu Z, Li T, Zhang J, Zhang Z, Cai M, Zhang W, Xiang J, Cai D. Apocynum venetum leaf extract reverses depressive-like behaviors in chronically stressed rats by inhibiting oxidative stress and apoptosis. Biomed Pharmacother 2018; 100: 394-406

[81] Wu T, Li X, Li T, Cai M, Yu Z, Zhang J, Zhang Z, Zhang W, Xiang J, Cai D. Apocynum venetum leaf extract exerts antidepressant-like effects and inhibits hippocampal and cortical apoptosis of rats exposed to chronic unpredictable mild stress. Evid Based Complement Alternat Med 2018; 2018: 5916451

[82] Abbas G, Naqvi S, Erum S, Ahmed S, Atta-ur-Rahman, Dar A. Potential antidepressant activity of Areca catechu nut via elevation of serotonin and noradrenaline in the hippocampus of rats. Phytother Res 2013; 27: 39-45

[83] Peng W, Liu Y], Wu N, Sun T, He XY, Gao YX, Wu C]. Areca catechu L. (Arecaceae): a review of its traditional uses, botany, phytochemistry, pharmacology and toxicology. J Ethnopharmacol 2015; 164: 340-356

[84] Mahmoudi M, Ebrahimzadeh MA, Ansaroudi F, Nabavi SF, Nabavi SM. Antidepressant and antioxidant activities of Artemisia absinthium L. at flowering stage. Afri ] Biotechnol 2009; 8: 7170-7175

[85] Singh GK, Garabadu D, Muruganandam AV, Joshi VK, Krishnamurthy S. Antidepressant activity of Asparagus racemosus in rodent models. Pharmacol Biochem Behav 2009; 91: 283-290

[86] Meena J, Ojha R, Muruganandam AV, Krishnamurthy S. Asparagus racemosus competitively inhibits in vitro the acetylcholine and monoamine metabolizing enzymes. Neurosci Lett 2011; 503: 6-9

[87] Gohil KJ, Patel JA. A review on Bacopa monniera: current research and future prospects. Int J Green Pharm 2010; 4: 1-9

[88] Russo A, Borrelli F. Bacopa monniera, a reputed nootropic plant: an overview. Phytomedicine 2005; 12: 305-317

[89] Simpson T, Pase M, Stough C. Bacopa monnieri as an antioxidant therapy to reduce oxidative stress in the aging brain. Complement Alternat Med 2015; 2015: 615384

[90] Sairam K, Dorababu M, Goel RK, Bhattacharya SK. Antidepressant activity of standardized extract of Bacopa monniera in experimental models of depression in rats. Phytomedicine 2002; 9: 207-211

[91] Bhattacharya SK, Bhattacharya A, Kumar A, Ghosal S. Antioxidant activity of Bacopa monniera in rat frontal cortex, striatum and hippocampus. Phytother Res 2000; 14: 174-179

[92] Abhinayani G, Goud GN, Nagamani KC, Kaur D. Antidepressant and skeletal muscle relaxant activity of methanolic extracts of Basella alba L. Asian J Biomed Pharma Sci 2016; 6: 7-10

[93] Dhingra D, Joshi P. Antidepressant-like activity of Benincasa hispida fruits in mice: Possible involvement of monoaminergic and GABAergic systems. J Pharmacol Pharmacother 2012; 3: 60-62

[94] Stafford GI, Pedersen ME, van Staden J, Jäger AK. Review on plants with CNS-effects used in traditional South African medicine against mental diseases. J Ethnopharmacol 2008; 119: 513-537
[95] Kwon S, Lee B, Kim M, Lee H, Park H], Hahm DH. Antidepressant-like effect of the methanolic extract from Bupleurum falcatum in the tail suspension test. Prog Neuropsychopharmacol Biol Psychiatry 2010; 34: $265-270$

[96] Lee B, Yun HY, Shim I, Lee H, Hahm DH. Bupleurum falcatum prevents depression and anxiety-like behaviors in rats exposed to repeated restraint stress. J Microbiol Biotechnol 2012; 22: 422-430

[97] Prasanth MI, Sivamaruthi BS, Chaiyasut C, Tencomnao T. A review of the role of green tea (Camellia sinensis) in antiphotoaging, stress resistance, neuroprotection, and autophagy. Nutrients 2019; 11: E474

[98] Dong X, Yang C, Cao S, Gan Y, Sun H, Gong Y, Yang H, Yin X, Lu Z. Tea consumption and the risk of depression: a meta-analysis of observational studies. Aust N Z J Psychiatry 2015; 49: 334-345

[99] Zhu WL, Shi HS, Wei YM, Wang SJ, Sun CY, Ding ZB, Lu L. Green tea polyphenols produce antidepressant-like effects in adult mice. Pharmacol Res 2012; 65: 74-80

[100] Liu Y, Jia G, Gou L, Sun L, Fu X, Lan N, Li S, Yin X. Antidepressant-like effects of tea polyphenols on mouse model of chronic unpredictable mild stress. Pharmacol Biochem Behav 2013; 104: 27-32

[101] Di Lorenzo A, Nabavi SF, Sureda A, Moghaddam AH, Khanjani S, Arcidiaco P, Nabavi SM, Daglia M. Antidepressive-like effects and antioxidant activity of green tea and GABA green tea in a mouse model of post-stroke depression. Mol Nutr Food Res 2016; 60: 566-579

[102] Teng J, Zhou W, Zeng Z, Zhao W, Huang Y, Zhang X. Quality components and antidepressant-like effects of GABA green tea. Food Funct 2017; 8: 3311-3318

[103] Barauna SC, Kaster MP, Heckert BT, do Nascimento KS, Rossi FM, Teixeira EH, Cavada BS, Rodrigues AL, Leal RB. Antidepressant-like effect of lectin from Canavalia brasiliensis ( $\mathrm{ConBr}$ ) administered centrally in mice. Pharmacol Biochem Behav 2006; 85: 160-169

[104] Rieger DK, Cunha RM, Lopes MW, Costa AP, Budni J, Rodrigues AL, Walz R, Teixeira EH, Nascimento KS, Cavada BS, Leal RB. ConBr, a lectin from Canavalia brasiliensis seeds, modulates signaling pathways and increases BDNF expression probably via a glycosylated target. J Mol Recognit 2014; 27: 746-754

[105] Rieger DK, Costa AP, Budni ], Moretti M, Barbosa SG, Nascimento KS, Teixeira EH, Cavada BS, Rodrigues AL, Leal RB. Antidepressant-like effect of Canavalia brasiliensis (ConBr) lectin in mice: evidence for the involvement of the glutamatergic system. Pharmacol Biochem Behav 2014; 122: 53-60

[106] Zhao G, Gai Y, Chu WJ, Qin GW, Guo LH. A novel compound $N^{1}, N^{5}-(Z)$ $N^{10}$-(E)-tri-p-coumaroylspermidine isolated from Carthamus tinctorius L. and acting by serotonin transporter inhibition. Eur Neuropsychopharmacol 2009; 19: 749-758

[107] Qazi N, Khan RA, Rizwani GH. Short communication-Evaluation of antianxiety and antidepressant properties of Carthamus tinctorius L. (Safflower) petal extract. Pak J Pharm Sci 2015; 28: 991-995

[108] Abbasi-Maleki S, Mousavi Z. Hydroethanolic extract of Carthamus tinctorius induces antidepressant-like effects: modulation by dopaminergic and serotonergic systems in tail suspension test in mice. Iran J Basic Med Sci 2017; 20: 1063-1073

[109] Mora S, Diaz-Veliz G, Lungenstrass H, García-González M, CotoMorales T, Poletti C, De Lima TC, Herrera-Ruiz M, Tortoriello J. Central nervous system activity of the hydroalcoholic extract of Casimiroa edulis in rats and mice. J Ethnopharmacol 2005; 97: 191-197

[110] Han XH, Hong SS, Hwang JS, Lee MK, Hwang BY, Ro JS. Monoamine oxidase inhibitory components from Cayratia japonica. Arch Pharm Res 2007; 30: 13-17

[111] Bylka W, Znajdek-Awiżeń P, Studzińska-Sroka E, Dańczak-Pazdrowska A, Brzezińska M. Centella asiatica in dermatology: an overview. Phytother Res 2014; 28: 1117-1124 
[112] Brinkhaus B, Lindner M, Schuppan D, Hahn EG. Chemical, pharmacological and clinical profile of the East Asian medical plant Centella asiatica. Phytomedicine 2000; 7: 427-448

[113] Chen Y, Han T, Qin L, Rui Y, Zheng H. Effect of total triterpenes from Centella asiatica on the depression behavior and concentration of amino acid in forced swimming mice. Zhong Yao Cai 2003; 26: 870873

[114] Chen Y, Han T, Rui Y, Yin M, Qin L, Zheng H. Effects of total triterpenes of Centella asiatica on the corticosterone levels in serum and contents of monoamine in depression rat brain. Zhong Yao Cai 2005; 28: 492496

[115] Ceremuga TE, Valdivieso D, Kenner C, Lucia A, Lathrop K, Stailey O, Bailey H, Criss J, Linton J, Fried J, Taylor A, Padron G, Johnson AD. Evaluation of the anxiolytic and antidepressant effects of asiatic acid, a compound from gotu kola or Centella asiatica, in the male Sprague Dawley rat. AANA J 2015; 83: 91-98

[116] Agrawal A, Mohan M, Kasture S, Foddis C, Frau MA, Loi MC, Maxia A. Antidepressant activity of Ceratonia siliqua L. fruit extract, a source of polyphenols. Nat Prod Res 2011; 25: 450-456

[117] Zhang Y], Huang W, Huang X, Wang Y, Wang Z, Wang C, Zhong BW, Sheng CX, Wang B, Zhang SF, Su NX, Liu ZQ, Zhou HH, Ren P. Fructus aurantii induced antidepressant effect via its monoaminergic mechanism and prokinetic action in rat. Phytomedicine 2012; 19: 1101-1107

[118] Potdar VH, Kibile S]. Evaluation of antidepressant-like effect of Citrus maxima leaves in animal models of depression. Iran J Basic Med Sci 2011; 14: 478-483

[119] Mallick N, Khan RA. Behavioral effects of Citrus paradisi in rats. Metab Brain Dis 2016; 31: 329-335

[120] Mukherjee PK, Kumar V, Kumar NS, Heinrich M. The Ayurvedic medicine Clitoria ternatea-from traditional use to scientific assessment. J Ethnopharmacol 2008; 120: 291-301

[121] Kulkarni C, Pattanshetty JR, Amruthraj G. Effect of alcoholic extract of Clitoria ternatea Linn. on central nervous system in rodents. Indian J Exp Biol 1988; 26: 957-960

[122] Jain NN, Ohal CC, Shroff SK, Bhutada RH, Somani RS, Kasture VS, Kasture SB. Clitoria ternatea and the CNS. Pharmacol Biochem Behav 2003; 75: 529-536

[123] Malik J, Karan M, Vasisht K. Nootropic, anxiolytic and cns-depressant studies on different plant sources of shankhpushpi. Pharm Biol 2011; 49: 1234-4122

[124] Parvathi M, Ravishankar K. Evaluation of antidepressant, motor coordination and locomotor activities of ethanolic root extract of Clitoria ternatea. J Nat Rem 2013; 13: 19-24

[125] Dhingra D, Valecha R. Evaluation of the antidepressant-like activity of Convolvulus pluricaulis Choisy in the mouse forced swim and tail suspension tests. Med Sci Monit 2007; 13: BR155-BR161

[126] Gupta GL, Fernandes J. Protective effect of Convolvulus pluricaulis against neuroinflammation associated depressive behavior induced by chronic unpredictable mild stress in rat. Biomed Pharmacother 2019; 109: 1698-1708

[127] Ríos JL, Recio MC, Giner RM, Máñez S. An update review of saffron and its active constituents. Phytother Res 1996; 10: 189-193

[128] D’Auria M, Mauriello G, Rana GL. Volatile organic compounds from saffron. Flavour Fragr ] 2004; 19: 17-23

[129] Gresta F, Lombardo GM, Siracusa L, Ruperto G. Saffron, an alternative crop for sustainable agricultural systems. A review. Agron Sustain Dev 2008; 28: 95-112

[130] Padmavati ], Kumar CP, Saraswathi VS, Saravanan D, Lakshmi IA, Bindu NHS, Hemafaith V. Pharmacological, pharmacognostic and phytochemical review of saffron. Int J Pharm Technol 2011; 3: 1214-1234

[131] Ríos JL, Andújar I. Saffron Crocus (Crocus sativus): from Kitchen to Clinic. In: Teixeira Duarte MC, Rai M, eds. Therapeutic medicinal Plants. From Lab to the Market. Boca Raton: CRC Press; 2016: 77-94
[132] Winterhalter $P$, Straubinger M. Saffron-renewed interest in an ancient spice. Food Rev Int 2000; 16: 39-59

[133] Schmidt M, Betti G, Hensel A. Saffron in phytotherapy: pharmacology and clinical uses. Wien Med Wochenschr 2007; 157: 315-319

[134] Srivastava R, Ahmed H, Dixit RK, Dharamveer, Saraf SA. Crocus sativus L.: A comprehensive review. Pharmacogn Rev 2010; 4: 200-208

[135] Bathaie SZ, Mousavi SZ. New applications and mechanisms of action of saffron and its important ingredients. Crit Rev Food Sci Nutr 2010; 50 : 761-786

[136] Mousavi SZ, Bathaie SZ. Historical uses of saffron: identifying potential new avenues for modern research. Avicenna J Phytomed 2011; 1: 5766

[137] Hosseinzadeh H, Nassiri-Asl M. Avicenna's (Ibn Sina) the Canon of Medicine and saffron (Crocus sativus): a review. Phytother Res 2013 27: 475-483

[138] Siddiqui M], Saleh MSM, Basharuddin SNBB, Zamri SHB, Mohd Najib MHB, Che Ibrahim MZB, Binti Mohd Noor NA, Binti Mazha HN, Mohd Hassan N, Khatib A. Saffron (Crocus sativus L.): as an antidepressant. J Pharm Bioallied Sci 2018; 10: 173-180

[139] Hosseinzadeh H, Noraei NB. Anxiolytic and hypnotic effect of Crocus sativus aqueous extract and its constituents, crocin and safranal, in mice. Phytother Res 2009; 23: 768-774

[140] Rezaee R, Hosseinzadeh H. Safranal: from an aromatic natural product to a rewarding pharmacological agent. Iran J Basic Med Sci 2013; 16: $12-26$

[141] Pellegrini N, Serafini M, Salvatore S, Del Rio D, Bianchi M, Brighenti F. Total antioxidant capacity of spices, dried fruits, nuts, pulses, cereals and sweets consumed in Italy assessed by three different in vitro assays. Mol Nutr Food Res 2006; 50: 1030-1038

[142] Kamalipour M, Akhondzadeh S. Cardiovascular effects of saffron: an evidence-based review. Tehran Heart Cent 2011; 6: 59-61

[143] Hosseinzadeh H, Sadeghnia HR. Protective effect of safranal on pentylenetetrazol-induced seizures in the rat: involvement of GABAergic and opioids systems. Phytomedicine 2007; 14: 256-262

[144] Lechtenberg M, Schepmann D, Niehues M, Hellenbrand N, Wünsch B Hensel A. Quality and functionality of saffron: quality control, species assortment and affinity of extract and isolated saffron compounds to NMDA and o1 (sigma-1) receptors. Planta Med 2008; 74: 764-772

[145] Khazdair MR, Boskabady MH, Hosseini M, Rezaee R, M Tsatsakis A. The effects of Crocus sativus (saffron) and its constituents on nervous system: a review. Avicenna J Phytomed 2015; 5: 376-391

[146] Umadevi P, Murugan S, Jennifer Suganthi S, Subakanmani S. Evaluation of antidepressant like activity of Cucurbita pepo seed extracts in rats. Int J Curr Pharma Res 2011; 3: 108-113

[147] Chen Y, Kong LD, Xia X, Kung HF, Zhang L. Behavioral and biochemical studies of total furocoumarins from seeds of Psoralea corylifolia in the forced swimming test in mice. J Ethnopharmacol 2005; 96: 451-459

[148] Xu Q, Pan Y, Yi LT, Li YC, Mo SF, jiang FX, Qiao CF, Xu HX, Lu XB, Kong LD, Kung HF. Antidepressant-like effects of psoralen isolated from the seeds of Psoralea corylifolia in the mouse forced swimming test. Biol Pharm Bull 2008; 31: 1109-1114

[149] Yi LT, Li YC, Pan Y, Li JM, Xu Q, Mo SF, Qiao CF, jiang FX, Xu HX, Lu XB, Kong LD, Kung HF. Antidepressant-like effects of psoralidin isolated from the seeds of Psoralea corylifolia in the forced swimming test in mice. Prog Neuropsychopharmacol Biol Psychiatry 2008; 32: 510-519

[150] Blumenthal M (Ed). The complete German Commission E Monographs. Therapeutic Guide to herbal Medicines. Austin: American Botanical Council; 1998

[151] Vanaclocha B, Cañigueral S. Fitoterapia. Vademécum de Prescripción de Plantas Medicinales. 4a ed. Barcelona: Masson; 2003

[152] European Medicines Agency (EMA) Committee on Herbal Medicinal Products (HMPC). Draft assessment report on Curcuma longa L. (C. do- 
mestica Valeton), rhizome-Revision 1. London: EMA. Doc. Ref.: EMA/ HMPC/749518/2016. Publicación: 8/12/2017

[153] European Medicines Agency (EMA) Committee on Herbal Medicinal Products (HMPC). Draft European Union herbal monograph on Curcuma longa L. (C. domestica Valeton), rhizome-Revision 1. London: EMA. Doc. Ref.: EMA/HMPC/329755/2017. Publicación: 8/12/2017

[154] European Medicines Agency (EMA) Committee on Herbal Medicinal Products (HMPC). Draft list of references supporting the assessment of Curcuma longa L. (C. domestica Valeton), rhizome-Revision 1. London: EMA. Doc. Ref.: EMA/434955/2017. Publicación: 8/12/2017

[155] Ammon HP, Wahl MA. Pharmacology of Curcuma longa. Planta Med 1991; 57: 1-7

[156] Amro MS, Teoh SL, Norzana AG, Srijit D. The potential role of herbal products in the treatment of Parkinson's disease. Clin Ter 2018; 169: e23-e33

[157] Srivastav S, Fatima M, Mondal AC. Important medicinal herbs in Parkinson's disease pharmacotherapy. Biomed Pharmacother 2017; 92: 856-863

[158] Kulkarni S, Dhir A, Akula KK. Potentials of curcumin as an antidepressant. Sci World J 2009; 9: 1233-1241

[159] Kulkarni SK, Dhir A. An overview of curcumin in neurological disorders. Indian J Pharm Sci 2010; 72: 149-154

[160] Lopresti AL, Hood SD, Drummond PD. Multiple antidepressant potential modes of action of curcumin: a review of its anti-inflammatory, monoaminergic, antioxidant, immune-modulating and neuroprotective effects. J Psychopharmacol 2012; 26: 1512-1524

[161] Sanmukhani ], Anovadiya A, Tripathi CB. Evaluation of antidepressant like activity of curcumin and its combination with fluoxetine and imipramine: an acute and chronic study. Acta Pol Pharm 2011; 68: 769-775

[162] Wang R, Xu Y, Wu HL, Li YB, Li YH, Guo JB, Li XJ. The antidepressant effects of curcumin in the forced swimming test involve $5-\mathrm{HT}_{1}$ and 5- $\mathrm{HT}_{2}$ receptors. Eur J Pharmacol 2008; 578: 43-50

[163] Li YC, Wang FM, Pan Y, Qiang LQ, Cheng G, Zhang WY, Kong LD. Antidepressant-like effects of curcumin on serotonergic receptor-coupled AC-cAMP pathway in chronic unpredictable mild stress of rats. Prog Neuropsychopharmacol Biol Psychiatry 2009; 33: 435-449

[164] Kulkarni SK, Bhutani MK, Bishnoi M. Antidepressant activity of curcumin: involvement of serotonin and dopamine system. Psychopharmacology (Berl) 2008; 201: 435-442

[165] Bhutani MK, Bishnoi M, Kulkarni SK. Antidepressant like effect of curcumin and its combination with piperine in unpredictable chronic stress-induced behavioral, biochemical and neurochemical changes. Pharmacol Biochem Behav 2009; 92: 39-43

[166] Song C, Leonard BE. The olfactory bulbectomised rat as a model of depression. Neurosci Biobehav Rev 2005; 29: 627-647

[167] Xu Y, Ku BS, Yao HY, Lin YH, Ma X, Zhang YH, Li XJ. Antidepressant effects of curcumin in the forced swim test and olfactory bulbectomy models of depression in rats. Pharmacol Biochem Behav 2005; 82: 200-206

[168] Arora V, Kuhad A, Tiwari V, Chopra K. Curcumin ameliorates reserpineinduced pain-depression dyad: Behavioural, biochemical, neurochemical and molecular evidences. Psychoneuroendocrinology 2011; 36 : 1570-1581

[169] Huang Z, Zhong XM, Li ZY, Feng CR, Pan AJ, Mao QQ. Curcumin reverses corticosterone-induced depressive-like behavior and decrease in brain BDNF levels in rats. Neurosci Lett 2011; 493: 145-148

[170] Xu Y, Ku B, Cui L, Li X, Barish PA, Foster TC, Ogle WO. Curcumin reverses impaired hippocampal neurogenesis and increases serotonin receptor $1 \mathrm{~A}$ mRNA and brain-derived neurotrophic factor expression in chronically stressed rats. Brain Res 2007; 1162: 9-18

[171] Ceremuga TE, Helmrick K, Kufahl Z, Kelley J, Keller B, Philippe F, Golder J, Padrón G. Investigation of the anxiolytic and antidepressant effects of curcumin, a compound from turmeric (Curcuma longa), in the adult male Sprague-Dawley rat. Holist Nurs Pract 2017; 31: 193-203

[172] Ji CX, Li XY, Jia SB, Liu LL, Ge YC, Yang QX, Zhang J]. The antidepressant effect of Cynanchum auriculatum in mice. Pharm Biol 2012; 50: 10671072

[173] Huang L, Zhao H, Huang B, Zheng C, Peng W, Qin L. Acanthopanax senticosus: review of botany, chemistry and pharmacology. Pharmazie 2011; 66: 83-97

[174] Jin L, Wu F, Li X, Li H, Du C, Jiang Q, You J, Li S, Xu Y. Anti-depressant effects of aqueous extract from Acanthopanax senticosus in mice. Phytother Res 2013; 27: 1829-1833

[175] Wu F, Li H, Zhao L, Li X, You J, Jiang Q, Li S, Jin L, Xu Y. Protective effects of aqueous extract from Acanthopanax senticosus against corticosterone-induced neurotoxicity in PC12 cells. J Ethnopharmacol 2013; 148: $861-868$

[176] Gaire B, Lim D. Antidepressant effects of radix et caulis Acanthopanacis santicosi extracts on rat models with depression in terms of immobile behavior. J Tradit Chin Med 2014; 34: 317-323

[177] Pan Y, Kong LD, Li YC, Xia X, Kung HF, Jiang FX. Icariin from Epimedium brevicornum attenuates chronic mild stress-induced behavioral and neuroendocrinological alterations. Pharmacol Biochem Behav 2007; 87: $130-140$

[178] Colla AR, Machado DG, Bettio LE, Colla G, Magina MD, Brighente IM, Rodrigues $\mathrm{AL}$. Involvement of monoaminergic systems in the antidepressant-like effect of Eugenia brasiliensis Lam. (Myrtaceae) in the tail suspension test in mice. J Ethnopharmacol 2012; 143: 720-731

[179] Victoria FN, de Siqueira Brahm A, Savegnago L, Lenardão EJ. Involvement of serotoninergic and adrenergic systems on the antidepressant-like effect of $E$. uniflora $L$. leaves essential oil and further analysis of its antioxidant activity. Neurosci Lett 2013; 544: 105-109

[180] Chen PJ, Hsieh CL, Su KP, Hou YC, Chiang HM, Lin IH, Sheen LY. The Antidepressant effect of Gastrodia elata Bl. on the forced-swimming test in rats. Am J Chin Med 2008; 36: 95-106

[181] Zhan HD, Zhou HY, Sui P, Du XL, Wang WH, Dai L, Sui F, Huo HR, jiang TL. The rhizome of Gastrodia elata Blume-an ethnopharmacological review. J Ethnopharmacol 2016; 189: 361-385

[182] Lin YE, Chou ST, Lin SH, Lu KH, Panyod S, Lai YS, Ho CT, Sheen LY. Antidepressant-like effects of water extract of Gastrodia elata Blume on neurotrophic regulation in a chronic social defeat stress model. J Ethnopharmacol 2018; 215: 132-139

[183] Lin YE, Lin SH, Chen WC, Ho CT, Lai YS, Panyod S, Sheen LY. Antidepressant-like effects of water extract of Gastrodia elata Blume in rats exposed to unpredictable chronic mild stress via modulation of monoamine regulatory pathways. J Ethnopharmacol 2016; 187: 57-65

[184] Tomić M, Tovilović G, Butorović B, Krstić D, Janković T, Aljancić I, Menković N. Neuropharmacological evaluation of diethylether extract and xanthones of Gentiana kochiana. Pharmacol Biochem Behav 2005; 81: 535-542

[185] Sakakibara H, Ishida K, Grundmann O, Nakajima J, Seo S, Butterweck V, Minami Y, Saito S, Kawai Y, Nakaya Y, Terao Y. Antidepressant effect of extracts from Ginkgo biloba leaves in behavioral models. Biol Pharm Bull 2006; 29: 1767-1770

[186] Rojas P, Serrano-García N, Medina-Campos ON, Pedraza-Chaverri J, Ogren SO, Rojas C. Antidepressant-like effect of a Ginkgo biloba extract (EGb761) in the mouse forced swimming test: role of oxidative stress. Neurochem Int 2011; 59: 628-636

[187] Zhang L, Liu J, Ge Y, Liu M. Ginkgo biloba extract reduces hippocampus inflammatory responses, improves cardiac functions and depressive behaviors in a heart failure mouse model. Neuropsychiatr Dis Treat 2019; 15: 3041-3050

[188] Dhingra D, Sharma A. Antidepressant-like activity of Glycyrrhiza glabro L. in mouse models of immobility tests. Prog Neuropsychopharmacol Biol Psychiatry 2006; 30: 449-454 
[189] Wang W, Hu X, Zhao Z, Liu P, Hu Y, Zhou J, Zhou D, Wang Z, Guo D, Guo $H$. Antidepressant-like effects of liquiritin and isoliquiritin from Glycyrrhiza uralensis in the forced swimming test and tail suspension test in mice. Prog Neuropsychopharmacol Biol Psychiatry 2008; 32: 1179-1184

[190] Freitas AE, Budni J, Lobato KR, Binfaré RW, Machado DG, Jacinto J, Veronezi PO, Pizzolatti MG, Rodrigues AL. Antidepressant-like action of the ethanolic extract from Tabebuia avellanedae in mice: evidence for the involvement of the monoaminergic system. Prog Neuropsychopharmacol Biol Psychiatry 2010; 34: 335-343

[191] Freitas AE, Machado DG, Budni J, Neis VB, Balen GO, Lopes MW, de Souza LF, Veronezi PO, Heller M, Micke GA, Pizzolatti MG, Dafre AL, Leal $\mathrm{RB}$, Rodrigues AL. Antidepressant-like action of the bark ethanolic extract from Tabebuia avellanedae in the olfactory bulbectomized mice. J Ethnopharmacol 2013; 145: 737-745

[192] Freitas AE, Moretti M, Budni J, Balen GO, Fernandes SC, Veronezi PO, Heller M, Micke GA, Pizzolatti MG, Rodrigues AL. NMDA receptors and the L-arginine-nitric oxide-cyclic guanosine monophosphate pathway are implicated in the antidepressant-like action of the ethanolic extract from Tabebuia avellanedae in mice. J Med Food 2013; 16: 10301038

[193] Gonçalves AE, Bürger C, Amoah SK, Tolardo R, Biavatti MW, de Souza MM. The antidepressant-like effect of Hedyosmum brasiliense and its sesquiterpene lactone, podoandin in mice: evidence for the involvement of adrenergic, dopaminergic and serotonergic systems. Eur J Pharmacol 2012; 674: 307-314

[194] Gu L, Liu Y], Wang YB, Yi LT. Role for monoaminergic systems in the antidepressant-like effect of ethanol extracts from Hemerocallis citrina. J Ethnopharmacol 2012; 139: 780-787

[195] Yi LT, Li J, Li HC, Zhou Y, Su BF, Yang KF, Jiang M, Zhang YT. Ethanol extracts from Hemerocallis citrina attenuate the decreases of brain-derived neurotrophic factor, TrkB levels in rat induced by corticosterone administration. J Ethnopharmacol 2012; 144: 328-334

[196] Liu XL, Luo L, Liu BB, Li J, Geng D, Liu Q, Yi LT. Ethanol extracts from Hemerocallis citrina attenuate the upregulation of proinflammatory cytokines and indoleamine 2,3-dioxygenase in rats. J Ethnopharmacol 2014; 153: 484-490

[197] Du B, Tang X, Liu F, Zhang C, Zhao G, Ren F, Leng X. Antidepressant-like effects of the hydroalcoholic extracts of Hemerocallis citrina and its potential active components. BMC Complement Altern Med 2014; 14: 326

[198] Xu P, Wang KZ, Lu C, Dong LM, Le Zhai ], Liao YH, Aibai S, Yang Y, Liu XM. Antidepressant-like effects and cognitive enhancement of the total phenols extract of Hemerocallis citrina Baroni in chronic unpredictable mild stress rats and its related mechanism. J Ethnopharmacol 2016; 194: 819-826

[199] Li CF, Chen SM, Chen XM, Mu RH, Wang SS, Geng D, Liu Q, Yi LT. ERK-dependent brain-derived neurotrophic factor regulation by hesperidin in mice exposed to chronic mild stress. Brain Res Bull 2016; 124: $40-47$

[200] Shewale PB, Patil RA, Hiray YA. Antidepressant-like activity of anthocyanidins from Hibiscus rosa-sinensis flowers in tail suspension test and forced swim test. Indian J Pharmacol 2012; 44: 454-457

[201] da Silva AF, de Andrade JP, Bevilaqua LR, de Souza MM, Izquierdo I, Henriques AT, Zuanazzi JA. Anxiolytic-, antidepressant- and anticonvulsant-like effects of the alkaloid montanine isolated from Hippeastrum vittatum. Pharmacol Biochem Behav 2006; 85: 148-154

[202] Yamaura K, Nakayama N, Shimada M, Bi Y, Fukata H, Ueno K. Antidepressant-like effects of young green barley leaf (Hordeum vulgare L.) in the mouse forced swimming test. Pharmacognosy Res 2012; 4: 22-26

[203] Zanoli P, Rivasi M, Zavatti M, Brusiani F, Baraldi M. New insight in the neuropharmacological activity of Humulus lupulus L. J Ethnopharmacol 2005; 102: 102-106
[204] Dauncey EA, Irving JTW, Allkin R. A review of issues of nomenclature and taxonomy of Hypericum perforatum L. and Kew's Medicinal Plant Names Services. J Pharm Pharmacol 2019; 71: 4-14

[205] Heinrich M, Barnes J, Prieto JM, Gibbons S, Williamson EM. Fundamentals of Pharmacognosy and Phytotherapy, 3th ed. Amsterdam: Elsevier; 2018

[206] Butterweck V. Mechanism of action of St John's wort in depression. CNS Drugs 2003; 17: 539-562

[207] Wurglics M, Schubert-Zsilavecz M. Hypericum perforatum: A 'modern' herbal antidepressant. Clin Pharmacokinet 2006; 5: 449-468

[208] Bukhari IA, Dar A. Behavioral profile of Hypericum perforatum (St. John's Wort) extract. A comparison with standard antidepressants in animal models of depression. Eur Rev Med Pharmacol Sci 2013; 17: 10821089

[209] Zirak N, Shafiee M, Soltani G, Mirzaei M, Sahebkar A. Hypericum perforatum in the treatment of psychiatric and neurodegenerative disorders: current evidence and potential mechanisms of action. I Cell Physiol 2019; 234: 8496-8508

[210] Sánchez-Mateo CC, Bonkanka CX, Prado B, Rabanal RM. Antidepressant properties of some Hypericum canariense L. and Hypericum glandulosum Ait. extracts in the forced swimming test in mice. J Ethnopharmacol 2005; 97: 541-547

[211] Sánchez-Mateo CC, Prado B, Rabanal RM. Antidepressant effects of the methanol extract of several Hypericum species from the Canary Islands. J Ethnopharmacol 2002; 79: 119-127

[212] Viana A, do Rego JC, von Poser G, Ferraz A, Heckler AP, Costentin J, Kuze Rates SM. The antidepressant-like effect of Hypericum caprifoliatum Cham \& Schlecht (Guttiferae) on forced swimming test results from an inhibition of neuronal monoamine uptake. Neuropharmacology 2005; 49: 1042-1052

[213] Centurião FB, Braga A, Machado FR, Tagliari B, Müller LG, Kolling J, von Poser G, Wyse AT, Rates SM. Study of antidepressant-like activity of an enriched phloroglucinol fraction obtained from Hypericum caprifoliatum. Pharm Biol 2014; 52: 105-110

[214] Viana AF, do Rego JC, Munari L, Dourmap N, Heckler AP, Costa TD, von Poser GL, Costentin J, Rates SM. Hypericum caprifoliatum (Guttiferae) Cham. \& Schltd.: a species native to South Brazil with antidepressantlike activity. Fundam Clin Pharmacol 2006; 20: 507-514

[215] Viana A, Rates S, Naudin B, Janin F, Costentin J, do Rego JC. Effects of acute or 3-day treatments of Hypericum caprifoliatum Cham. \& Schltdt. (Guttiferae) extract or of two established antidepressants on basal and stress-induced increase in serum and brain corticosterone levels. J Psychopharmacol 2008; 22: 681-690

[216] Haas JS, Stolz ED, Betti AH, Stein AC, Schripsema J, Poser GL, Rates SM The anti-immobility effect of hyperoside on the forced swimming test in rats is mediated by the $D_{2}$-like receptors activation. Planta Med 2011; 77: 334-339

[217] Stolz ED, Viana AF, Hasse DR, von Poser GL, do Rego JC, Rates SM. Uliginosin B presents antinociceptive effect mediated by dopaminergic and opioid systems in mice. Prog Neuropsychopharmacol Biol Psychiatry 2012; 39: 80-87

[218] Diana G, Capasso A, Quaranta E, De Feo V. Differential effects of three species of Hypericum in an open field test. Phytother Res 2007; 21: 215-219

[219] do Rego JC, Benkiki N, Chosson E, Kabouche Z, Seguin E, Costentin J. Antidepressant-like effect of hyperfoliatin, a polyisoprenylated phloroglucinol derivative from Hypericum perfoliatum (Clusiaceae) is associated with an inhibition of neuronal monoamines uptake. Eur J Pharmacol 2007; 569: 197-203

[220] Stein AC, Viana AF, Müller LG, Nunes JM, Stolz ED, Do Rego JC, Costentin J, von Poser GL, Rates SM. Uliginosin B, a phloroglucinol derivative from Hypericum polyanthemum: a promising new molecular pattern for the development of antidepressant drugs. Behav Brain Res 2012; 228: 66-73 
[221] Li ], Geng D, Xu J, Weng L], Liu Q, Yi LT. Antidepressant-like effect of macranthol isolated from Illicium dunnianum tutch in mice. Eur J Pharmacol 2013; 707: 112-119

[222] Luo L, Liu XL, Li J, Mu RH, Liu Q, Yi LT, Geng D. Macranthol promotes hippocampal neuronal proliferation in mice via BDNF-TrkB-PI3K/Akt signaling pathway. Eur J Pharmacol 2015; 762: 357-363

[223] Weng L, Dong S, Wang S, Yi L, Geng D. Macranthol attenuates lipopolysaccharide-induced depressive-like behaviors by inhibiting neuroinflammation in prefrontal cortex. Physiol Behav 2019; 204: 33-40

[224] Sela VR, Hattanda I, Albrecht CM, De Almeida CB, Obici S, Cortez DA, Audi EA. Effect of xanthone from Kielmeyera coriacea stems on serotonergic neurons of the median raphe nucleus. Phytomedicine 2010; 17: 274-278

[225] Galdino PM, Nascimento MVM, Sampaio BL, Ferreira RN, Paula JR, Costa EA. Antidepressant-like effect of Lafoensia pacari A. St.-Hil. ethanolic extract and fractions in mice. J Ethnopharmacol 2009; 124: 581585

[226] Galdino PM, Carvalho AAV, Florentino IF, Martins JLR, Gazola AC, de Paula JR, de Paula JAM, Torres LMB, Costa EA, de Lima TCM. Involvement of monoaminergic systems in the antidepressant-like properties of Lafoensia pacari A. St. Hil. J Ethnopharmacol 2015; 170: 218-225

[227] Cavanagh HM, Wilkinson JM. Biological activities of lavender essential oil. Phytother Res 2002; 16: 301-308

[228] Hritcu L, Cioanca O, Hancianu M. Effects of lavender oil inhalation on improving scopolamine-induced spatial memory impairment in laboratory rats. Phytomedicine 2012; 19: 529-534

[229] Rahmati B, Kiasalari Z, Roghani M, Khalili M, Ansari F. Antidepressant and anxiolytic activity of Lavandula officinalis aerial parts hydroalcoholic extract in scopolamine-treated rats. Pharm Biol 2017; 55: 958965

[230] Gostner JM, Ganzera M, Becker K, Geisler S, Schroecksnadel S, Überall $\mathrm{F}$, Schennach $\mathrm{H}$, Fuchs $\mathrm{D}$. Lavender oil suppresses indoleamine 2,3-dioxygenase activity in human PBMC. BMC Complement Altern Med 2014; 14: 503

[231] López V, Nielsen B, Solas M, Ramírez M], Jäger AK. Exploring pharmacological mechanisms of lavender (Lavandula angustifolia) essential oil on central nervous system targets. Front Pharmacol 2017; 8: 280

[232] Caputo L, Reguilon MD, Miñarro J, De Feo V, Rodríguez-Arias M. Lavandula angustifolia essential oil and linalool counteract social aversion induced by social defeat. Molecules 2018; 23: E2694

[233] Sanna MD, Les F, Lopez V, Galeotti N. Lavender (Lavandula angustifolia Mill.) essential oil alleviates neuropathic pain in mice with spared nerve injury. Front Pharmacol 2019; 10: 472

[234] Ai Z, Cheng AF, Yu YT, Yu LJ, Jin W. Antidepressant-like behavioral, anatomical, and biochemical effects of petroleum ether extract from maca (Lepidium meyenii) in mice exposed to chronic unpredictable mild stress. J Med Food 2014; 17: 535-542

[235] Herraiz T, Guillén H. Monoamine oxidase-A inhibition and associated antioxidant activity in plant extracts with potential antidepressant actions. Biomed Res Int 2018; 2018: 4810394

[236] Zhang E, Yau SY, Lau BWM, Ma H, Lee TMC, Chang RCC, So KF. Synaptic plasticity, but not hippocampal neurogenesis, mediated the counteractive effect of wolfberry on depression in rats (1). Cell Transplant 2012; 21: 2635-2649

[237] Bhattamisra SK, Khanna VK, Agrawal AK, Singh PN, Singh SK. Antidepressant activity of standardised extract of Marsilea minuta Linn. J Ethnopharmacol 2008; 117: 51-57

[238] Shakeri A, Sahebkar A, Javadi B. Melissa officinalis L.-a review of its traditional uses, phytochemistry and pharmacology. I Ethnopharmacol 2016; 188: 204-228

[239] López V, Martín S, Gómez-Serranillos MP, Carretero ME, Jäger AK, Calvo MI. Neuroprotective and neurological properties of Melissa officinalis. Neurochem Res 2009; 34: 1955-1961
[240] Emamghoreishi M, Talebianpour M. Antidepressant effect of Melissa officinalis in the forced swimming test. Daru J Pharm Sci 2009; 17: 42-47

[241] Taiwo AE, Leite FB, Lucena GM, Barros M, Silveira D, Silva MV, Ferreira VM. Anxiolytic and antidepressant-like effects of Melissa officinalis (lemon balm) extract in rats: influence of administration and gender. Indian J Pharmacol 2012; 44: 189-192

[242] Lin SH, Chou ML, Chen WC, Lai YS, Lu KH, Hao CW, Sheen LY. A medicinal herb, Melissa officinalis L. ameliorates depressive-like behavior of rats in the forced swimming test via regulating the serotonergic neurotransmitter. J Ethnopharmacol 2015; 175: 266-272

[243] Patro G, Bhattamisra SK, Mohanty BK. Effects of Mimosa pudica L. leaves extract on anxiety, depression and memory. Avicenna J Phytomed 2016; 6: 696-710

[244] Idayu NF, Hidayat MT, Moklas MAM, Sharida F, Raudzah ARN, Shamima AR, Apryani E. Antidepressant-like effect of mitragynine isolated from Mitragyna speciosa Korth in mice model of depression. Phytomedicine 2011; 18: 402-407

[245] Ishola IO, Akinyede AA, Sholarin AM. Antidepressant and anxiolytic properties of the methanolic extract of Momordica charantia Linn (Cucurbitaceae) and its mechanism of action. Drug Res (Stuttg) 2014; 64: 368-376

[246] Zhang JH, Xin HL, Xu YM, Shen Y, He YQ, Hsien-Yeh, Lin B, Song HT, Juan-Liu, Yang HY, Qin LP, Zhang QY, Du J. Morinda officinalis How.A comprehensive review of traditional uses, phytochemistry and pharmacology. J Ethnopharmacol 2018; 213: 230-255

[247] Zhang ZQ, Yuan L, Yang M, Luo ZP, Zhao YM. The effect of Morinda of ficinalis How, a Chinese traditional medicinal plant, on the DRL 72-s schedule in rats and the forced swimming test in mice. Pharmacol Biochem Behav 2002; 72: 39-43

[248] Li YF, Yuan L, Xu YK, Yang M, Zhao YM, Luo ZP. Antistress effect of oligosaccharides extracted from Morinda officinalis in mice and rats. Acta Pharmacol Sin 2001; 22: 1084-1088

[249] Li YF, Gong ZH, Yang M, Zhao YM, Luo ZP. Inhibition of the oligosaccharides extracted from Morinda officinalis, a Chinese traditional herbal medicine, on the corticosterone induced apoptosis in PC12 cells. Life Sci 2003; 72: 933-942

[250] Li YF, Liu YQ, Yang M, Wang HL, Huang WC, Zhao YM, Luo ZP. The cytoprotective effect of inulin-type hexasaccharide extracted from Morinda officinalis on PC12 cells against the lesion induced by corticosterone. Life Sci 2004; 75: 1531-1538

[251] Xu LZ, Xu DF, Han Y, Liu L], Sun CY, Deng JH, Zhang RX, Yuan M, Zhang SZ, Li ZM, Xu Y, Li JS, Xie SH, Li SX, Zhang HY, Lu L. BDNF-GSK-3 $\beta-\beta$ catenin pathway in the MPFC is involved in antidepressant-like effects of Morinda officinalis oligosaccharides in rats. Int J Neuropsychopharmacol 2017; 20: 83-93; Erratum in: Int J Neuropsychopharmacol 2018; 21: 499

[252] Kaur G, Invally M, Sanzagiri R, Buttar HS. Evaluation of the antidepressant activity of Moringa oleifera alone and in combination with fluoxetine. J Ayurveda Integr Med 2015; 6: 273-279

[253] Lim DW, Kim YT, Park JH, Baek NI, Han D. Antidepressant-like effects of the ethyl acetate soluble fraction of the root bark of Morus alba on the immobility behavior of rats in the forced swim test. Molecules 2014; 19: 7981-7989

[254] Rana DG, Galani VJ. Dopamine mediated antidepressant effect of Mucuna pruriens seeds in various experimental models of depression. Ayu 2014; 35: 90-97

[255] Dhingra D, Sharma A. Antidepressant-like activity of $n$-hexane extract of nutmeg (Myristica fragrans) seeds in mice. J Med Food 2006; 9: 8489

[256] Moinuddin G, Devi K, Khajuria DK. Evaluation of the anti-depressant activity of Myristica fragrans (nutmeg) in male rats. Avicenna J Phytomed 2012; 2: 72-78 
[257] Jalali S, Zarrinhaghighi A, Sadraei S, Ghasemi Y, Sakhteman A, Faridi P. A system pharmacology study for deciphering anti depression activity of Nardostachys jatamansi. Curr Drug Metab 2018; 19: 469-476

[258] Dhingra D, Goyal PK. Inhibition of MAO and GABA: probable mechanisms for antidepressant-like activity of Nardostachys jatamansi DC in mice. Indian J Exp Biol 2008; 46: 212-218

[259] Sugimoto Y, Furutani S, Nishimura K, Itoh A, Tanahashi T, Nakajima H, Oshiro H, Sun S, Yamada J. Antidepressant-like effects of neferine in the forced swimming test involve the serotonin $1 \mathrm{~A}\left(5-\mathrm{HT}_{1 \mathrm{~A}}\right)$ receptor in mice. Eur J Pharmacol 2010; 634: 62-67

[260] Sugimoto Y, Nishimura K, Itoh A, Tanahashi T, Nakajima H, Oshiro H, Sun S, Toda T, Yamada J. Serotonergic mechanisms are involved in antidepressant-like effects of bisbenzylisoquinolines liensinine and its analogs isolated from the embryo of Nelumbo nucifera Gaertner seeds in mice. J Pharm Pharmacol 2015; 67: 1716-1722

[261] Rajput MA, Khan RA. Phytochemical screening, acute toxicity, anxiolytic and antidepressant activities of the Nelumbo nucifera fruit. Metab Brain Dis 2017; 32: 743-749

[262] Chatterjee M, Verma P, Maurya R, Palit G. Evaluation of ethanol leaf extract of Ocimum sanctum in experimental models of anxiety and depression. Pharm Biol 2011; 49: 477-483

[263] Mao Q, Huang Z, Ip S, Che C. Antidepressant-like effect of ethanol extract from Paeonia lactiflora in mice. Phytother Res 2008; 22: 1496 1499

[264] Mao QQ, Ip SP, Xian YF, Hu H, Che CT. Anti-depressant-like effect of peony: a mini-review. Pharm Biol 2012; 50: 72-77

[265] Mao QQ, Ip SP, Ko KM, Tsai SH, Xian YF, Che CT. Effects of peony glycosides on mice exposed to chronic unpredictable stress: further evidence for antidepressant-like activity. J Ethnopharmacol 2009; 124 : 316-320

[266] Song J, Hou X, Hu X, Lu C, Liu C, Wang J, Liu W, Teng L, Wang D. Not only serotonergic system, but also dopaminergic system involved in albiflorin against chronic unpredictable mild stress-induced depression-like behavior in rats. Chem Biol Interact 2015; 242: 211-217

[267] Rajabian A, Rameshrad M, Hosseinzadeh H. Therapeutic potential of Panax ginseng and its constituents, ginsenosides and gintonin, in neurological and neurodegenerative disorders: a patent review. Expert Opin Ther Pat 2019; 29: 55-72

[268] Wang G, Lei C, Tian Y, Wang Y, Zhang L, Zhang R. Rb1, the primary active ingredient in Panax ginseng C.A. Meyer, exerts antidepressant-like effects via the BDNF-Trkb-CREB Pathway. Front Pharmacol 2019; 10 : 1034

[269] Jin Y, Cui R, Zhao L, Fan J, Li B. Mechanisms of Panax ginseng action as an antidepressant. Cell Prolif 2019; 52: e12696

[270] Choi JH, Lee M], Jang M, Kim HJ, Lee S, Lee SW, Kim YO, Cho IH. Panax ginseng exerts antidepressant-like effects by suppressing neuroinflammatory response and upregulating nuclear factor erythroid 2 related factor 2 signaling in the amygdala. J Ginseng Res 2018; 42: 107-115

[271] Boonlert W, Benya-Aphikul H, Umka Welbat J, Rodsiri R. Ginseng extract $\mathrm{G} 115$ attenuates ethanol-induced depression in mice by increasing brain BDNF levels. Nutrients 2017; 9: E931

[272] Wang W, Liu X, Liu J, Cai E, Zhao Y, Li H, Zhang L, Li P, Gao Y. Sesquiterpenoids from the root of Panax ginseng attenuates lipopolysaccharideinduced depressive-like behavior through the brain-derived neurotrophic factor/tropomyosin-related kinase $b$ and sirtuin type 1/nuclear factor-KB signaling pathways. J Agric Food Chem 2018; 66: 265-271

[273] Chen L, Wang X, Lin ZX, Dai JG, Huang YF, Zhao YN. Preventive effects of ginseng total saponins on chronic corticosterone-induced impairment in astrocyte structural plasticity and hippocampal atrophy. Phytother Res 2017; 31: 1341-1348

[274] Jiang B, Xiong Z, Yang J, Wang W, Wang Y, Hu ZL, Wang F, Chen JG. Antidepressant-like effects of ginsenoside $\mathrm{Rg} 1$ are due to activation of the BDNF signalling pathway and neurogenesis in the hippocampus. Br J Pharmacol 2012; 166: 1872-1887

[275] Wang GL, He ZM, Zhu HY, Gao YG, Zhao Y, Yang H, Zhang LX. Involvement of serotonergic, noradrenergic and dopaminergic systems in the antidepressant-like effect of ginsenoside Rb1, a major active ingredient of Panax ginseng C.A. Meyer. J Ethnopharmacol 2017; 204: 118124

[276] Wang GL, Wang YP, Zheng JY, Zhang LX. Monoaminergic and aminoacidergic receptors are involved in the antidepressant-like effect of ginsenoside Rb1 in mouse hippocampus (CA3) and prefrontal cortex. Brain Res 2018; 1699: 44-53

[277] Mou Z, Huang Q, Chu SF, Zhang MJ, Hu JF, Chen NH, Zhang JT. Antidepressive effects of ginsenoside Rg1 via regulation of HPA and HPG axis. Biomed Pharmacother 2017; 92: 962-971

[278] Xia CY, Chu SF, Zhang S, Gao Y, Ren Q, Lou YX, Luo P, Tian MT, Wang ZQ, Du GH, Tomioka Y, Yamakuni T, Zhang Y, Wang ZZ, Chen NH. Ginsenoside Rg1 alleviates corticosterone-induced dysfunction of gap junctions in astrocytes. J Ethnopharmacol 2017; 208: 207-213

[279] Xu D, Wang C, Zhao W, Gao S, Cui Z. Antidepressant-like effects of ginsenoside $\mathrm{Rg} 5$ in mice: involving of hippocampus BDNF signaling pathway. Neurosci Lett 2017; 645: 97-105

[280] Xie W, Meng X, Zhai Y, Zhou P, Ye T, Wang Z, Sun G, Sun X. Panax notoginseng saponins: a review of its mechanisms of antidepressant or anxiolytic effects and network analysis on phytochemistry and pharmacology. Molecules 2018; 23: E940

[281] Zhang H, Chen Z, Zhong Z, Gong W, Li J. Total saponins from the leaves of Panax notoginseng inhibit depression on mouse chronic unpredictable mild stress model by regulating circRNA expression. Brain Behav 2018; 8: e01127

[282] Campos AR, Barros AIS, Albuquerque FAA, Leal LKAM, Rao VSN. Acute effects of guarana (Paullinia cupana Mart.) on mouse behaviour in forced swimming and open field tests. Phytother Res 2005; 19: 441 443

[283] Lee HC, Ko HK, Huang BE, Chu YH, Huang SY. Antidepressant-like effects of Perilla frutescens seed oil during a forced swimming test. Food Funct 2014; 5: 990-996

[284] Ji WW, Li RP, Li M, Wang SY, Zhang X, Niu XX, Li W, Yan L, Wang Y, Fu $Q$, Ma SP. Antidepressant-like effect of essential oil of Perilla frutescens in a chronic, unpredictable, mild stress-induced depression model mouse. Chin J Nat Med 2014; 12: 753-759

[285] Dhingra D, Joshi P, Gupta A, Chhillar R. Possible involvement of monoaminergic neurotransmission in antidepressant-like activity of Emblica officinalis fruits in mice. CNS Neurosci Ther 2012; 18: 419-425

[286] Xie H, Jin D, Kang Y, Shi X, Liu H, Shen H, Chen J, Yan M, Liu J, Pan S. The effect of Piper laetispicum extract (EAE-P) during chronic unpredictable mild stress based on interrelationship of inflammatory cytokines, apoptosis cytokines and neurotrophin in the hippocampus. BMC Complement Altern Med 2015; 15: 240

[287] Yao CY, Wang J, Dong D, Qian FG, Xie J, Pan SL. Laetispicine, an amide alkaloid from Piper laetispicum, presents antidepressant and antinociceptive effects in mice. Phytomedicine 2009; 16: 823-829

[288] Xie H, Yan MC, Jin D, Liu J], Yu M, Dong D, Cai CC, Pan SL. Studies on antidepressant and antinociceptive effects of ethyl acetate extract from Piper laetispicum and structure-activity relationship of its amide alkaloids. Fitoterapia 2011; 82: 1086-1092

[289] Hritcu L, Noumedem JA, Cioanca O, Hancianu M, Postu P, Mihasan M. Anxiolytic and antidepressant profile of the methanolic extract of Piper nigrum fruits in beta-amyloid (1-42) rat model of Alzheimer's disease. Behav Brain Funct 2015; 11: 13

[290] Li Q, Qu FL, Gao Y, Jiang YP, Rahman K, Lee KH, Han T, Qin LP. Piper sarmentosum Roxb. produces antidepressant-like effects in rodents, associated with activation of the CREB-BDNF-ERK signaling pathway and reversal of HPA axis hyperactivity. J Ethnopharmacol 2017; 199: 9-19 
[291] Cícero Bezerra Felipe F, Trajano Sousa Filho J, de Oliveira Souza LE, Alexandre Silveira J, Esdras de Andrade Uchoa D, Rocha Silveira E, Deusdênia Loiola Pessoa O, de Barros Viana GS. Piplartine, an amide alkaloid from Piper tuberculatum, presents anxiolytic and antidepressant effects in mice. Phytomedicine 2007; 14: 605-612

[292] Martins J, Suku B. Phytochemistry and pharmacology of anti-depressant medicinal plants: A review. Biomed Pharmacother 2018; 104: 343-365

[293] Bettio LE, Machado DG, Cunha MP, Capra JC, Missau FC, Santos AR, Pizzolatti MG, Rodrigues AL. Antidepressant-like effect of extract from Polygala paniculata: involvement of the monoaminergic systems. Pharm Biol 2011; 49: 1277-1285

[294] Capra JC, Cunha MP, Machado DG, Zomkowski AD, Mendes BG, Santos AR, Pizzolatti MG, Rodrigues AL. Antidepressant-like effect of scopoletin, a coumarin isolated from Polygala sabulosa (Polygalaceae) in mice: evidence for the involvement of monoaminergic systems. Eur J Pharmacol 2010; 643: 232-238

[295] Zhou Y, Ma C, Li BM, Sun C. Polygala japonica Houtt. reverses depression-like behavior and restores reduced hippocampal neurogenesis in chronic stress mice. Biomed Pharmacother 2018; 99: 986-996

[296] Hu Y, Liu P, Guo DH, Rahman K, Wang DX, Xie TT. Antidepressant effects of the extract YZ-50 from Polygala tenuifolia in chronic mild stress treated rats and its possible mechanisms. Pharm Biol 2010; 48: 794800

[297] Hu Y, Liu M, Liu P, Guo DH, Wei RB, Rahman K. Possible mechanism of the antidepressant effect of 3, 6'-disinapoyl sucrose from Polygala tenuifolia Willd. J Pharm Pharmacol 2011; 63: 869-874

[298] Aragão GF, Carneiro LM, Junior AP, Vieira LC, Bandeira PN, Lemos TL, Viana GS. A possible mechanism for anxiolytic and antidepressant effects of alpha- and beta-amyrin from Protium heptaphyllum (Aubl.) March. Pharmacol Biochem Behav 2006; 85: 827-834

[299] Piato AL, Rizon LP, Martins BS, Nunes DS, Elisabetsky E. Antidepressant profile of Ptychopetalum olacoides Bentham (Marapuama) in mice. Phytother Res 2009; 23: 519-524

[300] Piato AL, Detanico BC, Jesus JF, Lhullier FL, Nunes DS, Elisabetsky E. Effects of Marapuama in the chronic mild stress model: further indication of antidepressant properties. J Ethnopharmacol 2008; 118: 300304

[301] Yan B, Wang DY, Xing DM, Ding Y, Wang RF, Lei F, Du LJ. The antidepressant effect of ethanol extract of radix puerariae in mice exposed to cerebral ischemia reperfusion. Pharmacol Biochem Behav 2004; 78: 319-325

[302] Ali BH, Bashir AK, Tanira MO, Medvedev AE, Jarrett N, Sandler M, Glover V. Effect of extract of Rhazya stricta, a traditional medicinal plant, on rat brain tribulin. Pharmacol Biochem Behav 1998; 59: 671675

[303] Ali BH, Bashir AK, Tanira MO. The effect of Rhazya stricta Decne, a traditional medicinal plant, on the forced swimming test in rats. Pharmacol Biochem Behav 1998; 59: 547-550

[304] Tirupathi H, Golla P. To evaluate and compare antidepressant activity of Rosa damascena in mice by using forced swimming test. Int J Basic Clin Pharmacol 2016; 5: 1949-1952

[305] Akram M, Riaz M, Munir N, Akhter N, Zafar S, Jabeen F, Ali Shariati M, Akhtar N, Riaz Z, Altaf SH, Daniyal M, Zahid R, Said Khan F. Chemical constituents, experimental and clinical pharmacology of Rosa damascena: a literature review. J Pharm Pharmacol 2020; 72: 161-174

[306] Machado DG, Bettio LE, Cunha MP, Capra JC, Dalmarco JB, Pizzolatti MG, Rodrigues AL. Antidepressant-like effect of the extract of Rosmarinus officinalis in mice: involvement of the monoaminergic system. Prog Neuropsychopharmacol Biol Psychiatry 2009; 33: 642-650

[307] Machado DG, Cunha MP, Neis VB, Balen GO, Colla AR, Grando J, Brocardo PS, Bettio LE, Dalmarco JB, Rial D, Prediger RD, Pizzolatti MG, Rodrigues AL. Rosmarinus officinalis L. hydroalcoholic extract, similar to fluoxetine, reverses depressive-like behavior without altering learning deficit in olfactory bulbectomized mice. J Ethnopharmacol 2012; 143: 158-169

[308] Machado DG, Neis VB, Balen GO, Colla A, Cunha MP, Dalmarco JB, Pizzolatti MG, Prediger RD, Rodrigues AL. Antidepressant-like effect of ursolic acid isolated from Rosmarinus officinalis L. in mice: evidence for the involvement of the dopaminergic system. Pharmacol Biochem Behav 2012; 103: 204-211

[309] Machado DG, Cunha MP, Neis VB, Balen GO, Colla A, Bettio LE, Oliveira A, Pazini FL, Dalmarco JB, Simionatto EL, Pizzolatti MG, Rodrigues AL. Antidepressant-like effects of fractions, essential oil, carnosol and betulinic acid isolated from Rosmarinus officinalis L. Food Chem 2013; 136: 999-1005

[310] Sasaki K, El Omri A, Kondo S, Han ], Isoda H. Rosmarinus officinalis polyphenols produce anti-depressant like effect through monoaminergic and cholinergic functions modulation. Behav Brain Res 2013; 238: 86-94

[311] Ferlemi AV, Katsikoudi A, Kontogianni VG, Kellici TF, latrou G, Lamari FN, Tzakos AG, Margarity M. Rosemary tea consumption results to anxiolytic- and anti-depressant-like behavior of adult male mice and inhibits all cerebral area and liver cholinesterase activity; phytochemical investigation and in silico studies. Chem Biol Interact 2015; 237: 47-57

[312] Abdelhalim A, Karim N, Chebib M, Aburjai T, Khan I, Johnston GA Hanrahan J. Antidepressant, anxiolytic and antinociceptive activities of constituents from Rosmarinus officinalis. J Pharm Pharm Sci 2015; 18: $448-459$

[313] Guo Y, Xie J, Li X, Yuan Y, Zhang L, Hu W, Luo H, Yu H, Zhang R. Antidepressant effects of rosemary extracts associate with anti-inflammatory effect and rebalance of gut microbiota. Front Pharmacol 2018; 9: 1126

[314] Carbajal D, Ravelo Y, Molina V, Mas R, Arruzazabala ML. D-004, a lipid extract from royal palm fruit, exhibits antidepressant effects in the forced swim test and the tail suspension test in mice. Pharmacol Biochem Behav 2009; 92: 465-458

[315] Braida D, Capurro V, Zani A, Rubino T, Viganò D, Parolaro D, Sala M. Potential anxiolytic- and antidepressant-like effects of salvinorin $\mathrm{A}$, the main active ingredient of Salvia divinorum, in rodents. $\mathrm{Br}$ J Pharmacol 2009; 157: 844-853

[316] Mora S, Millán R, Lungenstrass H, Díaz-Véliz G, Morán JA, Herrera-Ruiz $\mathrm{M}$, Tortoriello J. The hydroalcoholic extract of Salvia elegans induces anxiolytic- and antidepressant-like effects in rats. J Ethnopharmacol 2006; 106: 76-81

[317] Seol GH, Shim HS, Kim PJ, Moon HK, Lee KH, Shim I, Suh SH, Min SS Antidepressant-like effect of Salvia sclarea is explained by modulation of dopamine activities in rats. J Ethnopharmacol 2010; 130: 187-190

[318] Loria M], Ali Z, Abe N, Sufka K], Khan IA. Effects of Sceletium tortuosum in rats. J Ethnopharmacol 2014; 155: 731-735

[319] Dimpfel W, Schombert L, Gericke N. Electropharmacogram of Sceletium tortuosum extract based on spectral local field power in conscious freely moving rats. J Ethnopharmacol 2016; 177: 140-147

[320] Carpenter JM, Jourdan MK, Fountain EM, Ali Z, Abe N, Khan IA, Sufka KJ. The effects of Sceletium tortuosum (L.) N.E. Br. extract fraction in the chick anxiety-depression model. J Ethnopharmacol 2016; 193: 329332

[321] Krstenansky JL. Mesembrine alkaloids: Review of their occurrence, chemistry, and pharmacology. J Ethnopharmacol 2017; 195: 10-19

[322] Harvey AL, Young LC, Viljoen AM, Gericke NP. Pharmacological actions of the South African medicinal and functional food plant Sceletium tortuosum and its principal alkaloids. J Ethnopharmacol 2011; 137: 11241129

[323] Machado DG, Kaster MP, Binfaré RW, Dias M, Santos AR, Pizzolatti MG, Brighente IM, Rodrigues AL. Antidepressant-like effect of the extract from leaves of Schinus molle L. in mice: evidence for the involvement 
of the monoaminergic system. Prog Neuropsychopharmacol Biol Psychiatry 2007; 31: 421-428

[324] Machado DG, Bettio LE, Cunha MP, Santos AR, Pizzolatti MG, Brighente IM, Rodrigues AL. Antidepressant-like effect of rutin isolated from the ethanolic extract from Schinus molle L. in mice: evidence for the involvement of the serotonergic and noradrenergic systems. Eur J Pharmacol 2008; 587: 163-168

[325] Yan T, Xu M, Wan S, Wang M, Wu B, Xiao F, Bi K, Jia Y. Schisandra chinensis produces the antidepressant-like effects in repeated corticosterone-induced mice via the BDNF/TrkB/CREB signaling pathway. Psychiatry Res 2016; 243: 135-142

[326] Yan T, He B, Wan S, Xu M, Yang H, Xiao F, Bi K, Jia Y. Antidepressant-like effects and cognitive enhancement of Schisandra chinensis in chronic unpredictable mild stress mice and its related mechanism. Sci Rep 2017; 7: 6903

[327] Yan T, Xu M, Wu B, Liao Z, Liu Z, Zhao X, Bi K, Jia Y. The effect of Schisandra chinensis extracts on depression by noradrenergic, dopaminergic, GABAergic and glutamatergic systems in the forced swim test in mice. Food Funct 2016; 7: 2811-2819

[328] Xu C, Luo L, Tan RX. Antidepressant effect of three traditional Chinese medicines in the learned helplessness model. J Ethnopharmacol 2004; 91: 345-349

[329] Kosari-Nasab M, Babri S, Fatehi-Gharehlar L, Doosti MH, Pakzad S. Involvement of GABAergic system in regulation of the anxiolytic- and antidepressant-like effects of Scrophularia striata extract in rats. Pharm Biol 2013; 51: 581-588

[330] Zhang R, Guo L, Ji Z, Li X, Zhang C, Ma Z, Fu Q, Qu R, Ma S. Radix scutellariae attenuates CUMS-induced depressive-like behavior by promoting neurogenesis via cAMP/PKA pathway. Neurochem Res 2018; 43: $2111-2120$

[331] Zhang R, Ma Z, Liu K, Li Y, Liu D, Xu L, Deng X, Qu R, Ma Z, Ma S. Baicalin exerts antidepressant effects through Akt/FOXG1 pathway promoting neuronal differentiation and survival. Life Sci 2019; 221: 241-248

[332] Limanaqi F, Biagioni F, Busceti CL, Polzella M, Fabrizi C, Fornai F. Potential antidepressant effects of Scutellaria baicalensis, Hericium erinaceus and Rhodiola rosea. Antioxidants (Basel) 2020; 9: E234

[333] Adebiyi RA, Elsa AT, Agaie BM, Etuk EU. Antinociceptive and antidepressant like effects of Securidaca longepedunculata root extract in mice. J Ethnopharmacol 2006; 107: 234-239

[334] Chiang HM, Chen HC, Wu CS, Wu PY, Wen KC. Rhodiola plants: Chemistry and biological activity. J Food Drug Anal 2015; 23: 359-369

[335] Recio MC, Giner RM, Máñez S. Immunmodulatory and antiproliferative properties of Rhodiola species. Planta Med 2016; 82: 952-960

[336] Tao H, Wu X, Cao J, Peng Y, Wang A, Pei J, Xiao J, Wang S, Wang Y. Rhodiola species: A comprehensive review of traditional use, phytochemistry, pharmacology, toxicity, and clinical study. Med Res Rev 2019; 39: 1779-1850

[337] Amsterdam JD, Panossian AG. Rhodiola rosea L. as a putative botanical antidepressant. Phytomedicine 2016; 23: 770-783

[338] Yang S], Yu HY, Kang DY, Ma ZQ, Qu R, Fu Q, Ma SP. Antidepressantlike effects of salidroside on olfactory bulbectomy-induced pro-inflammatory cytokine production and hyperactivity of HPA axis in rats. Pharmacol Biochem Behav 2014; 124: 451-457

[339] van Diermen D, Marston A, Bravo J, Reist M, Carrupt PA, Hostettmann K. Monoamine oxidase inhibition by Rhodiola rosea L. roots. J Ethnopharmacol 2009; 122: 397-401

[340] Panossian AG, Wikman G, Sarris ]. Rosenroot (Rhodiola rosea): traditional use, chemical composition, pharmacology and clinical efficacy. Phytomedicine 2010; 17: 481-493

[341] Alonso-Castro AJ, Alba-Betancourt C, Yáñez-Barrientos E, Luna-Rocha C, Páramo-Castillo AS, Aragón-Martínez OH, Zapata-Morales JR, CruzJiménez G, Gasca-Martínez D, González-Ibarra AA, Álvarez-Camacho DA, Devezé-Álvarez MA. Diuretic activity and neuropharmacological effects of an ethanol extract from Senna septemtrionalis (Viv.) H.S. Irwin \& Barneby (Fabaceae). J Ethnopharmacol 2019; 239: 111923

[342] Valli M, Betti AH, Danuello A, Pivatto M, Centurião F, Antonio CB, Rates SMK, Bolzani VS. Pyridinic analog of the natural product (-)-spectaline as potential adjuvant for the treatment of central nervous system disorders. Bioorg Med Chem Lett 2015; 25: 2247-2250

[343] Datusalia AK, Sharma S, Kalra P, Samal MK. Antidepressant-like potential of Sida tiagii Bhandari fruits in mice. J Health Sci 2009; 55: 641-648

[344] Rodrigues AL, da Silva GL, Mateussi AS, Fernandes ES, Miguel OG, Yunes RA, Calixto JB, Santos AR. Involvement of monoaminergic system in the antidepressant-like effect of the hydroalcoholic extract of Siphocampylus verticillatus. Life Sci 2002; 70: 1347-1358

[345] Momin R, Mohan M. Involvement of central noradrenaline, serotonin and dopamine system in the antidepressant activity of fruits of Solanum torvum (Solanaceae). Nat Prod Res 2012; 26: 416-422

[346] Mohan M, Attarde D, Momin R, Kasture S. Antidepressant, anxiolytic and adaptogenic activity of torvanol A: an isoflavonoid from seeds of Solanum torvum. Nat Prod Res 2013; 27: 2140-2143

[347] Vilela FC, Padilha MM, Alves-da-Silva G, Soncini R, Giusti-Paiva A. Antidepressant-like activity of Sonchus oleraceus in mouse models of immobility tests. J Med Food 2010; 13: 219-222

[348] Khulbe A, Pandey S, Sah SP. Antidepressant-like action of the hydromethanolic flower extract of Tagetes erecta $\mathrm{L}$. in mice and its possible mechanism of action. Indian J Pharmacol 2013; 45: 386-390

[349] Guadarrama-Cruz G, Alarcón-Aguilar F], Lezama-Velasco R, VázquezPalacios G, Bonilla-Jaime $H$. Antidepressant-like effects of Tagetes lucida Cav. in the forced swimming test. J Ethnopharmacol 2008; 120 : 277-281

[350] Guadarrama-Cruz G, Alarcón-Aguilar F], Vega-Ávila E, VázquezPalacios G, Bonilla-Jaime H. Antidepressant-like effect of Tagetes lucida Cav. extract in rats: involvement of the serotonergic system. Am J Chin Med 2012; 40: 753-768

[351] Bonilla-Jaime H, Guadarrama-Cruz G, Alarcon-Aguilar F], LimónMorales O, Vazquez-Palacios G. Antidepressant-like activity of Tagetes lucida Cav. is mediated by $5-\mathrm{HT}_{1 \mathrm{~A}}$ and $5-\mathrm{HT}_{2 \mathrm{~A}}$ receptors. J Nat Med 2015; 69: 463-470

[352] Cárdenas J, Reyes-Pérez V, Hernández-Navarro MD, Dorantes-Barrón AM, Almazán S, Estrada-Reyes R. Anxiolytic- and antidepressant-like effects of an aqueous extract of Tanacetum parthenium L. Schultz-Bip (Asteraceae) in mice. J Ethnopharmacol 2017; 200: 22-30

[353] Dhingra D, Valecha R. Evaluation of antidepressant-like activity of aqueous and ethanolic extracts of Terminalia bellirica Roxb. fruits in mice. Indian J Exp Biol 2007; 45: 610-616

[354] Messaoudi M, Bisson JF, Nejdi A, Rozan P, Javelot H. Antidepressant-like effects of a cocoa polyphenolic extract in Wistar-Unilever rats. Nutr Neurosci 2008; 11: 269-276

[355] Morteza-Semnani K, Mahmoudi M, Riahi G. Effects of essential oils and extracts from certain Thymus species on swimming performance in mice. Pharm Biol 2007; 45: 464-467

[356] Doosti MH, Ahmadi K, Fasihi-Ramandi M. The effect of ethanolic extract of Thymus kotschyanus on cancer cell growth in vitro and depression-like behavior in the mouse. J Tradit Complement Med 2018 ; 8: 89-94

[357] Dhingra D, Goyal PK. Evidences for the involvement of monoaminergic and GABAergic systems in antidepressant-like activity of Tinosporo cordifolia in mice. Indian J Pharm Sci 2008; 70: 761-767

[358] Campos MM, Fernandes ES, Ferreira J, Santos AR, Calixto JB. Anti depressant-like effects of Trichilia catigua (Catuaba) extract: evidence for dopaminergic-mediated mechanisms. Psychopharmacology (Berl) 2005; 182: 45-53

[359] Chassot JM, Longhini R, Gazarini L, Mello JC, de Oliveira RM. Preclinica evaluation of Trichilia catigua extracts on the central nervous system of mice. J Ethnopharmacol 2011; 137: 1143-1148 
[360] Taciany Bonassoli V, Micheli Chassot J, Longhini R, Milani H, Mello JC, de Oliveira RM. Subchronic administration of Trichilia catigua ethyl-acetate fraction promotes antidepressant-like effects and increases hippocampal cell proliferation in mice. J Ethnopharmacol 2012; 143: 179-184

[361] Bernardo J, Ferreres F, Gil-Izquierdo Á, Videira RA, Valentão P, Veiga F, Andrade PB. In vitro multimodal-effect of Trichilia catigua A. Juss. (Meliaceae) bark aqueous extract in CNS targets. J Ethnopharmacol 2018; 211: 247-255

[362] Jäger AK, Gauguin B, Andersen J, Adsersen A, Gudiksen L. Screening of plants used in Danish folk medicine to treat depression and anxiety for affinity to the serotonin transporter and inhibition of MAO-A. J Ethnopharmacol 2013; 145: 822-825

[363] Khursheed R, Rizwani GH, Sultana V, Ahmed M, Kamil A. Antidepressant effect and categorization of inhibitory activity of monoamine oxidase type A and B of ethanolic extract of seeds of Trigonella foenum-graecum Linn. Pak J Pharm Sci 2014; 27: 1419-1425

[364] Wang J, Cheng C, Xin C, Wang Z. The antidepressant-like effect of flavonoids from Trigonella foenum-graecum seeds in chronic restraint stress mice via modulation of monoamine regulatory pathways. Molecules 2019; 24: 1105

[365] Hsu LC, Ko Y], Cheng HY, Chang CW, Lin YC, Cheng YH, Hsieh MT, Peng WH. Antidepressant-like activity of the ethanolic extract from Uncaria lanosa Wallich var. appendiculata Ridsd in the forced swimming test and in the tail suspension test in mice. Evid Based Complement Alternat Med 2012; 2012: 497302

[366] Plushner SL. Valerian: Valeriana officinalis. Am J Health Syst Pharm 2000; 57: 328, 333, 335

[367] Hattesohl M, Feistel B, Sievers H, Lehnfeld R, Hegger M, Winterhoff H. Extracts of Valeriana officinalis L. s.I. show anxiolytic and antidepressant effects but neither sedative nor myorelaxant properties. Phytomedicine 2008; 15: 2-15

[368] Gonulalan EM, Bayazeid O, Yalcin FN, Demirezer LO. The roles of valerenic acid on BDNF expression in the SH-SY5Y cell. Saudi Pharm J 2018; 26: 960-964

[369] Liu XG, Gao PY, Wang GS, Song S], Li LZ, Li X, Yao XS, Zhang ZX. In vivo antidepressant activity of sesquiterpenes from the roots of Valeriana fauriei Briq. Fitoterapia 2012; 83: 599-603

[370] Choi JH, Lee M], Chang Y, Lee S, Kim HJ, Lee SW, Kim YO, Cho IH. Valeriana fauriei exerts antidepressant-like effects through anti-inflammatory and antioxidant activities by inhibiting brain-derived neurotrophic factor associated with chronic restraint stress. Rejuvenation Res 2020; 23: 245-255

[371] Müller LG, Salles LA, Stein AC, Betti AH, Sakamoto S, Cassel E, Vargas RF, von Poser GL, Rates SM. Antidepressant-like effect of Valeriana glechomifolia Meyer (Valerianaceae) in mice. Prog Neuropsychopharmacol Biol Psychiatry 2012; 36: 101-109

[372] Müller LG, Stolz ED, Betti AH, Herzfeldt V, Rates SM. Synergistic interaction between diene valepotriates from Valeriana glechomifolia Meyer (Valerianaceae) and classical antidepressants: an isobolographic analysis. J Pharm Pharmacol 2015; 67: 1008-1016

[373] Müller LG, Biojone C, Sales AJ, Betti AH, Herzfeldt V, Joca SRL, Rates SMK. A valepotriate-enriched fraction from Valeriana glechomifolia decreases DNA methylation and up-regulate TrkB receptors in the hippocampus of mice. Behav Pharmacol 2020; 31: 333-342

[374] Sah SP, Mathela CS, Chopra K. Antidepressant effect of Valeriana wallichii patchouli alcohol chemotype in mice: Behavioural and biochemical evidence. J Ethnopharmacol 2011; 135: 197-200

[375] Dasari R, Sathyavathi D, Belide SK, Soumy BR. Pharmacological evaluation for antidepressant activity of Vanda spathulata in mice. Int J Pharm Bio Sci 2013; 4: 866-872

[376] Karim N, Khan I, Abdelhalim A, Khan A, Halim SA. Antidepressant potential of novel flavonoids derivatives from sweet violet (Viola odorata L): Pharmacological, biochemical and computational evi- dences for possible involvement of serotonergic mechanism. Fitoterapia 2018; 128: 148-161

[377] Bhattacharya SK, Bhattacharya A, Sairam K, Ghosal S. Anxiolytic-antidepressant activity of Withania somnifera glycowithanolides: an experimental study. Phytomedicine 2000; 7: 463-469

[378] Shah PC, Trivedi NA, Bhatt JD, Hemavathi KG. Effect of Withania somnifera on forced swimming test induced immobility in mice and its interaction with various drugs. Indian J Physiol Pharmacol 2006; 50: 409415

[379] Gupta GL, Rana AC. Protective effect of Withania somnifera dunal root extract against protracted social isolation induced behavior in rats. Indian J Physiol Pharmacol 2007; 51: 345-353

[380] Attari M, Jamaloo F, Shadvar S, Fakhraei N, Dehpour AR. Effect of Withania somnifera Dunal root extract on behavioral despair model in mice: a possible role for nitric oxide. Acta Med Iran 2016; 54: 165-172

[381] Biney RP, Benneh CK, Ameyaw EO, Boakye-Gyasi E, Woode E. Xylopia aethiopica fruit extract exhibits antidepressant-like effect via interaction with serotonergic neurotransmission in mice. J Ethnopharmacol 2016; 184: 49-57

[382] Sharma PK, Singh V, Ali M, Kumar S. Effect of ethanolic extract of Zingiber officinale Roscoe on central nervous system activity in mice. Indian J Exp Biol 2016; 54: 664-669

[383] Martínez DM, Barcellos A, Casaril AM, Savegnago L, Lernardão E]. Antidepressant-like activity of dehydrozingerone: involvement of the serotonergic and noradrenergic systems. Pharmacol Biochem Behav 2014; 127: $111-117$

[384] Kukula-Koch W, Koch W, Czernicka L, Głowniak K, Asakawa Y, Umeyama A, Marzec Z, Kuzuhara T. MAO-A inhibitory potential of terpene constituents from ginger rhizomes-a bioactivity guided fractionation. Molecules 2018; 23: 1301

[385] Sharma VK, Chauhan NS, Lodhi S, Singhai AK. Anti-depressant activity of Zizyphus xylopyrus. Int ] Phytomed 2009; 1: 12-17

[386] Alonso-Castro AJ, Zapata-Morales JR, Arana-Argáez V, Torres-Romero JC, Ramírez-Villanueva E, Pérez-Medina SE, Ramírez-Morales MA, Juárez-Méndez MA, Infante-Barrios YP, Martínez-Gutiérrez F, Carranza-Álvarez C, Isiordia-Espinoza MA, Flores-Santos A. J Pharmacological and toxicological study of a chemical-standardized ethanol extract of the branches and leaves from Eysenhardtia polystachya (Ortega) Sarg. (Fabaceae). Ethnopharmacol 2018; 224: 314-322

[387] Ishola IO, Olayemi SO, Yemitan OK, Umeh EA. Antidepressant and anxiolytic effects of the methanol root extract of Capparis thonningii: Involvement of monoaminergic, cholinergic and GABAergic systems. Drug Res (Stuttg) 2015; 65: 205-213

[388] Ishola IO, Chatterjee M, Tota S, Tadigopulla N, Adeyemi OO, Palit G, Shukla R. Antidepressant and anxiolytic effects of amentoflavone isolated from Cnestis ferruginea in mice. Pharmacol Biochem Behav 2012; 103: $322-331$

[389] Wang Q, Dwivedi Y. Advances in novel molecular targets for antidepressants. Prog Neuropsychopharmacol Biol Psychiatry 2021; 104 : 110041

[390] Polyakova M, Beyer F, Mueller K, Sander C, Witte V, Lampe L, Rodrigues F, Riedel-Heller S, Kratzsch J, Hoffmann KT, Villringer A, Schoenknecht $\mathrm{P}$, Schroeter ML. Serum BDNF levels correlate with regional cortical thickness in minor depression: a pilot study. Sci Rep 2020; 10: 14524

[391] Liu B, Liu J, Wang M, Zhang Y, Li L. From serotonin to neuroplasticity: evolvement of theories for major depressive disorder. Front Cell Neurosci 2017; 11: 305

[392] Dale E, Bang-Andersen B, Sánchez C. Emerging mechanisms and treatments for depression beyond SSRIs and SNRIs. Biochem Pharmacol 2015; 95: 81-97

[393] McNally L, Bhagwagar Z, Hannestad J. Inflammation, glutamate, and glia in depression: a literature review. CNS Spectr 2008; 13: 501-510 
[394] Berman RM, Cappiello A, Anand A, Oren DA, Heninger GR, Charney DS, Krystal JH. Antidepressant effects of ketamine in depressed patients. Biol Psychiatry 2000; 47: 351-354

[395] Lin TY, Lu CW, Wang CC, Wang YC, Wang S]. Curcumin inhibits glutamate release in nerve terminals from rat prefrontal cortex: possible relevance to its antidepressant mechanism. Prog Neuropsychopharmacol Biol Psychiatry 2011; 35: 1785-1793

[396] Gao SF, Bao AM. Corticotropin-releasing hormone, glutamate, and $\gamma$-aminobutyric acid in depression. Neuroscientist 2011; 17: 124-144

[397] Luscher B, Shen Q, Sahir N. The GABAergic deficit hypothesis of major depressive disorder. Mol Psychiatry 2011; 16: 383-406
[398] Lee $\mathrm{CH}$, Giuliani F. The role of inflammation in depression and fatigue. Front Immunol 2019; 10: 1-12

[399] Zanelati TV, Biojone C, Moreira FA, Guimarães FS, Joca SRL. Antidepressant-like effects of cannabidiol in mice: possible involvement of 5- $\mathrm{HT}_{1 \mathrm{~A}}$ receptors. $\mathrm{Br}$ J Pharmacol 2010; 159: 122-128

[400] Sales AJ, Crestani CC, Guimarães FS, Joca SRL. Antidepressant-like effect induced by cannabidiol is dependent on brain serotonin levels. Prog Neuropsychopharmacol Biol Psychiatry 2018; 86: 255-261

[401] Sales A], Fogaça MV, Sartim AG, Pereira VS, Wegener G, Guimarães FS, Joca SRL. Cannabidiol induces rapid and sustained antidepressant-like effects through increased BDNF signaling and synaptogenesis in the prefrontal cortex. Mol Neurobiol 2019; 56: 1070-1081 